Illinois State University

ISU ReD: Research and eData

Theses and Dissertations

4-24-2014

\title{
The Story of Don Rabbit and Sexy Carrot
}

Lisa Eleazarian

Illinois State University, Imeleazarian@gmail.com

Follow this and additional works at: https://ir.library.illinoisstate.edu/etd

Part of the Music Commons

\section{Recommended Citation}

Eleazarian, Lisa, "The Story of Don Rabbit and Sexy Carrot" (2014). Theses and Dissertations. 164.

https://ir.library.illinoisstate.edu/etd/164

This Thesis is brought to you for free and open access by ISU ReD: Research and eData. It has been accepted for inclusion in Theses and Dissertations by an authorized administrator of ISU ReD: Research and eData. For more information, please contact ISUReD@ilstu.edu. 


\section{THE STORY OF DON RABBIT AND SEXY CARROT FOR VARIETY ORCHESTRA}

\section{Lisa M. Eleazarian}

This thesis project follows the form and model of a tone poem using a compositional style of cartoon music.

The piece acts as a musical representation of a cartoon, in which a rabbit falls in love with a carrot, chases the carrot, and finally catches the carrot only to eat it and die at the end of his meal. The plot line fits well into sonata form, a common western classical music form. The piece is divided into three movements based on a handful of frames from the cartoon. The first movement introduces the main character. The second movement begins and develops the story. The third movement focuses on one particular frame from the cartoon.

This orchestral piece includes several instruments not commonly found in an orchestra such as two saxophones, an electric guitar, a drum set, a coffee grinder and dish sets. The piece uses these instruments both to create sound effects and to represent the personalities of the characters in the story.

The piece utilizes three main themes. Two of these themes represent the two main characters, while the other represents a love theme. Different events of the story control the development or changes of these themes.

The piece utilizes several different compositional techniques depending on the events of the story. The first movement uses a purely diatonic harmonic language, while the other two movements alternate between diatonic and other harmonic techniques. Several musical genres 
appear in this piece to represent the characters' personalities and different location settings. 


\section{THE STORY OF DON RABBIT AND SEXY CARROT FOR VARIETY ORCHESTRA}

LISA M. ELEAZARIAN

A Thesis Submitted in Partial Fulfillment of the Requirements for the Degree of

MASTER OF MUSIC

School of Music

ILLINOIS STATE UNIVERSITY 
(C2014 Lisa M. Eleazarian 


\section{THE STORY OF DON RABBIT AND SEXY CARROT \\ FOR VARIETY ORCHESTRA}

LISA M. ELEAZARIAN

COMMITTEE MEMBERS:

Martha C. Horst, Chair

Glenn Block

Chen Yao 


\section{CONTENTS}

Page

CONTENTS

INSTRUMENTATION

PERFORMANCE NOTES iv

MOVEMENTS

I. INTRODUCING DON RABBIT 1

II. THAT MORNING AT STUMPTOWN COFFEE, DON RABBIT SEES SEXY CARROT

III. DON RABBIT DECIDES TO CHASE SEXY CARROT 


\section{INSTRUMENTATION}

Piccolo

2 Flutes

2 Oboes

2 Clarinets in B-flat

Bass Clarinet

Alto Saxophone

Tenor Saxophone

2 Bassoons

Contrabassoon

4 Horns in $\mathrm{F}$

2 Trumpets in $\mathrm{C}$

2 Tenor Trombones

Tuba

Timpani

Drum Set

Percussion (4):

Triangle

Tambourine

Suspended Cymbal (medium yarn mallets)

Crash Cymbals

Tamtam (heavy yam beater)

Whip

Woodblocks (5)

Castanets

Coffee Grinder/ Ratchet

Dish set

Bowl of water and pitcher

Snare drum

Bass drum (heavy felt beater)

Glockenspiel (hard plastic mallets)

Xylophone (hard wood mallets)

Vibraphone (motor on slow, medium yarn mallets)

Movement I (3 Percussion):

Percussion 1: Glockenspiel

Percussion 2: Triangle, Tambourine

Percussion 3: Bass Drum 
Movement 2 (3 Percussion):

Percussion 1: Glockenspiel, Coffee Grinder, Bowl of Water, Xylophone

Percussion 2: Bicycle Bell, Dish Set, Tamtam, Vibraphone, Crash Cymbal

Percussion 3: Triangle, Tambourine

Movement 3 (4 Percussion):

Percussion 1: Xylophone

Percussion 2: Crash Cymbal, Suspended Cymbal, Tamtam, Tambourine

Percussion 3: Whip, Snare Drum, Triangle, Tambourine, Woodblocks (5)

Percussion 4: Bass Drum

Electric Guitar (with distortion)

Celesta

Piano

Violin I

Violin II

Viola

Celli

Contrabass

Score in C

The Piccolo, Xylophone, and Celesta sound an octave higher than written. The Glockenspiel sounds two octaves higher than written. The Contrabassoon, Electric Guitar, and Contrabass sound an octave lower than written.

Performance Duration: Approximately 16 minutes 


\section{PERFORMANCE NOTES}

Percussion Notes:

1. Map of Drum Set:

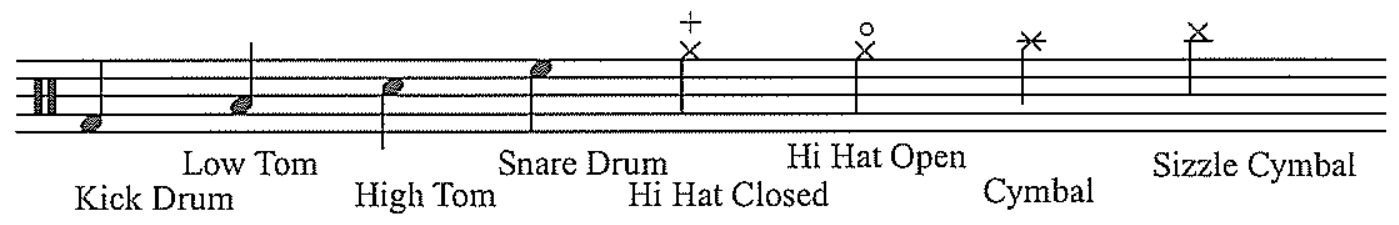

2. Cymbals are notated with $X$ note-heads

3. The Coffee Grinder, Dish Set, and Water Pitcher must be amplified. During the performance, follow the directions in the score. Do these activities over the amount of measures indicated in the score. It should sound more like sound effects than any particular rhythmic pattern. If there is no coffee grinder or electrical outlet available, then substitute a ratchet for the coffee grinder.

Other Performance Notes:

1. Start all glissandi immediately. Glissandi are indicated by a straight line connected between notes.

2. Glissandi to notes without a note-head mean that the performer may end the glissando on any pitch in the indicated area.

3. All performers may be required to provide sound effects such as talking or scooting their chairs. Follow the directions in the score.

4. Electric Guitar must use distortion. It should produce a grungy tone. The guitarist must play with a pick

5. During all conversation portions of the piece the conversation subject matter will be divided as follows:

Flutes: talk about food

Oboes: call out random coffee drink names

Bassoons and Contrabassoon: talk about the weather

French Horns: talk about summer plans

Trombones and Tuba: pretend to be on a first date 
Electric Guitar: complain about computers (please refrain from inappropriate language)

Violins: talk about school

Violas and Celli: talk about favorite TV shows or movies 
Score in C

MOVEMENT I
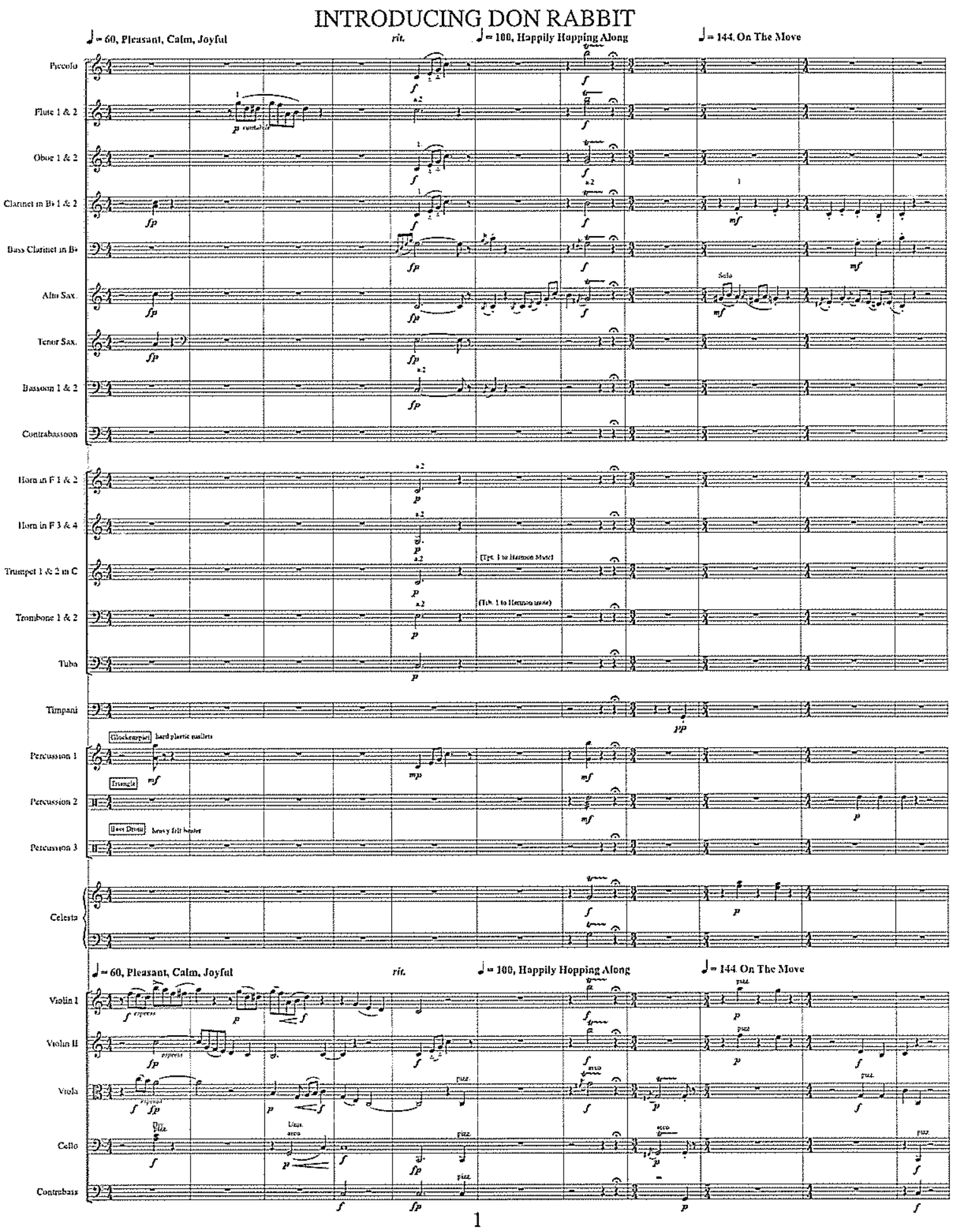


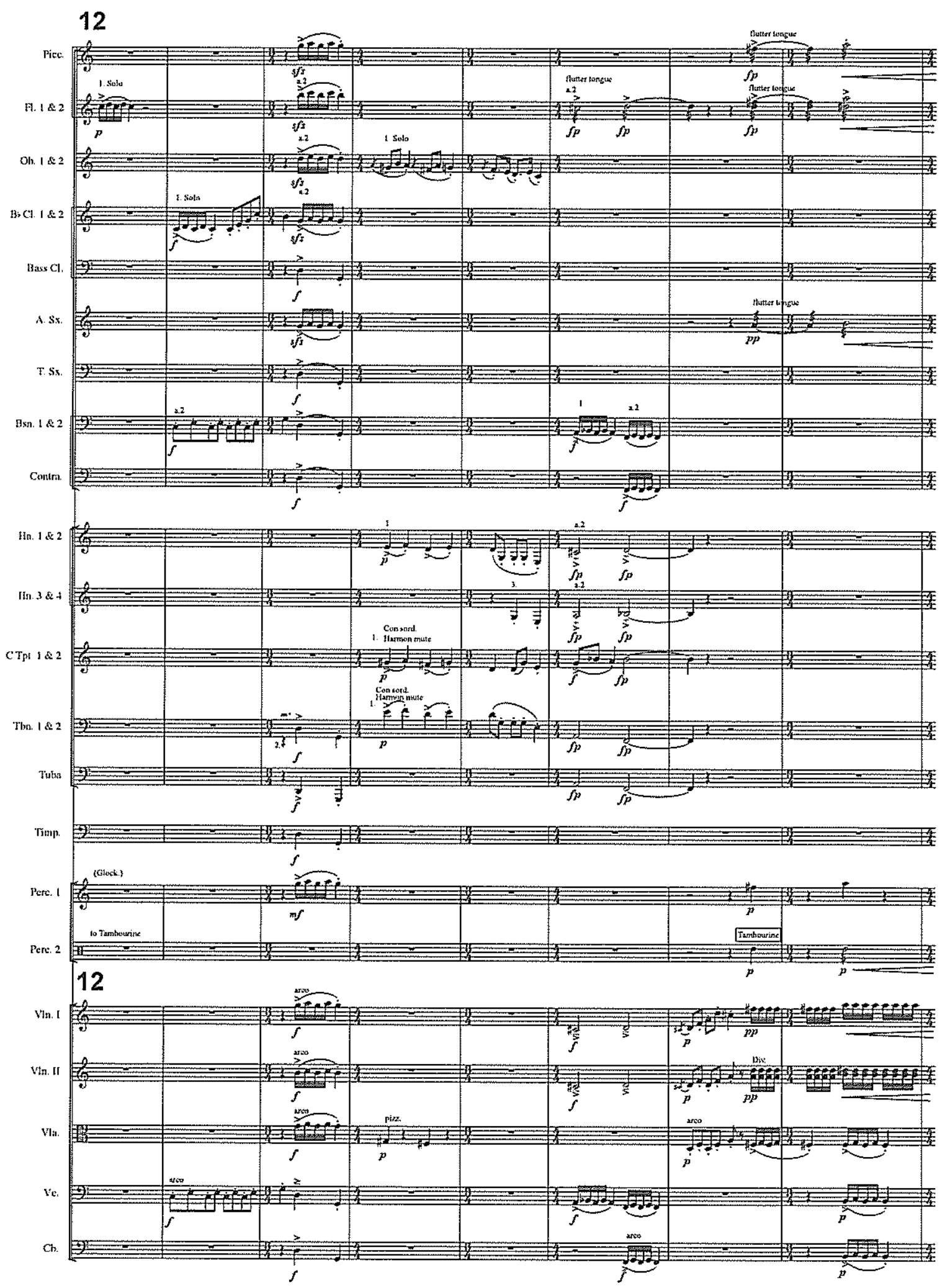




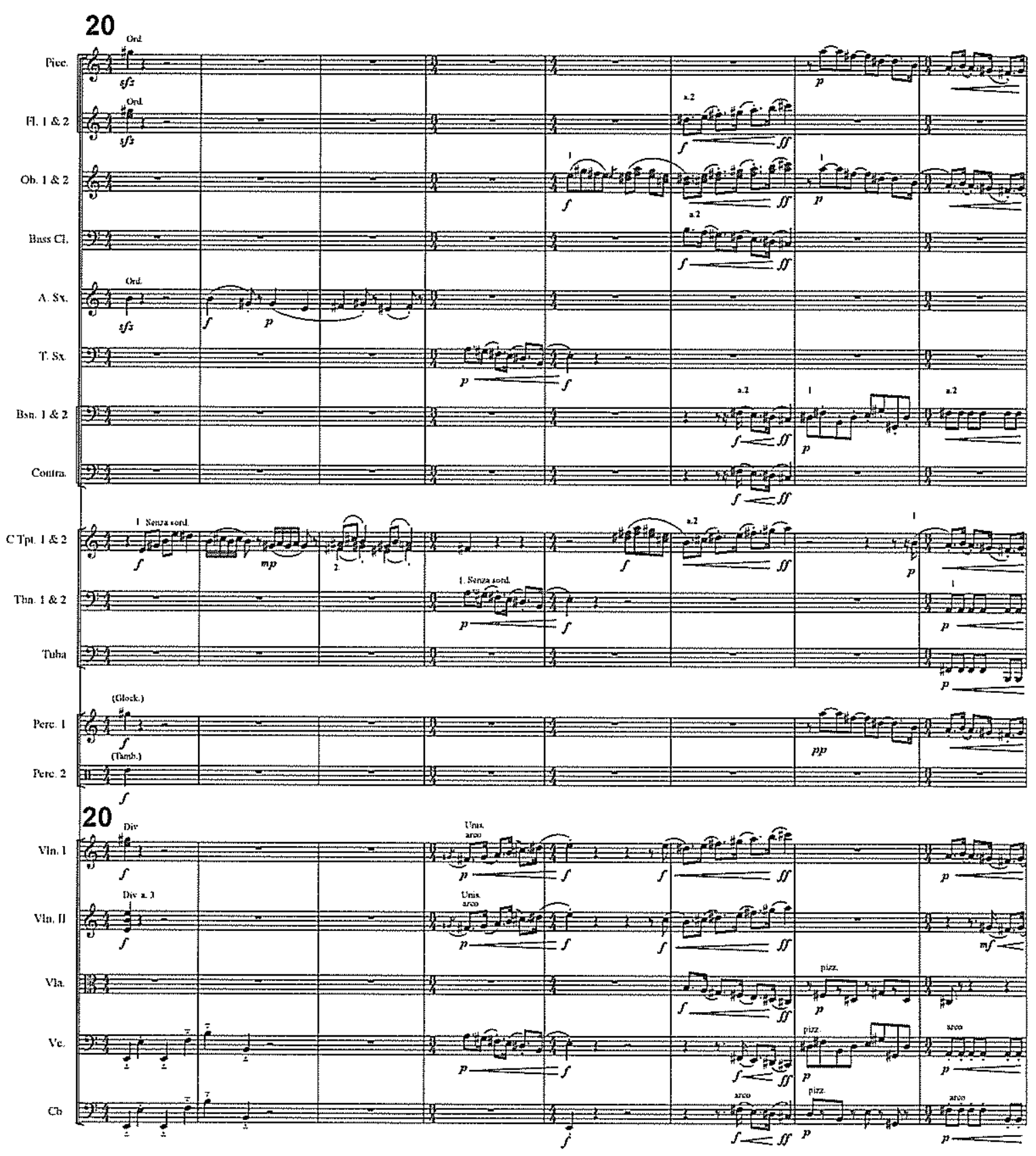




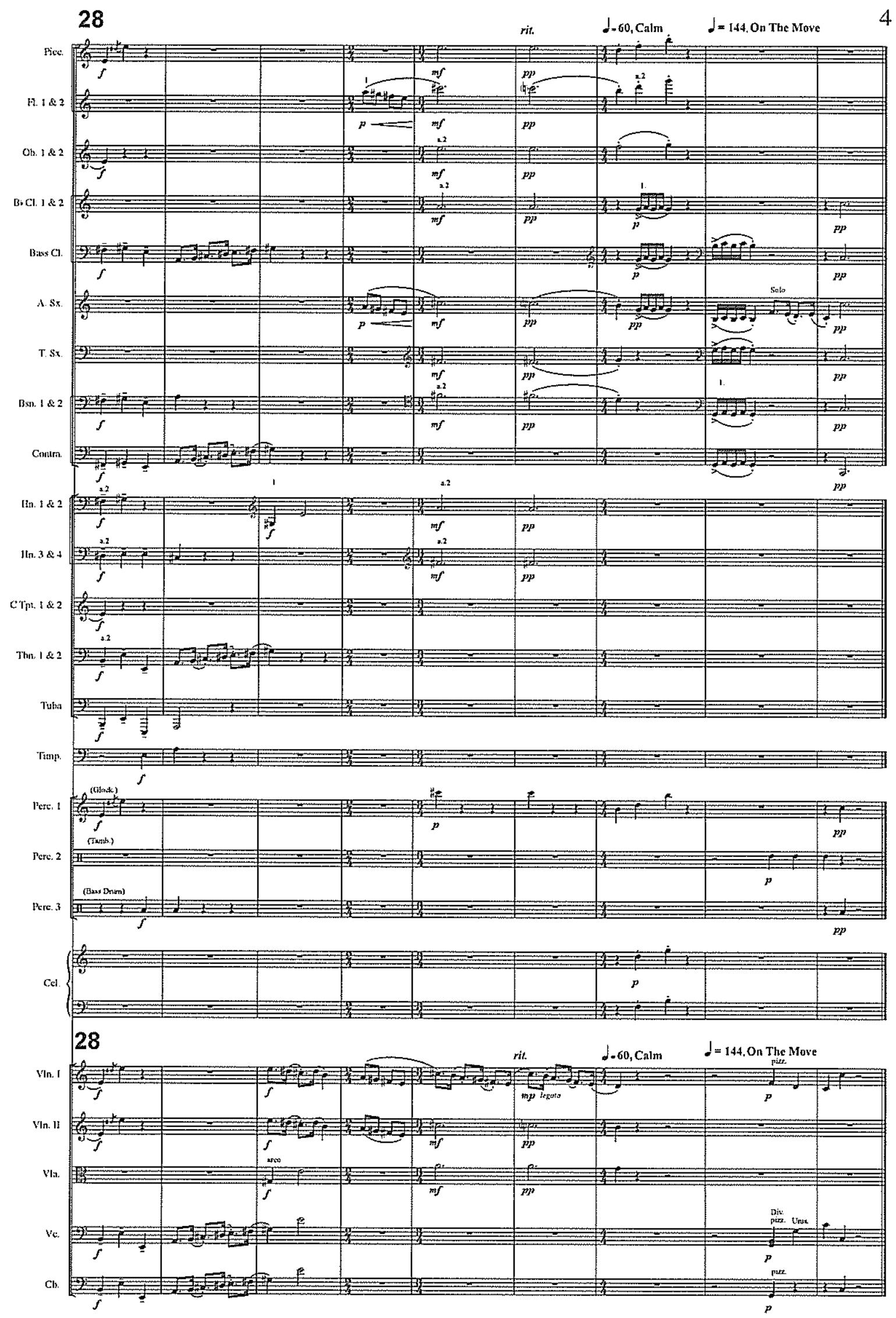




\section{MOVEMENT II}

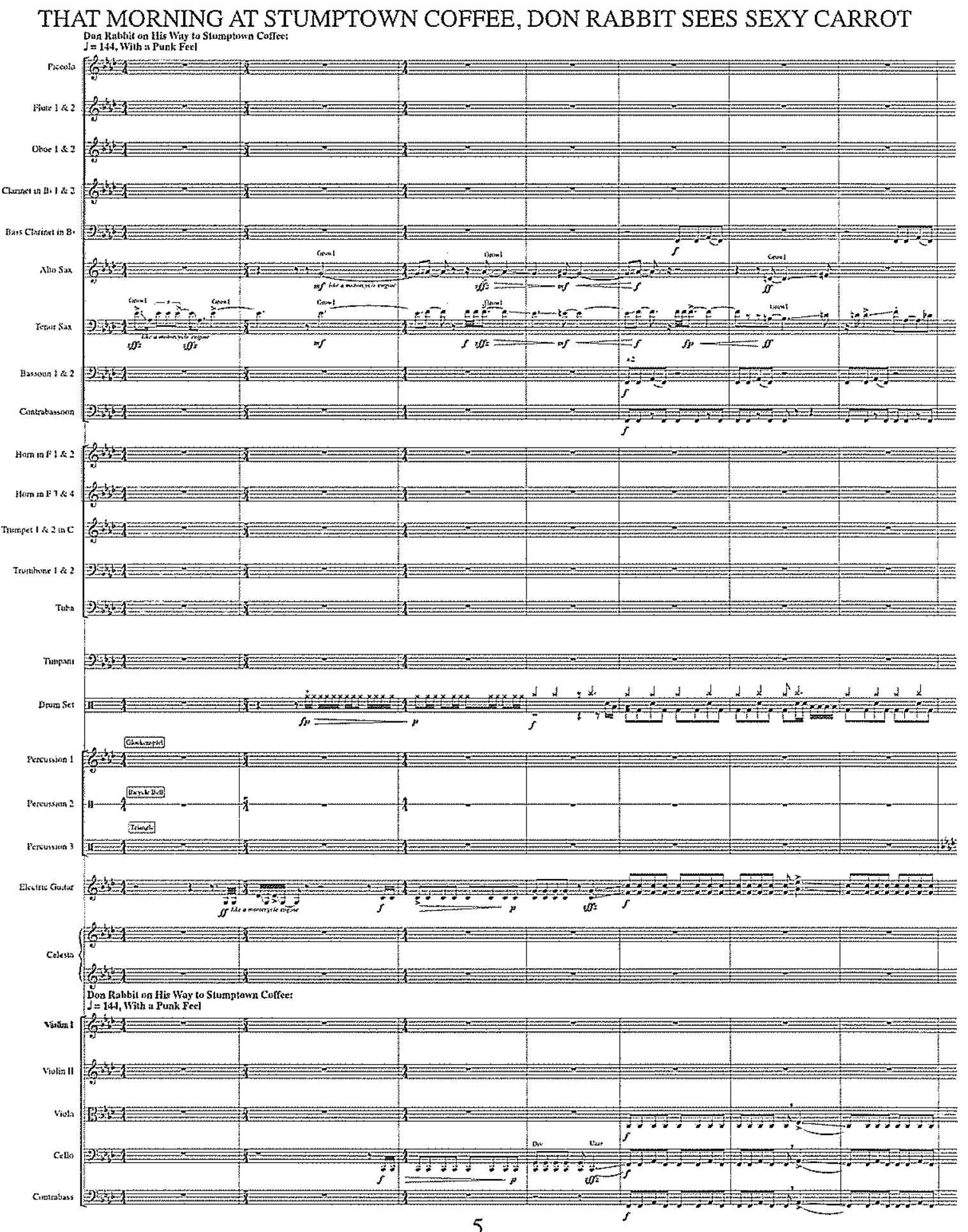




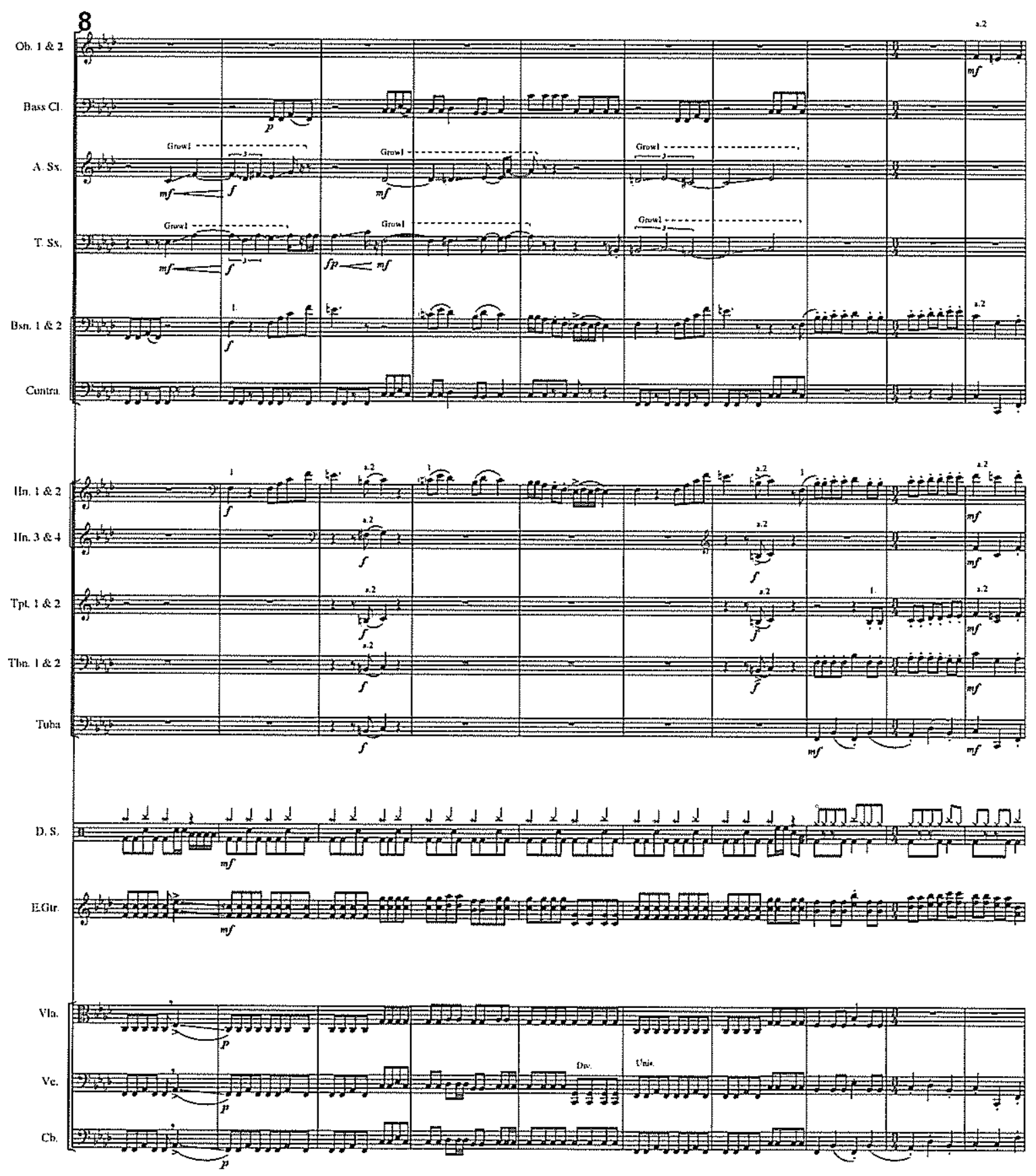



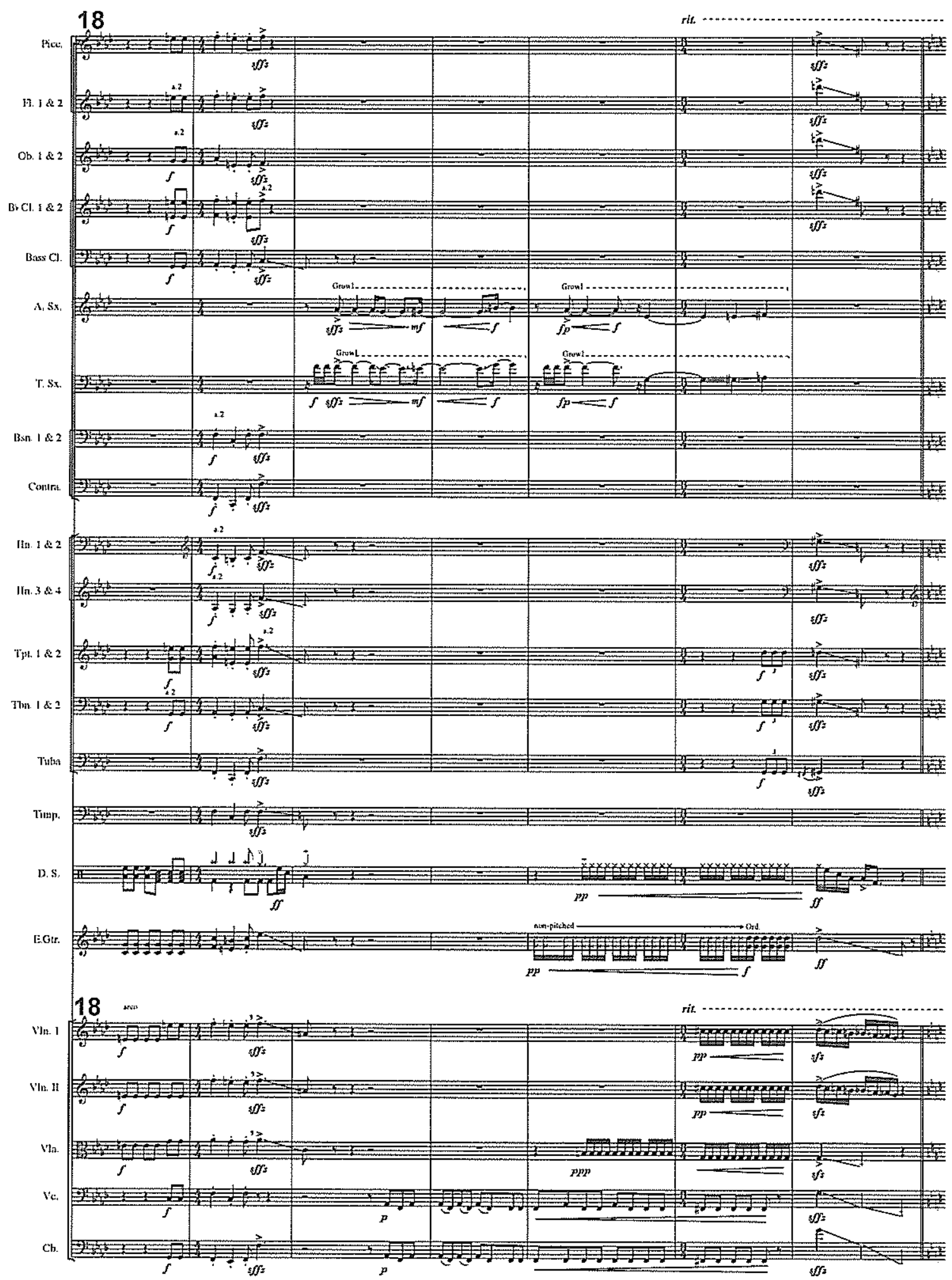


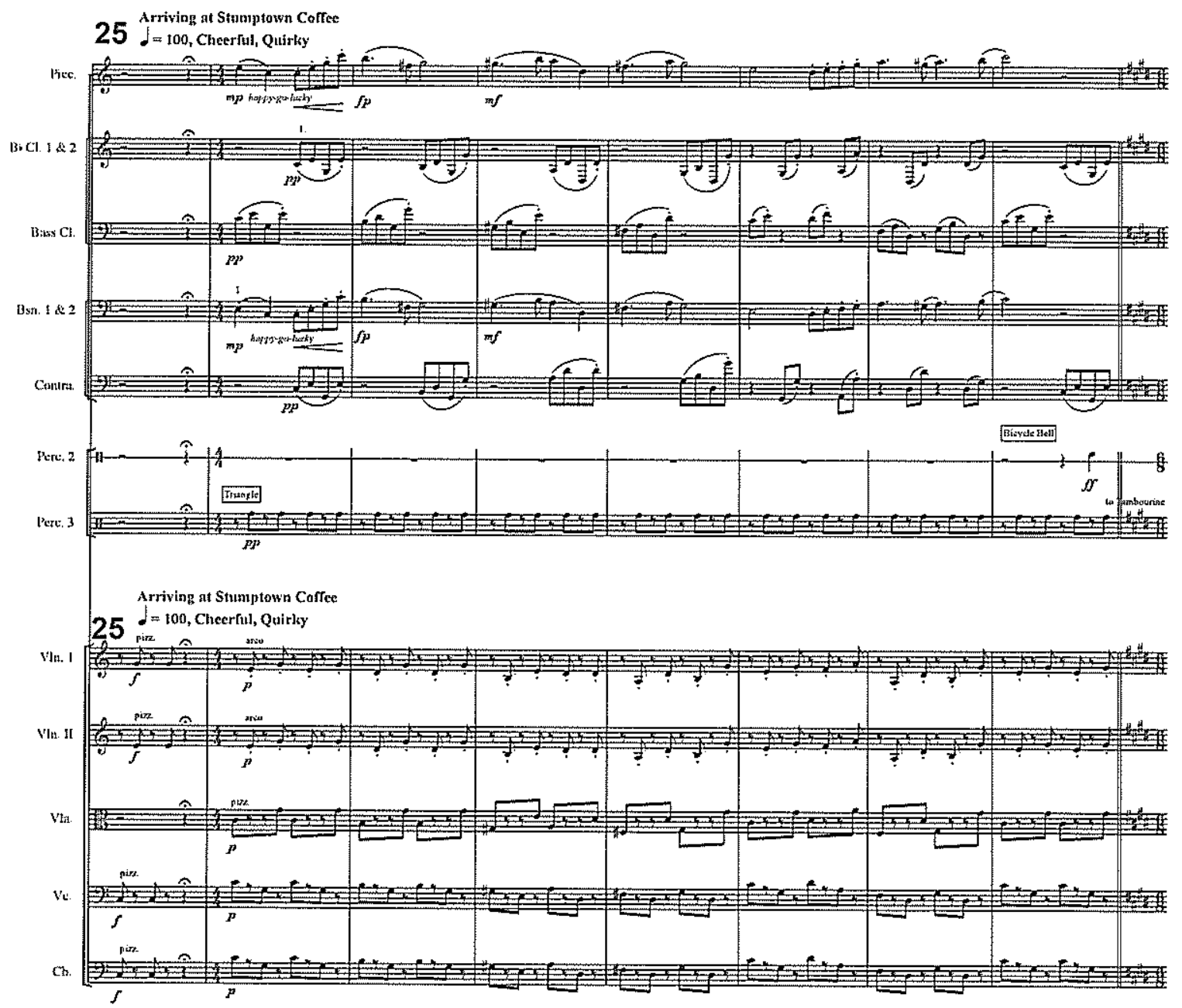


Inside Stumptown Coffee

33 J. - 112, Relnxes, Singer/Song-writer Feel with Some Noise
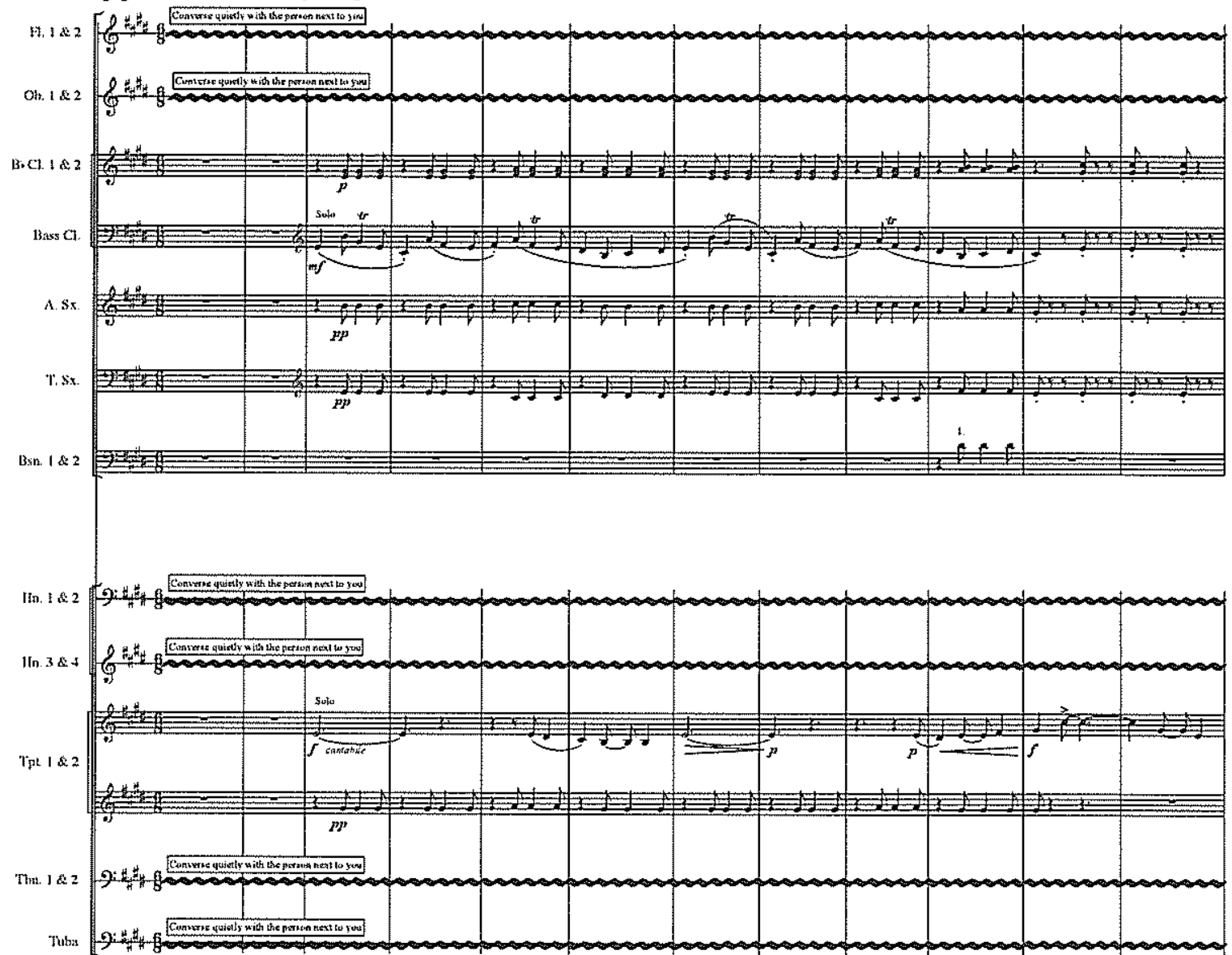

Jubs

Grind Cotres

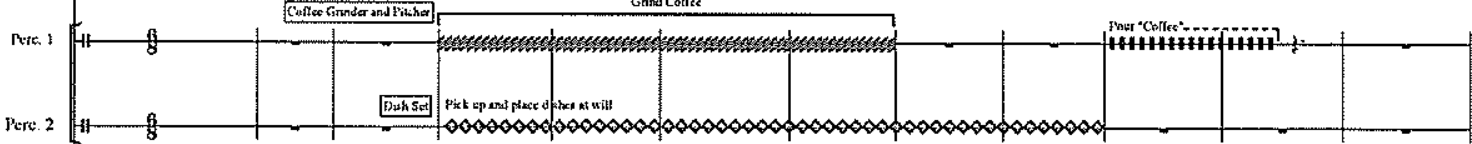

Insile Stuntpiown Coffee

33 d. *112, Relaxed, Singer/Sang-writer Feel with Some Noise

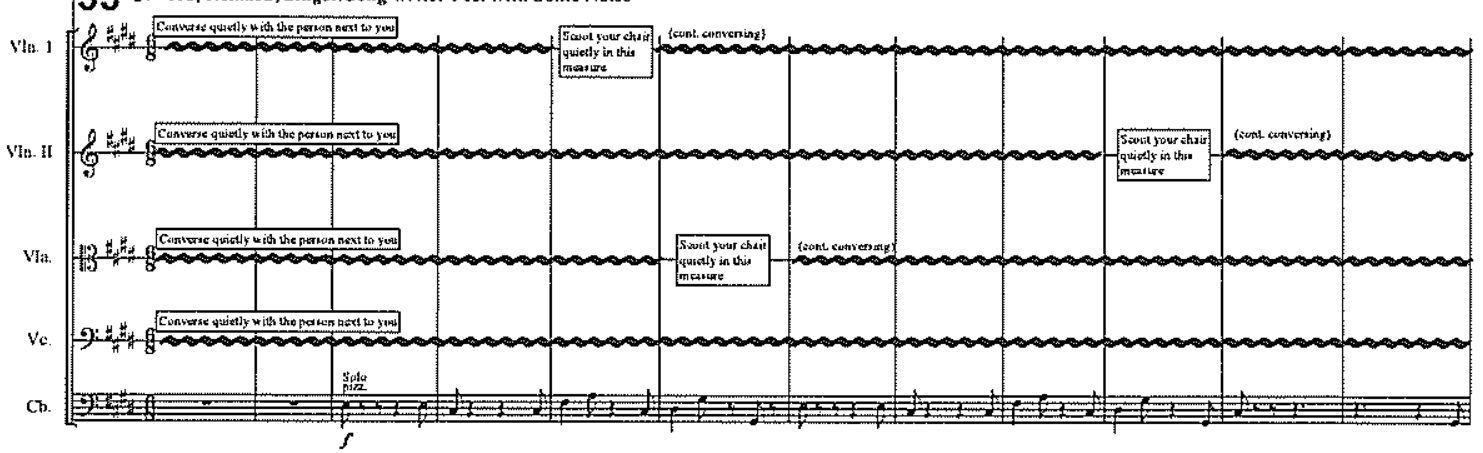




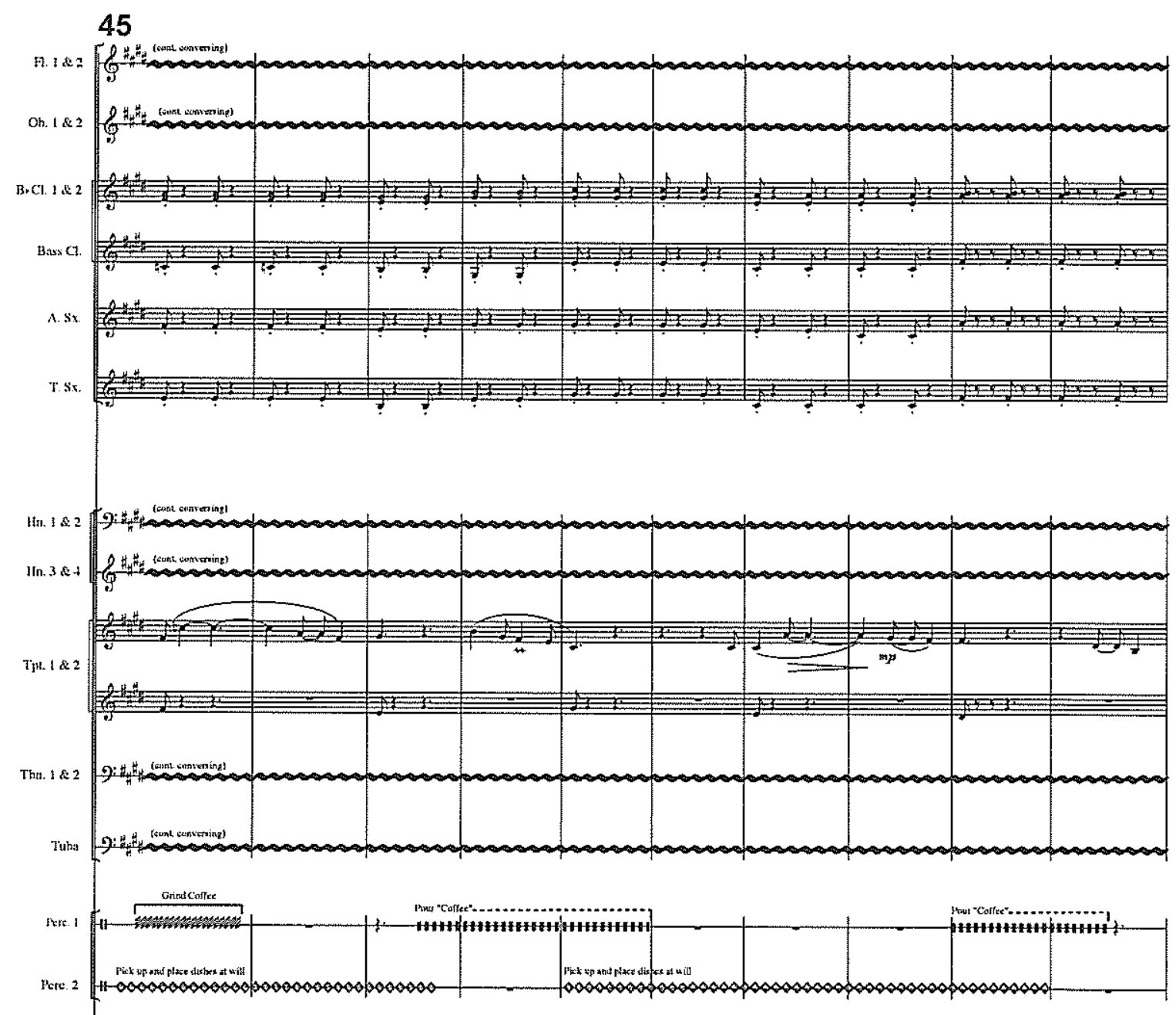

45

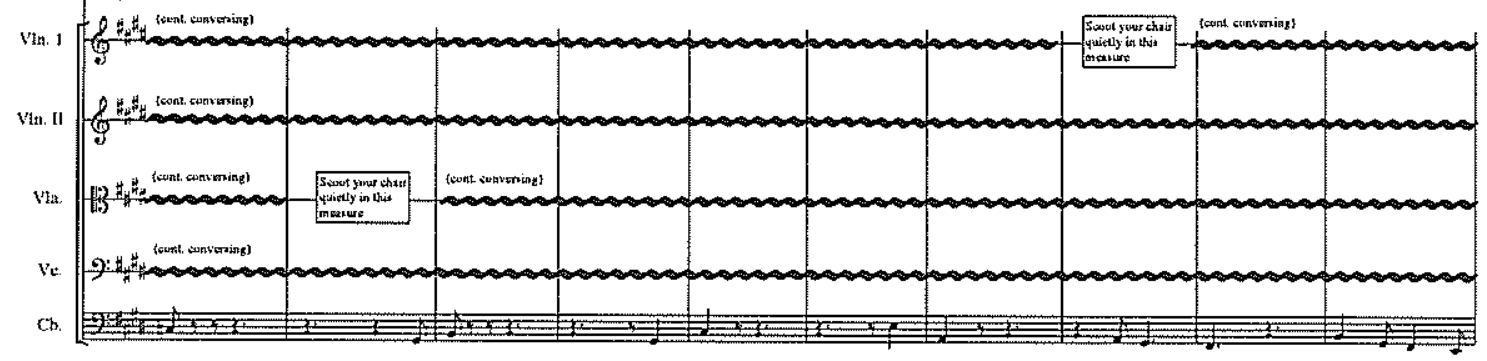




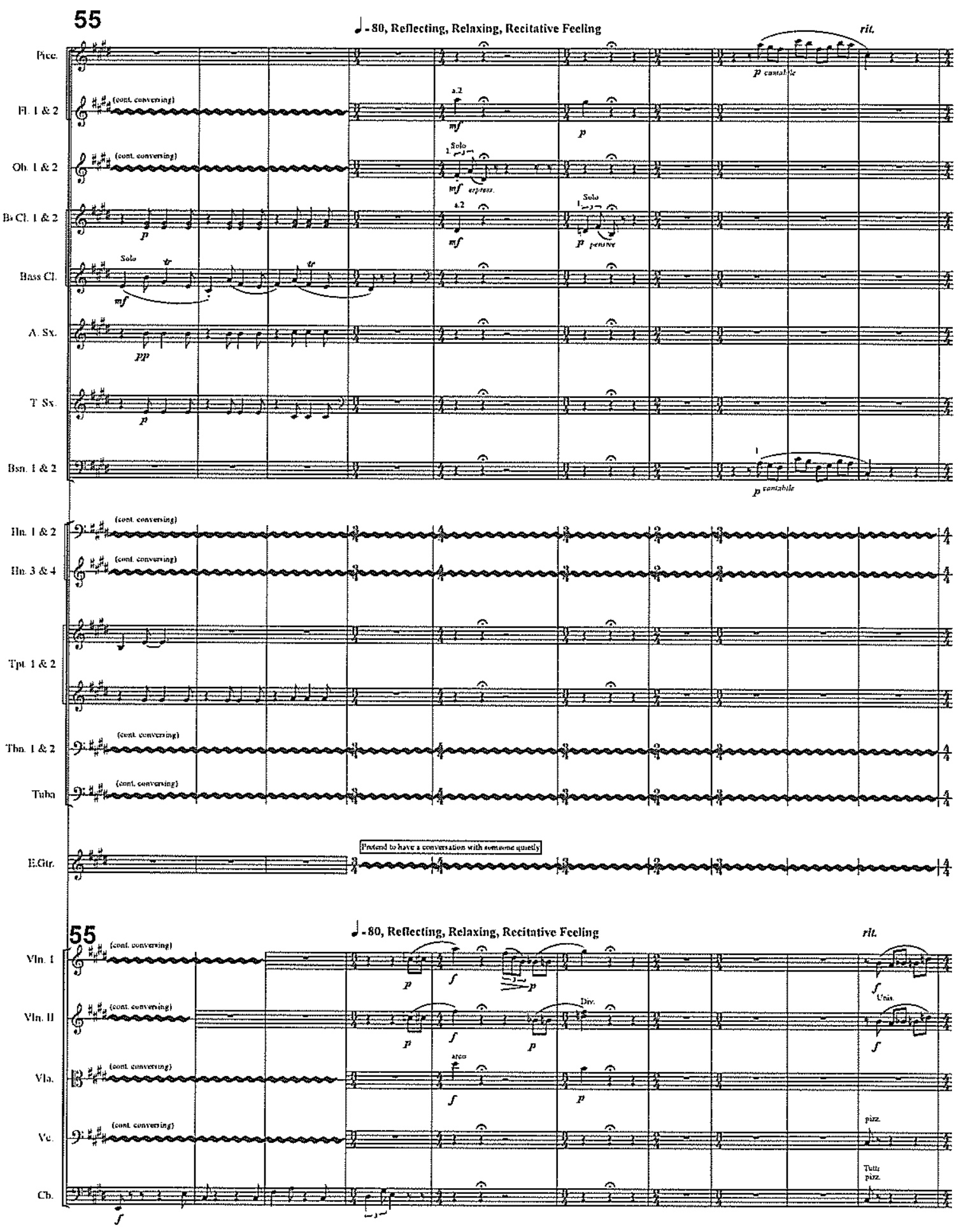




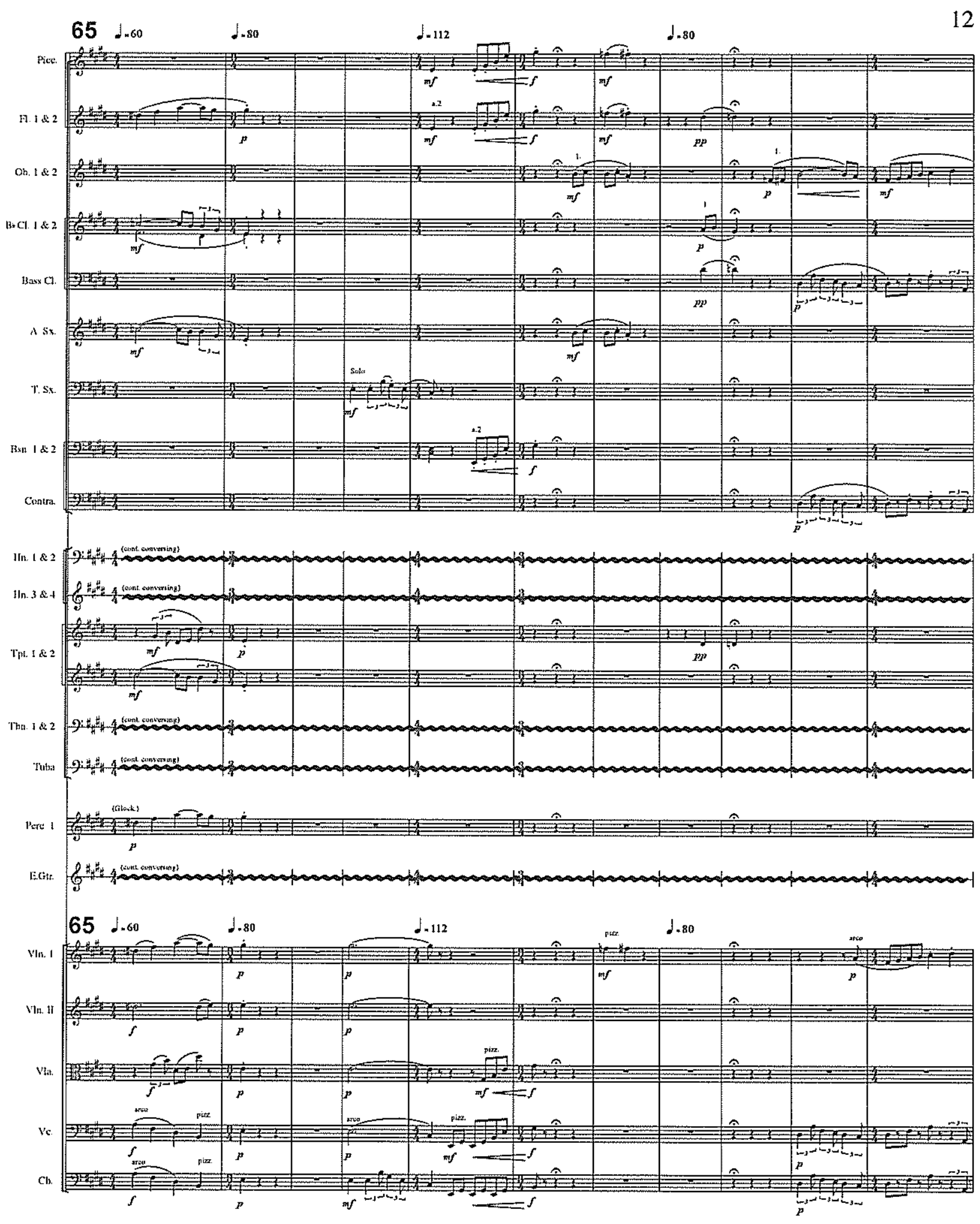




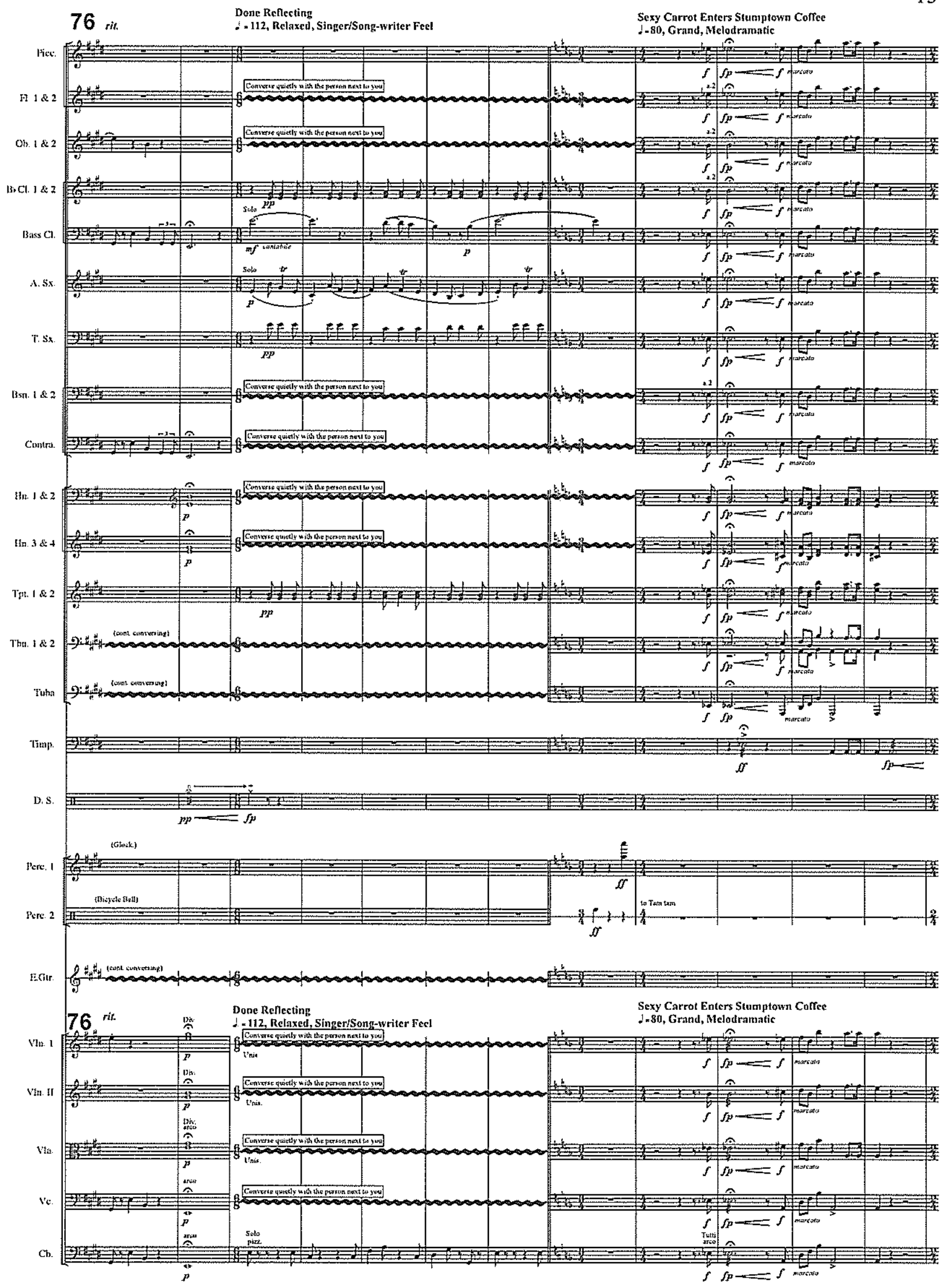




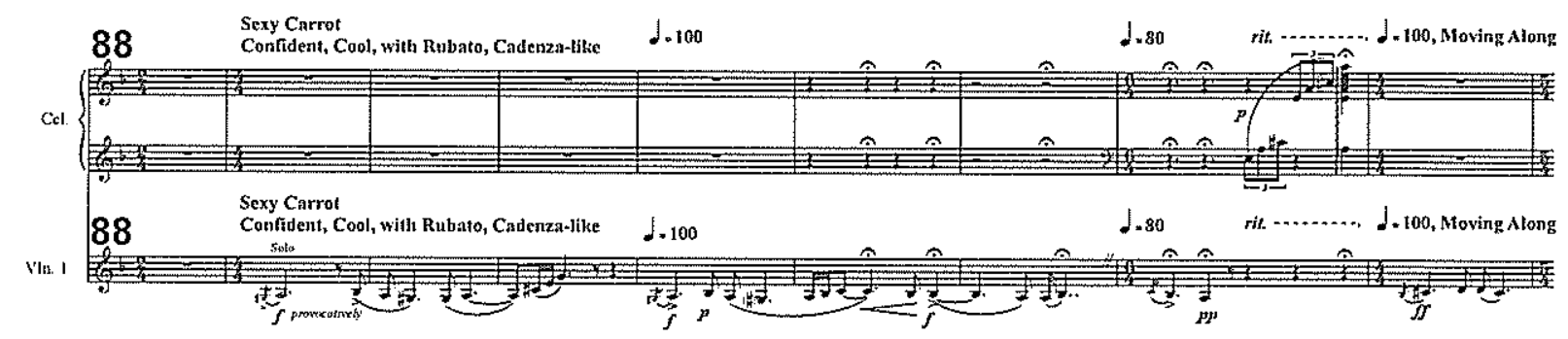




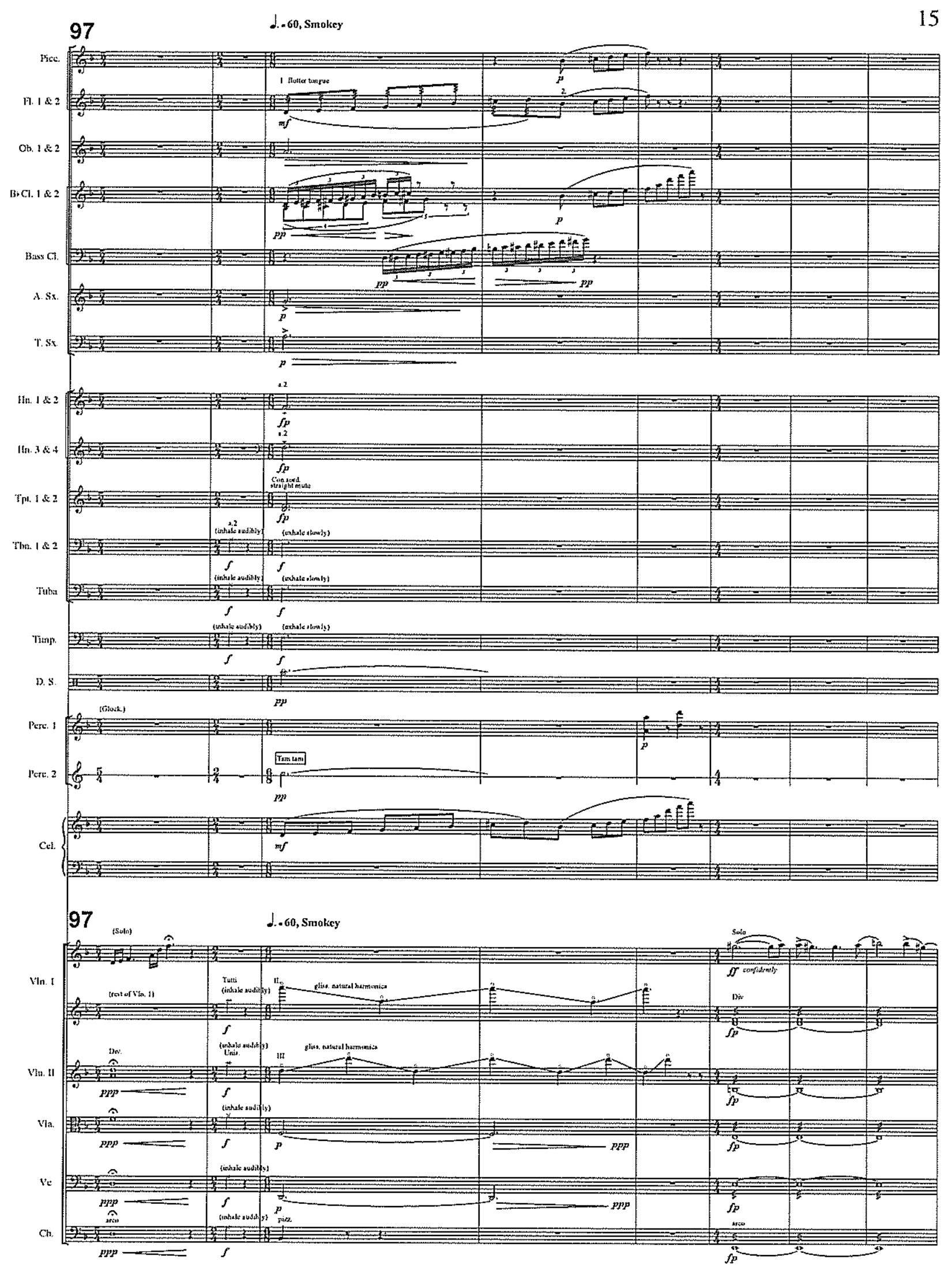




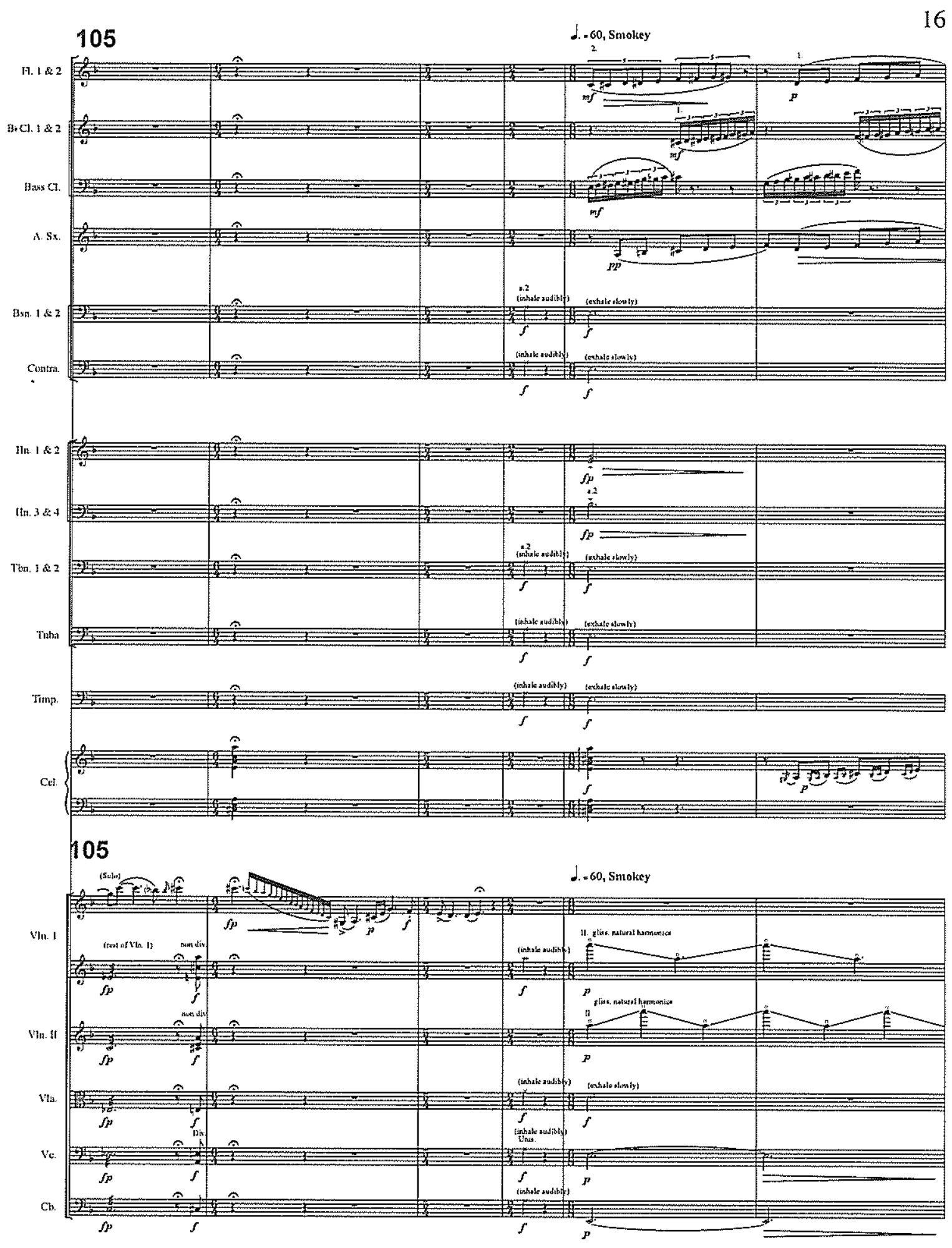




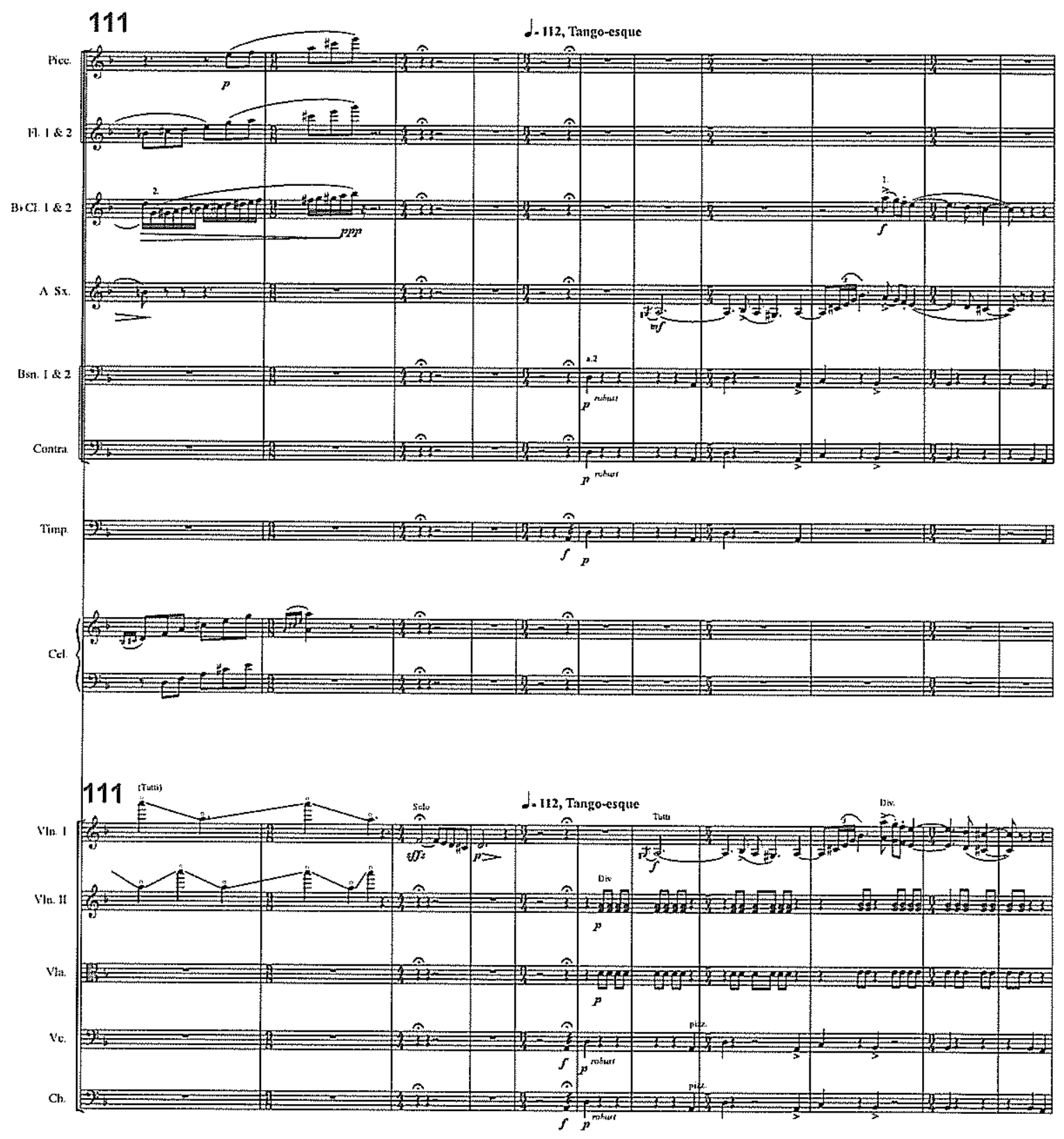




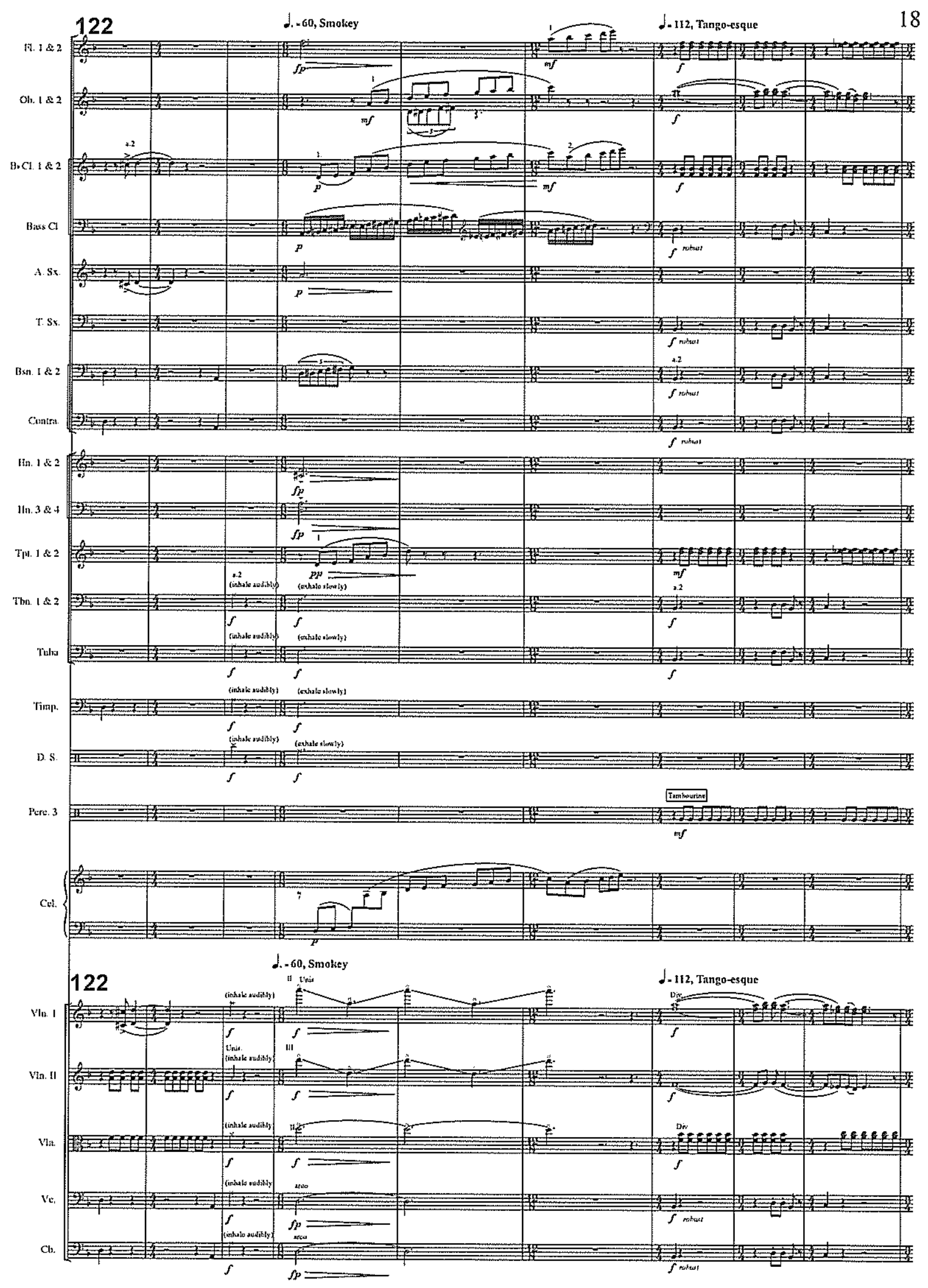




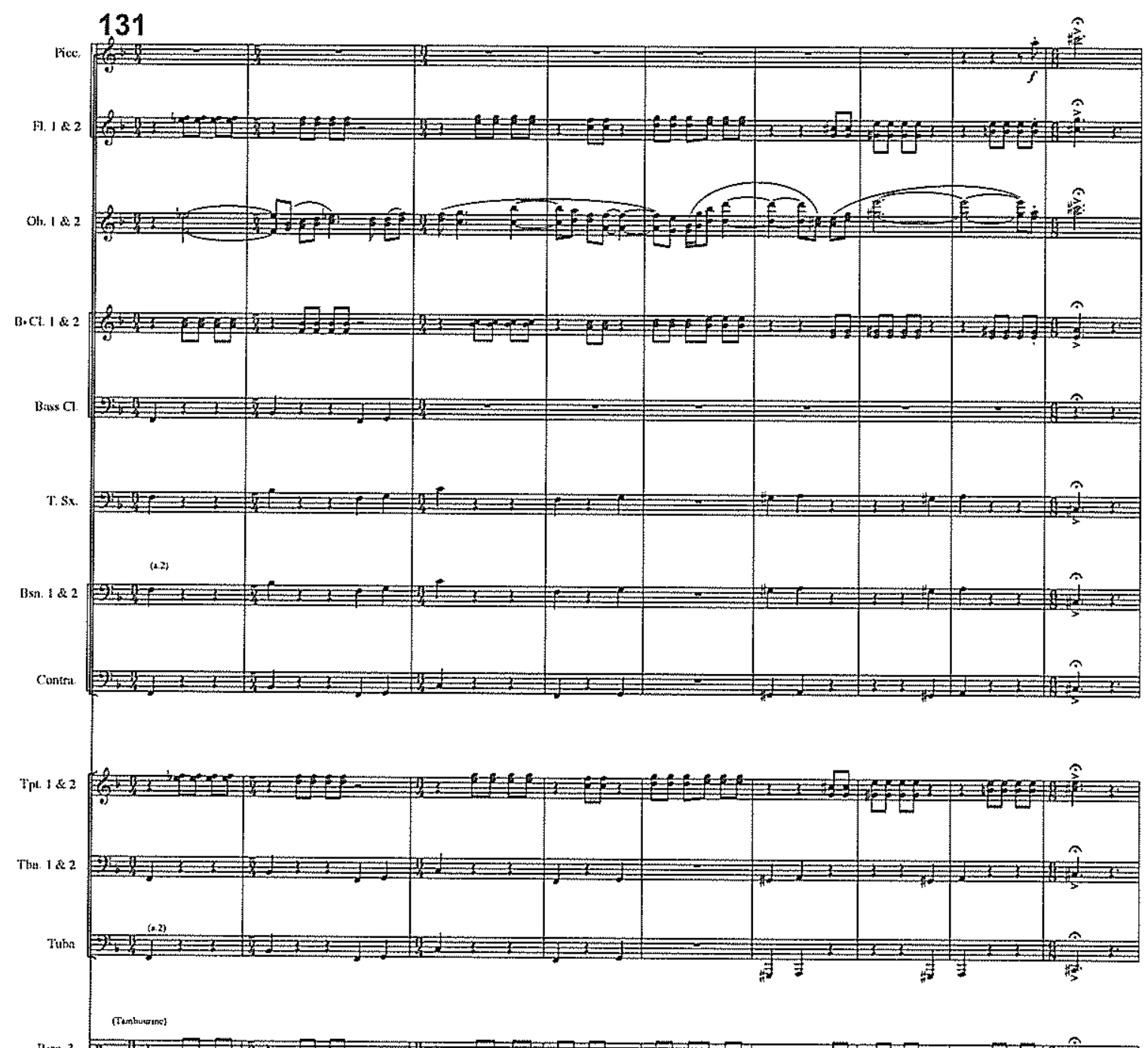

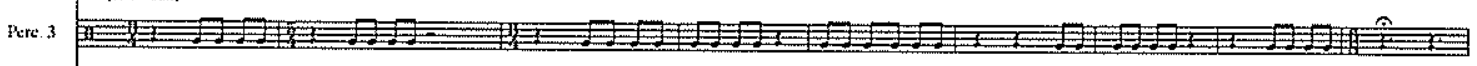

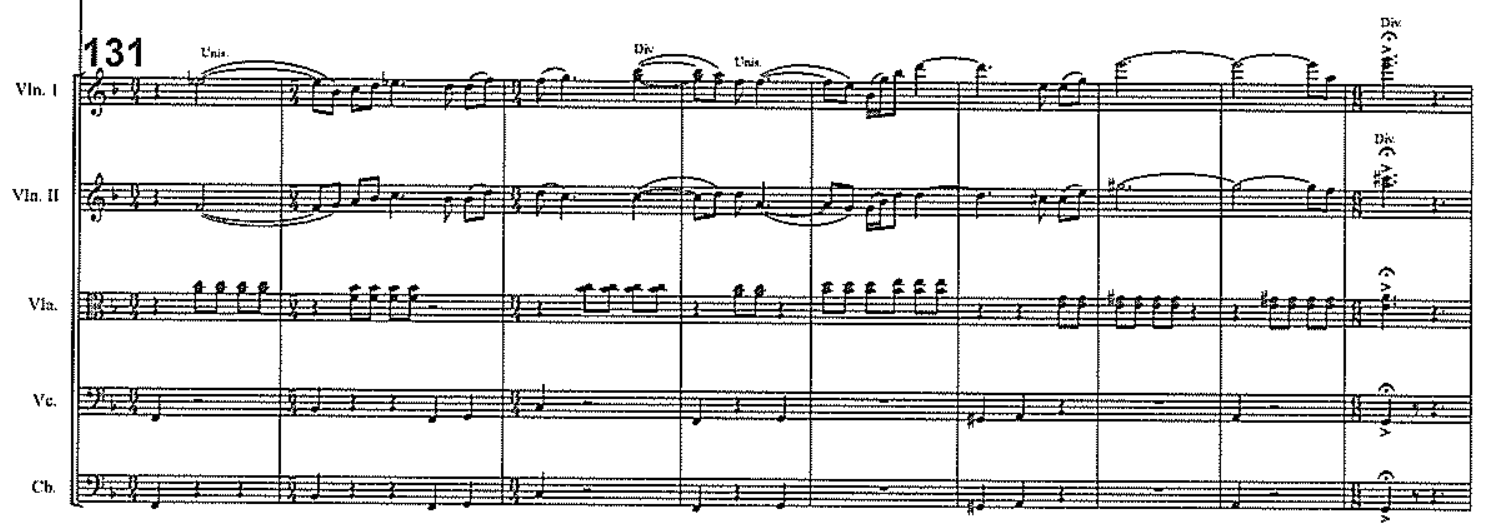




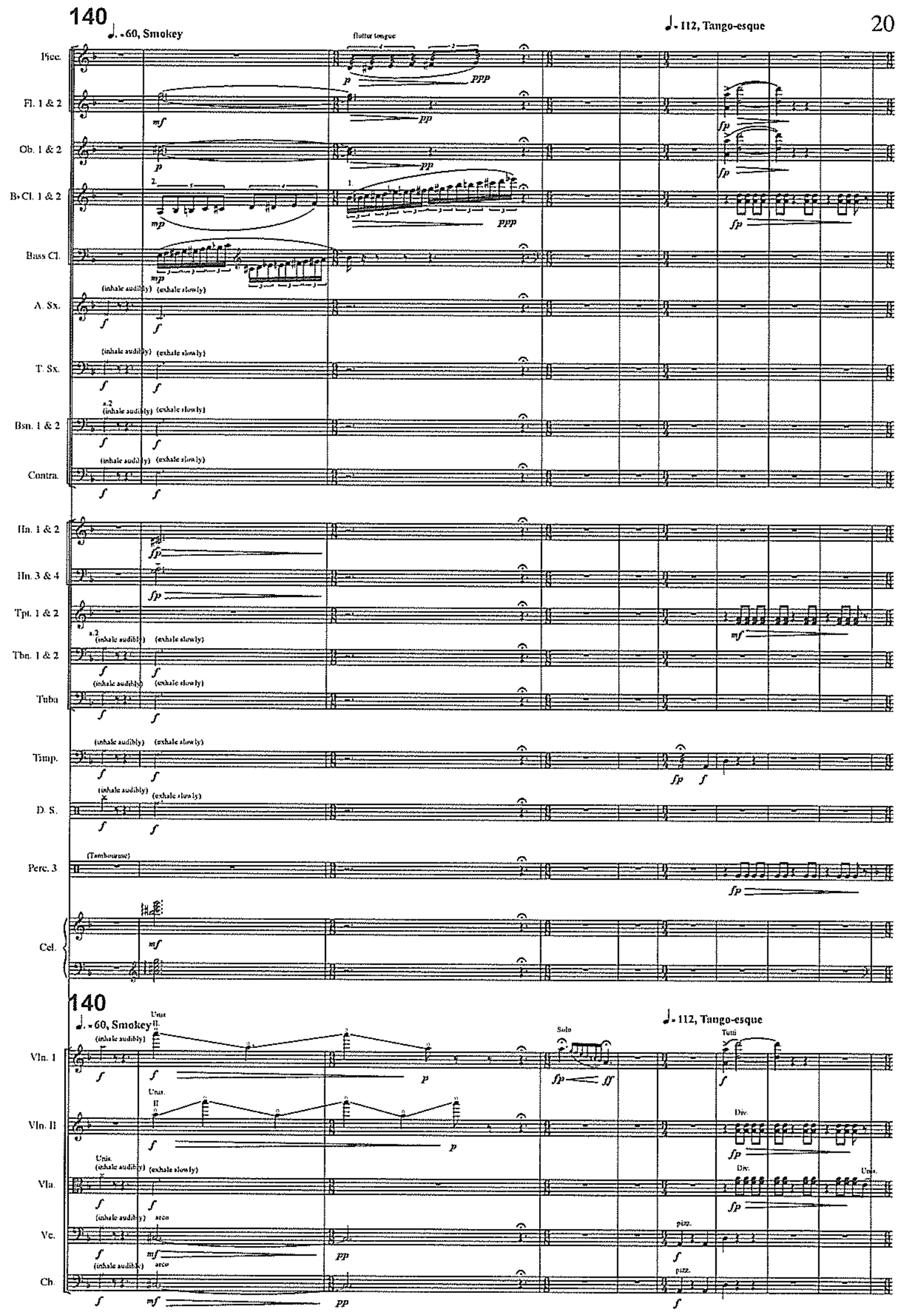



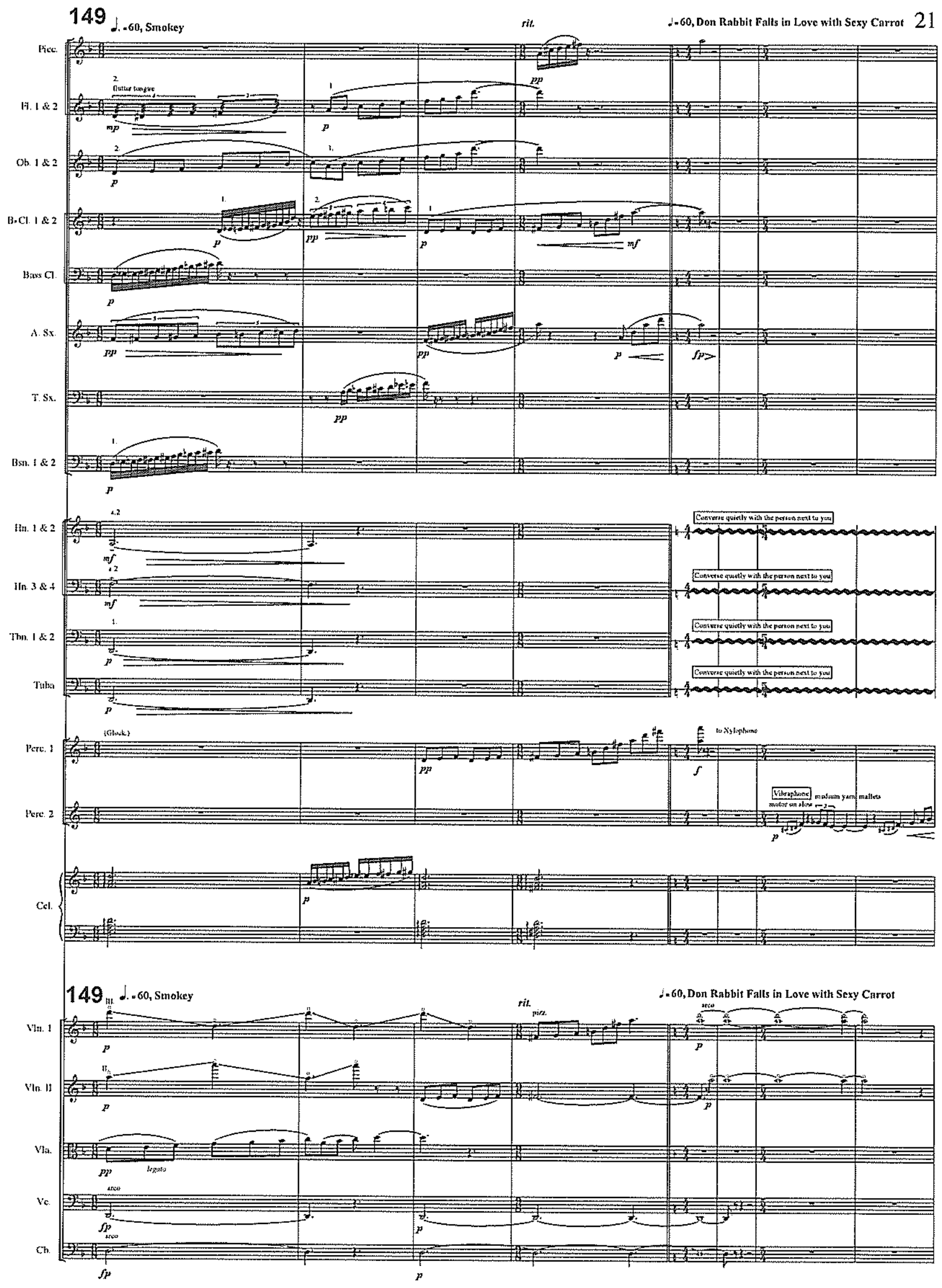


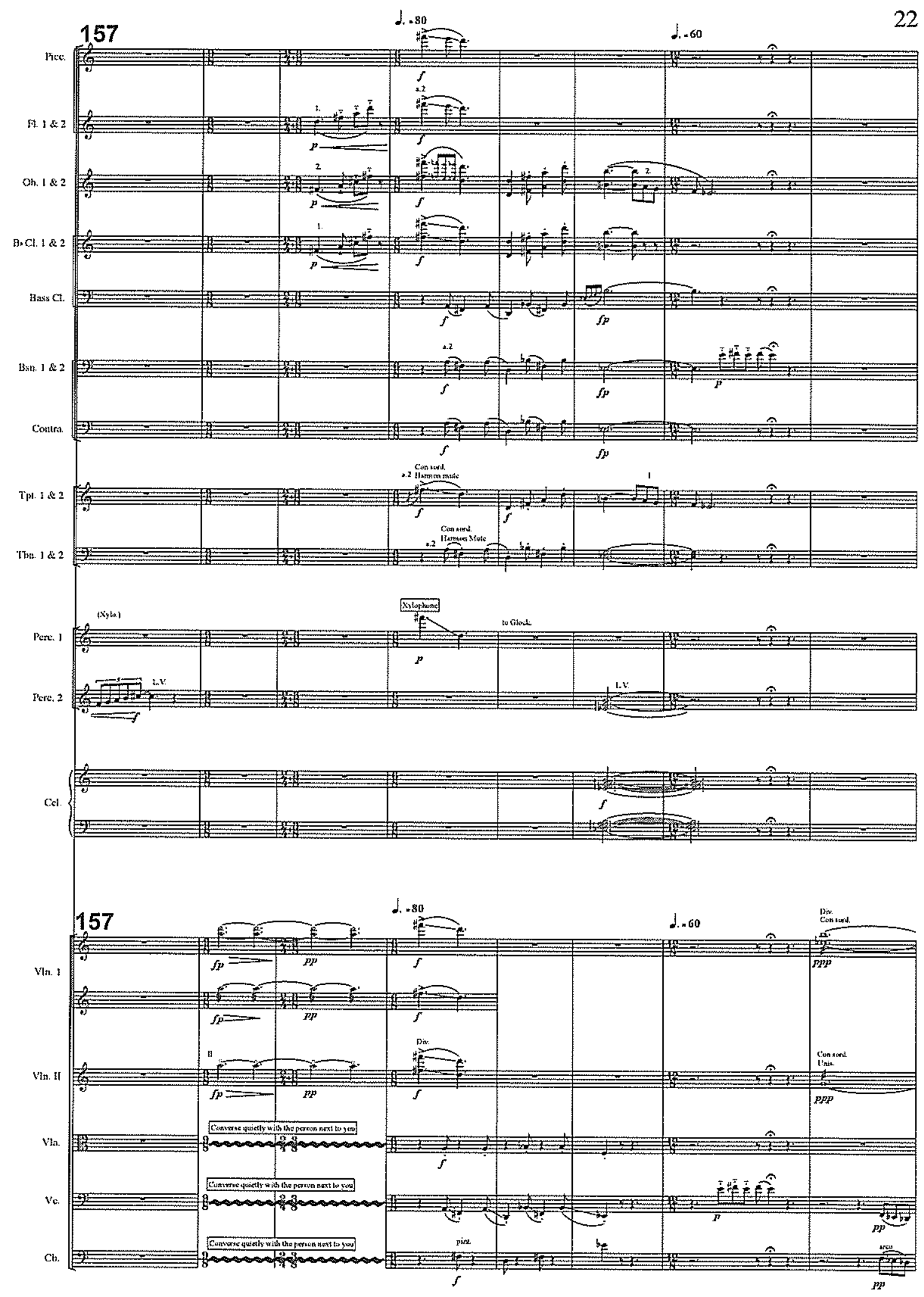



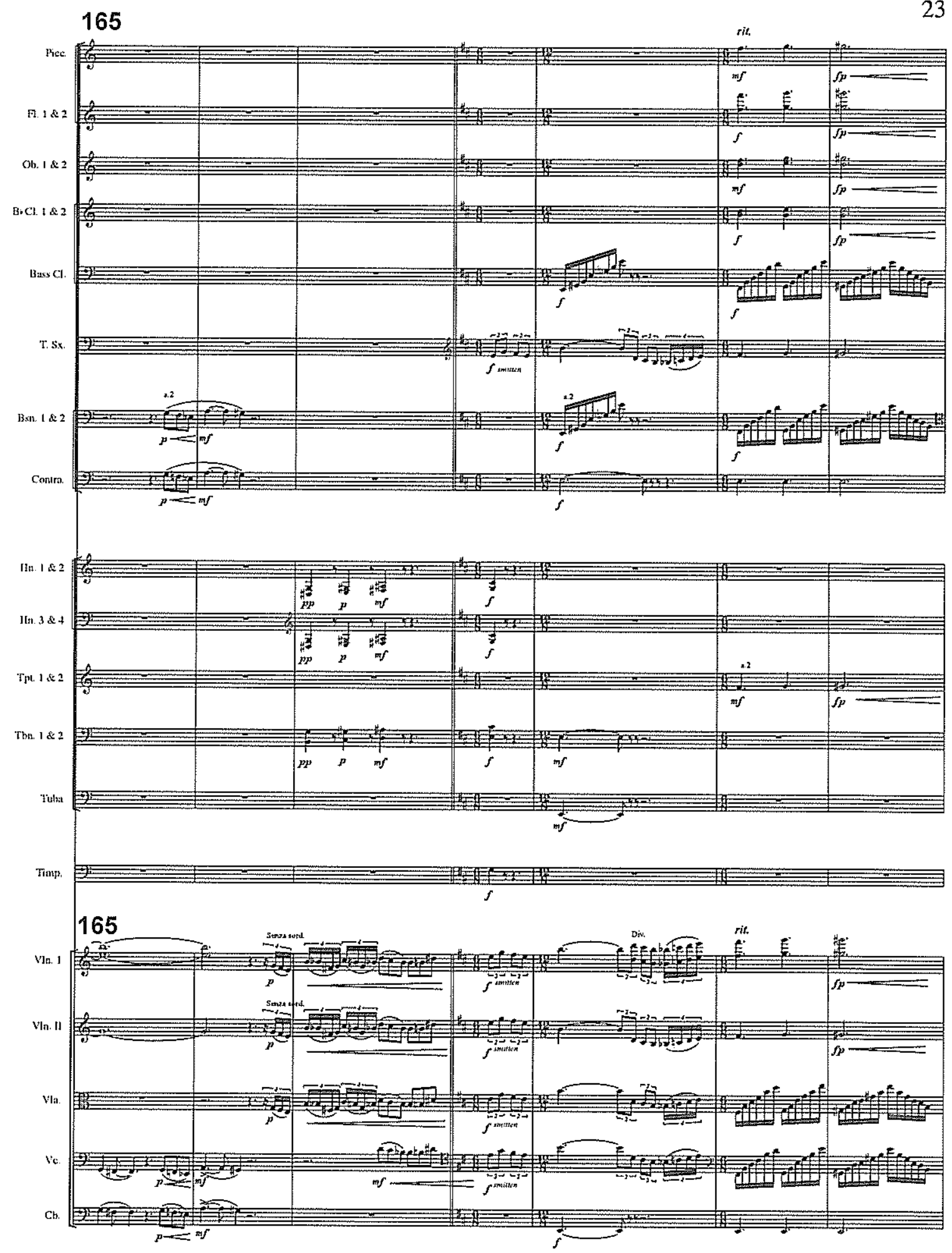


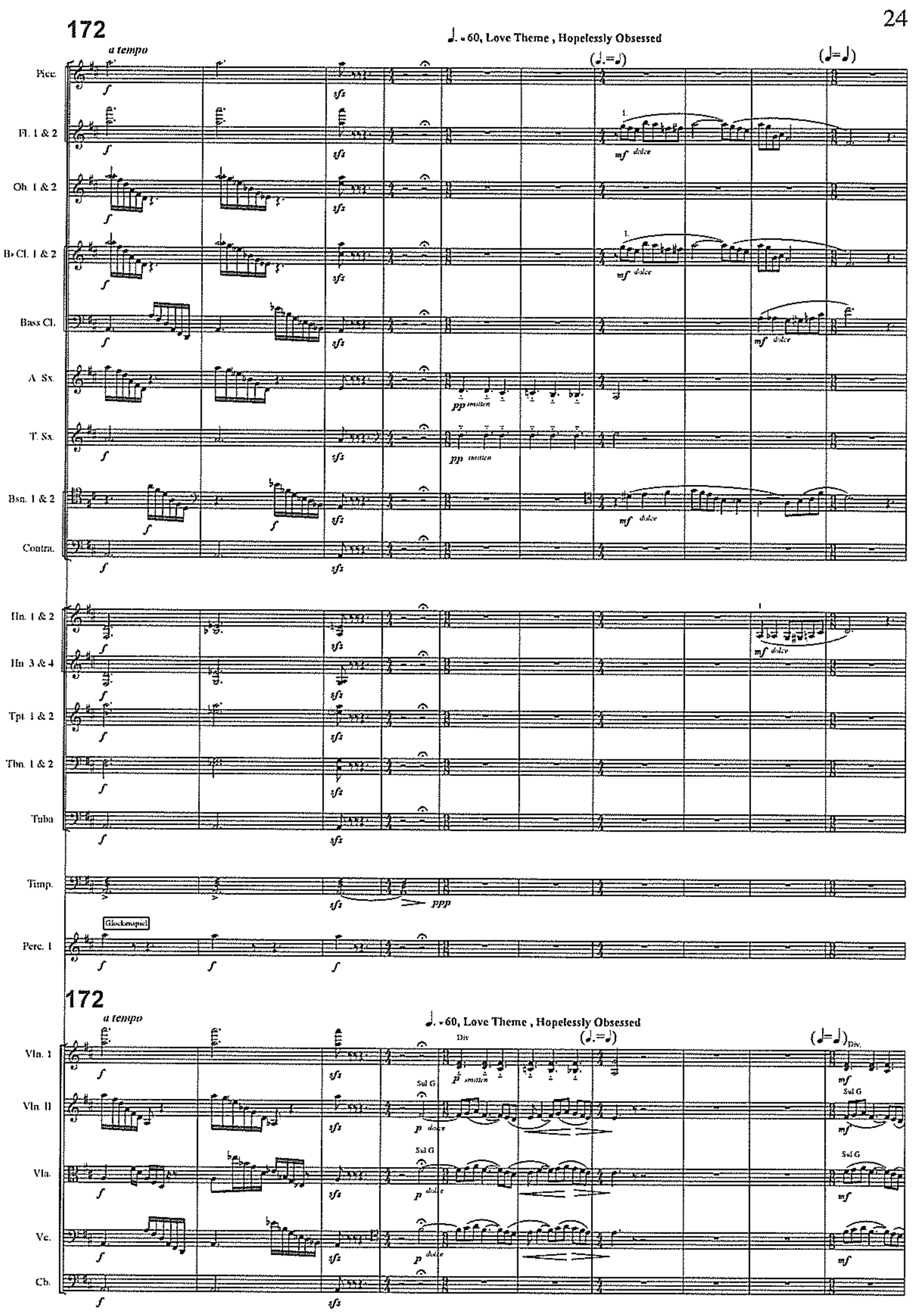




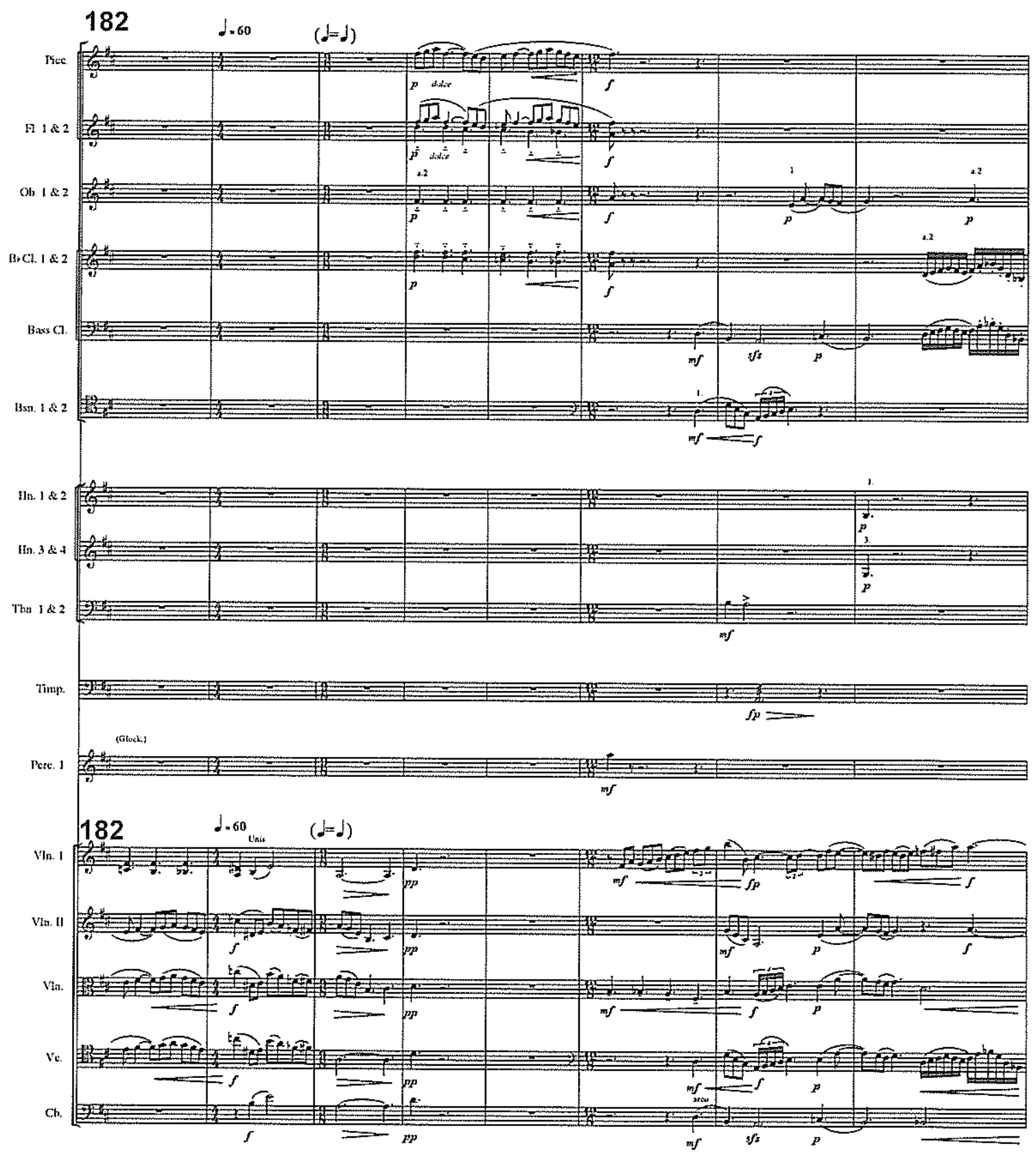




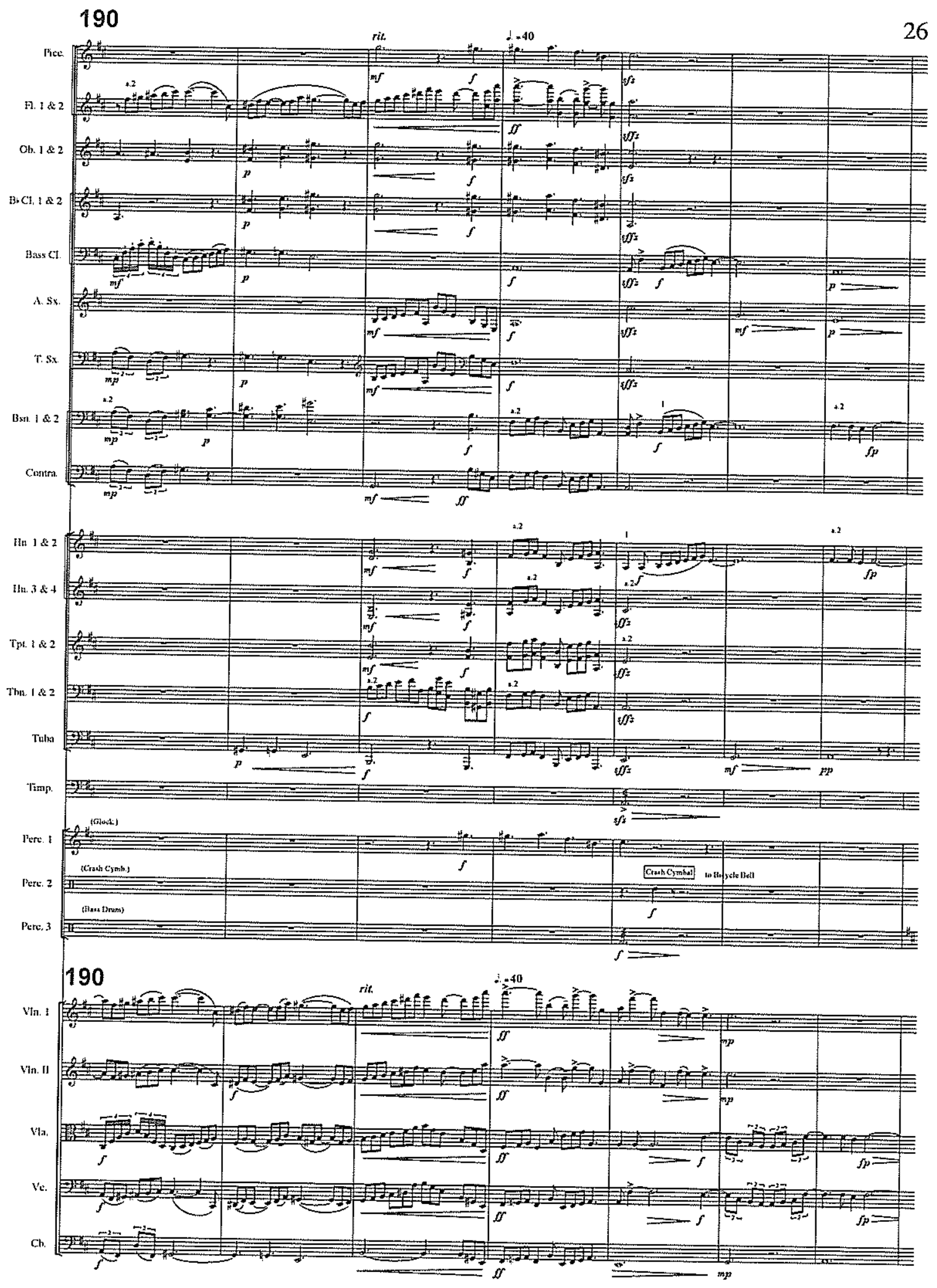




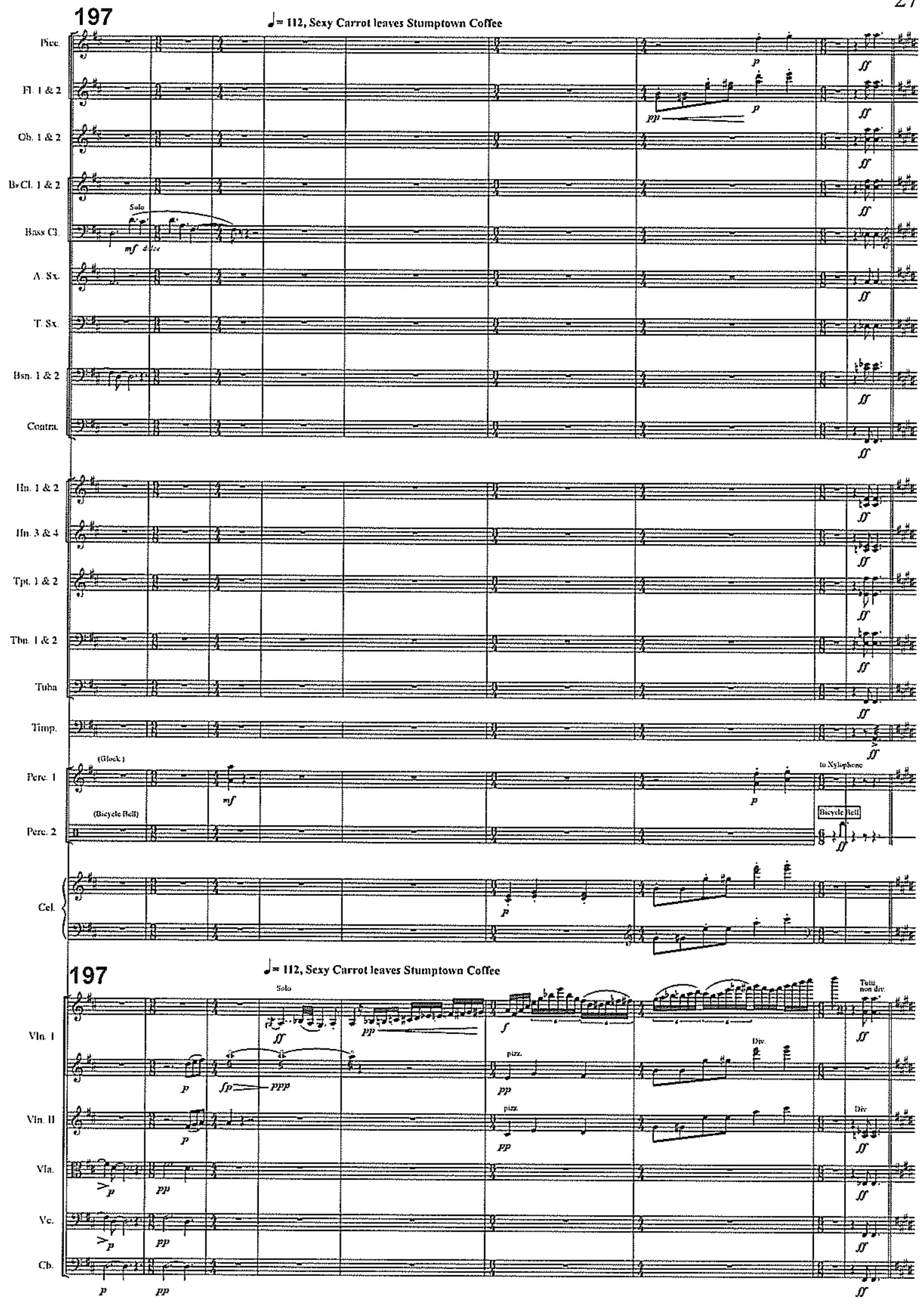


206

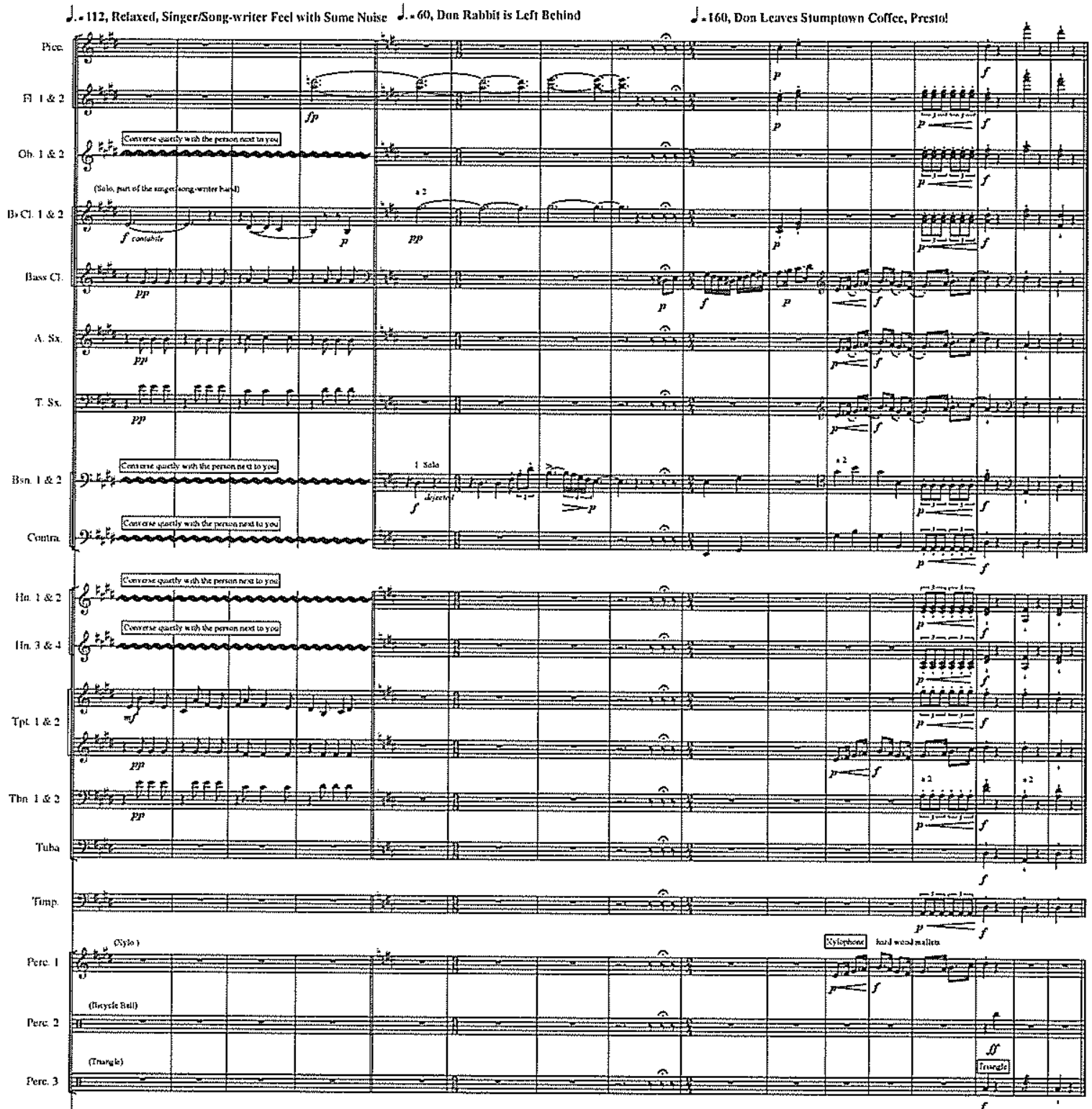

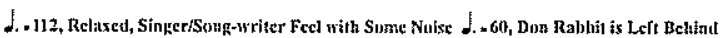

d-16u, Don Leares Stumptuwn Curree, Prestu!

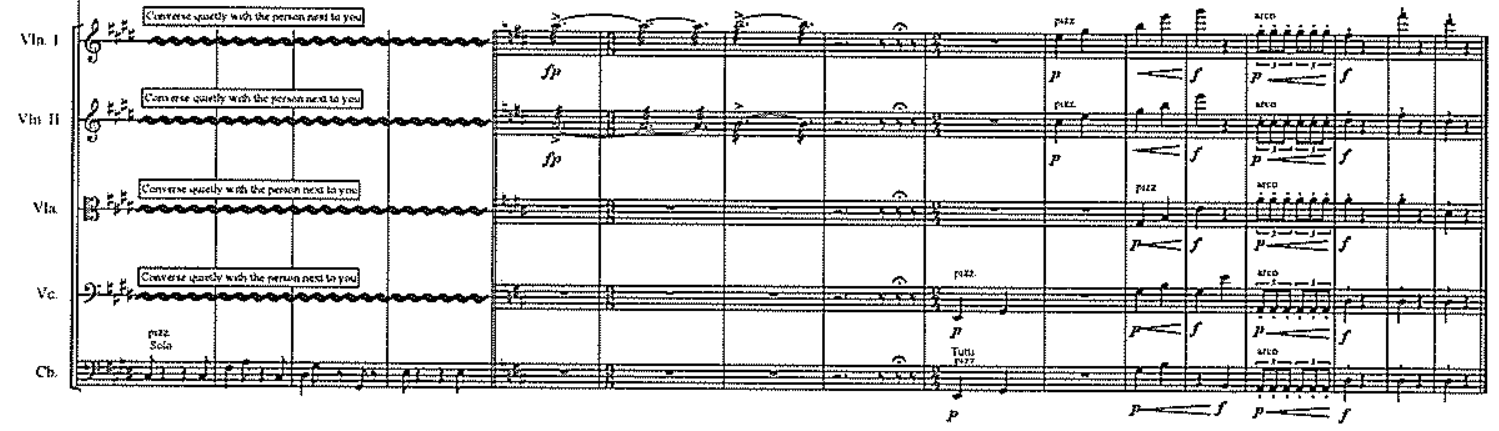




\section{MOVEMENT III}

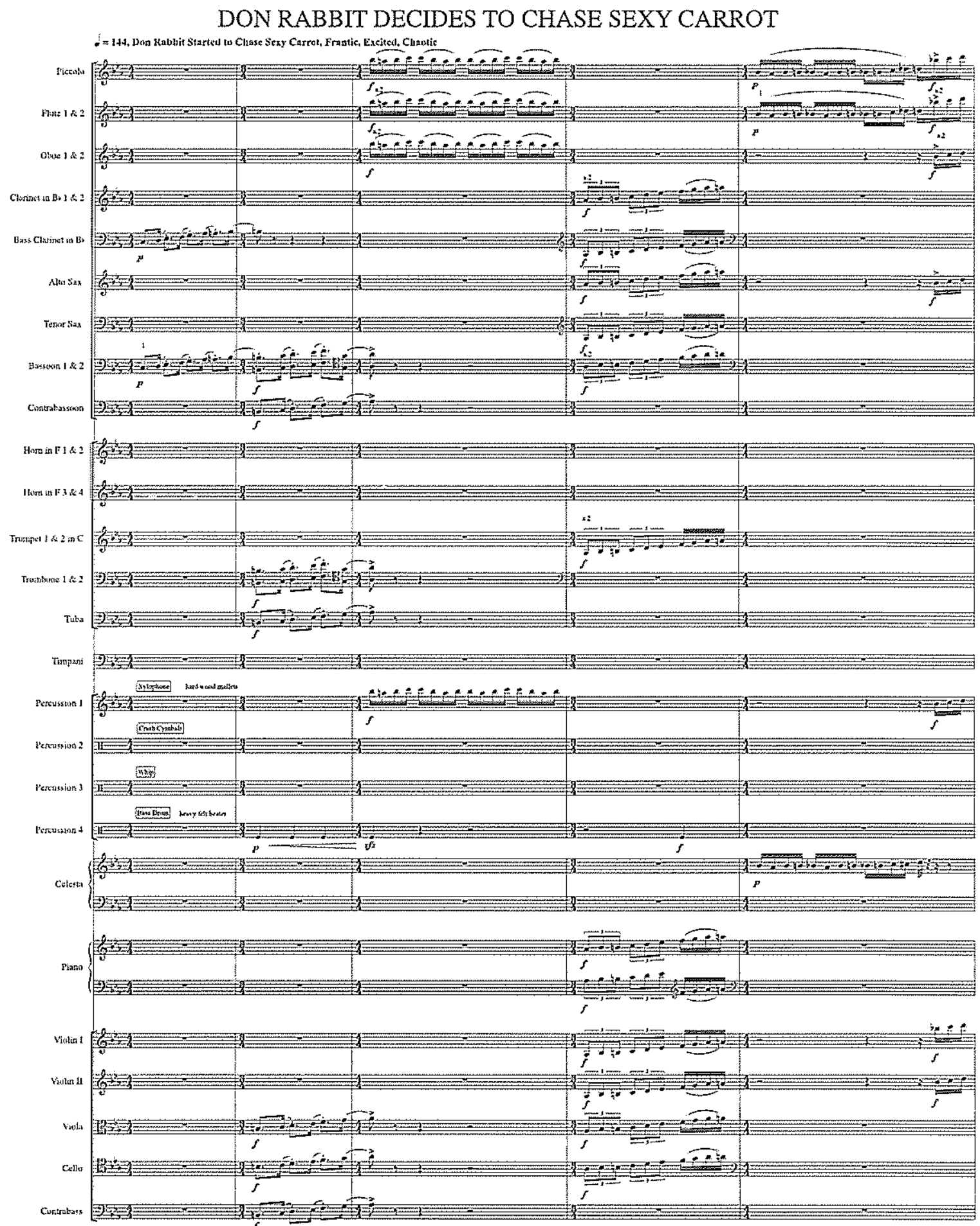




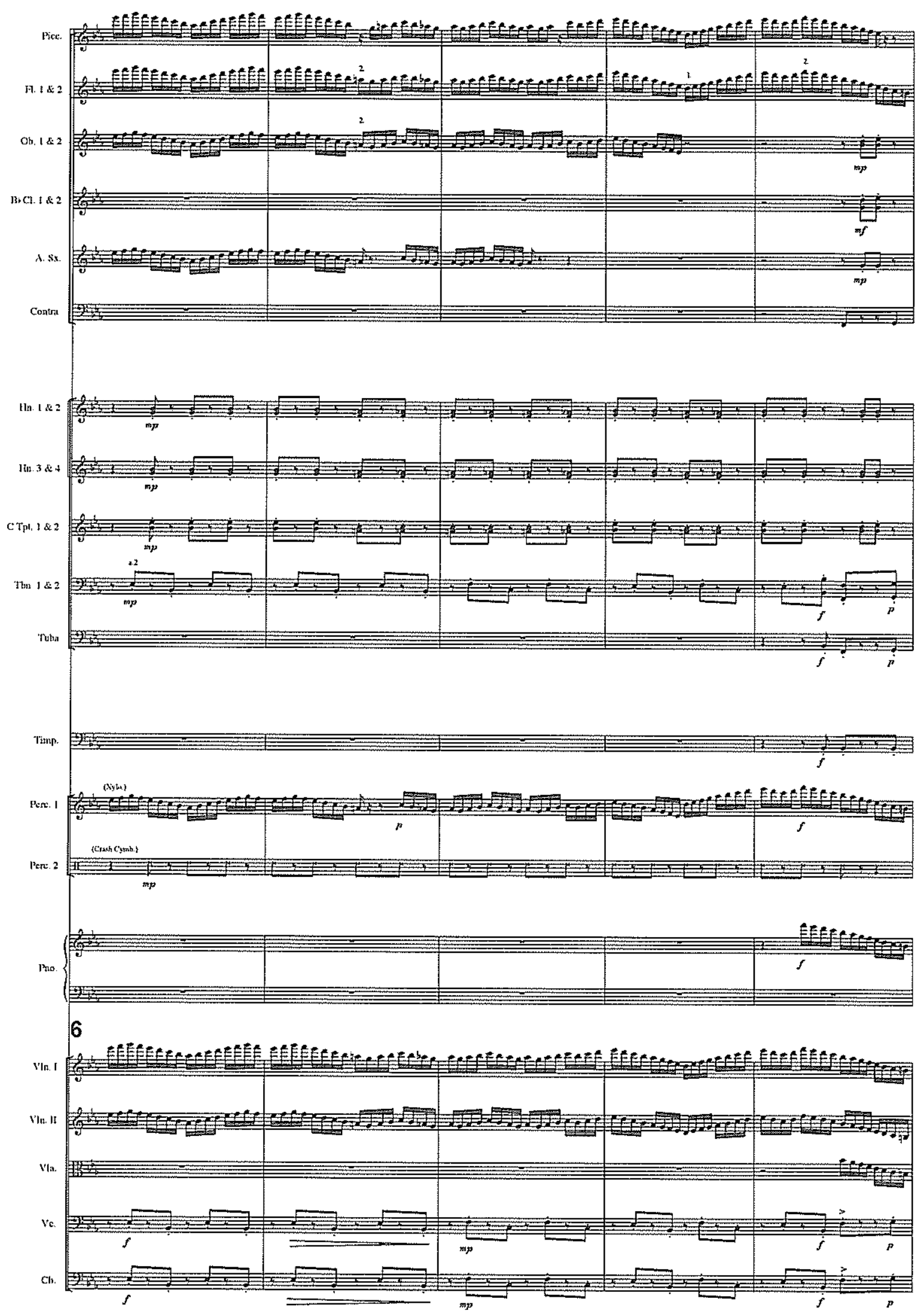


11

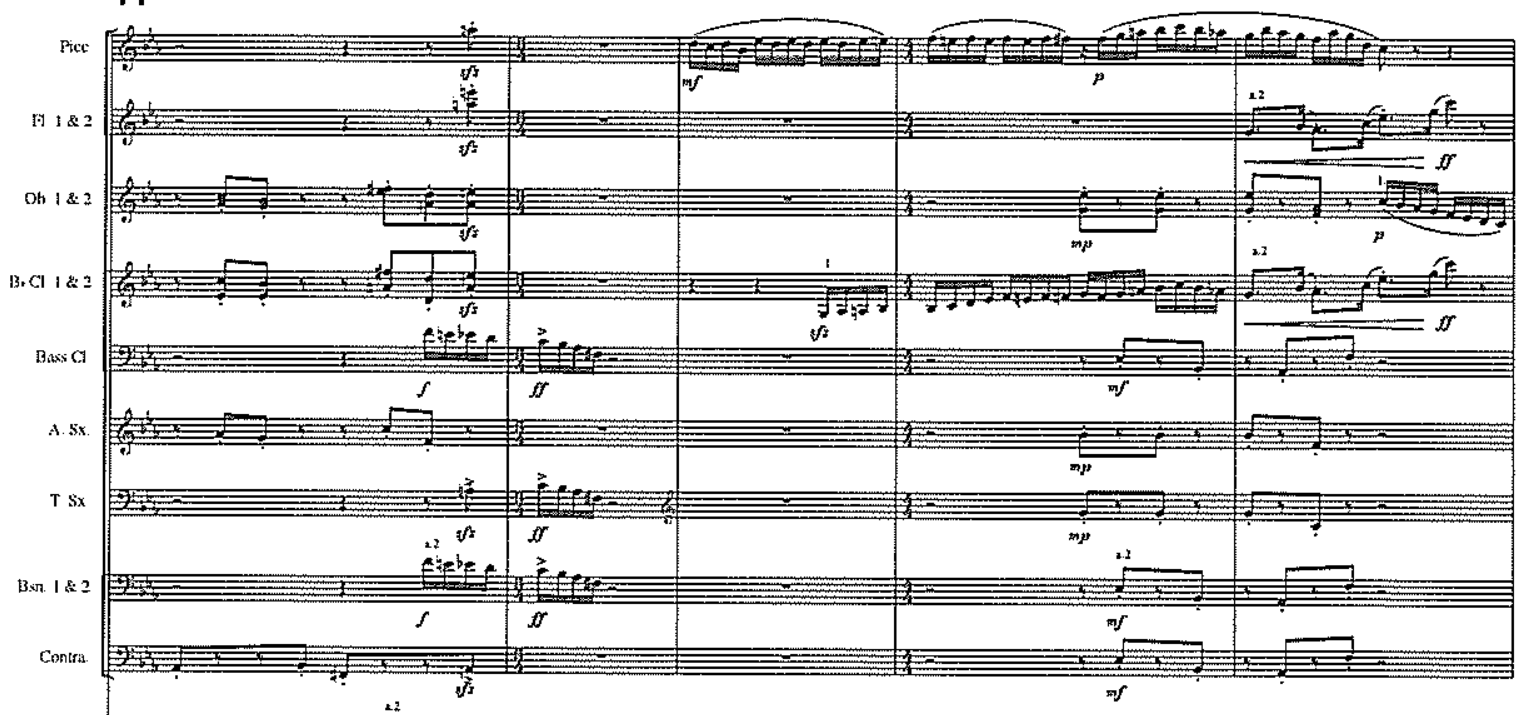

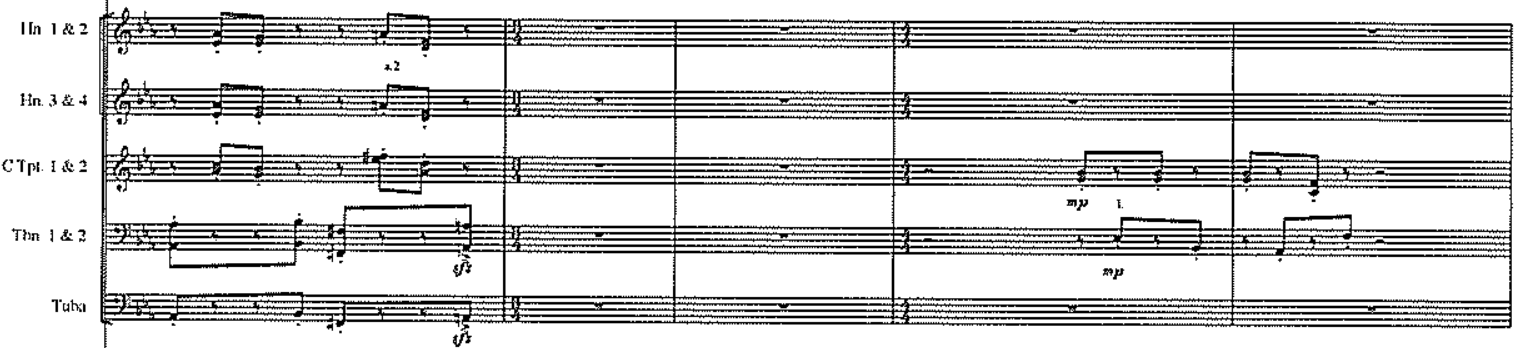

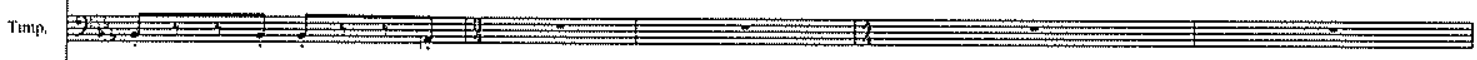

Date
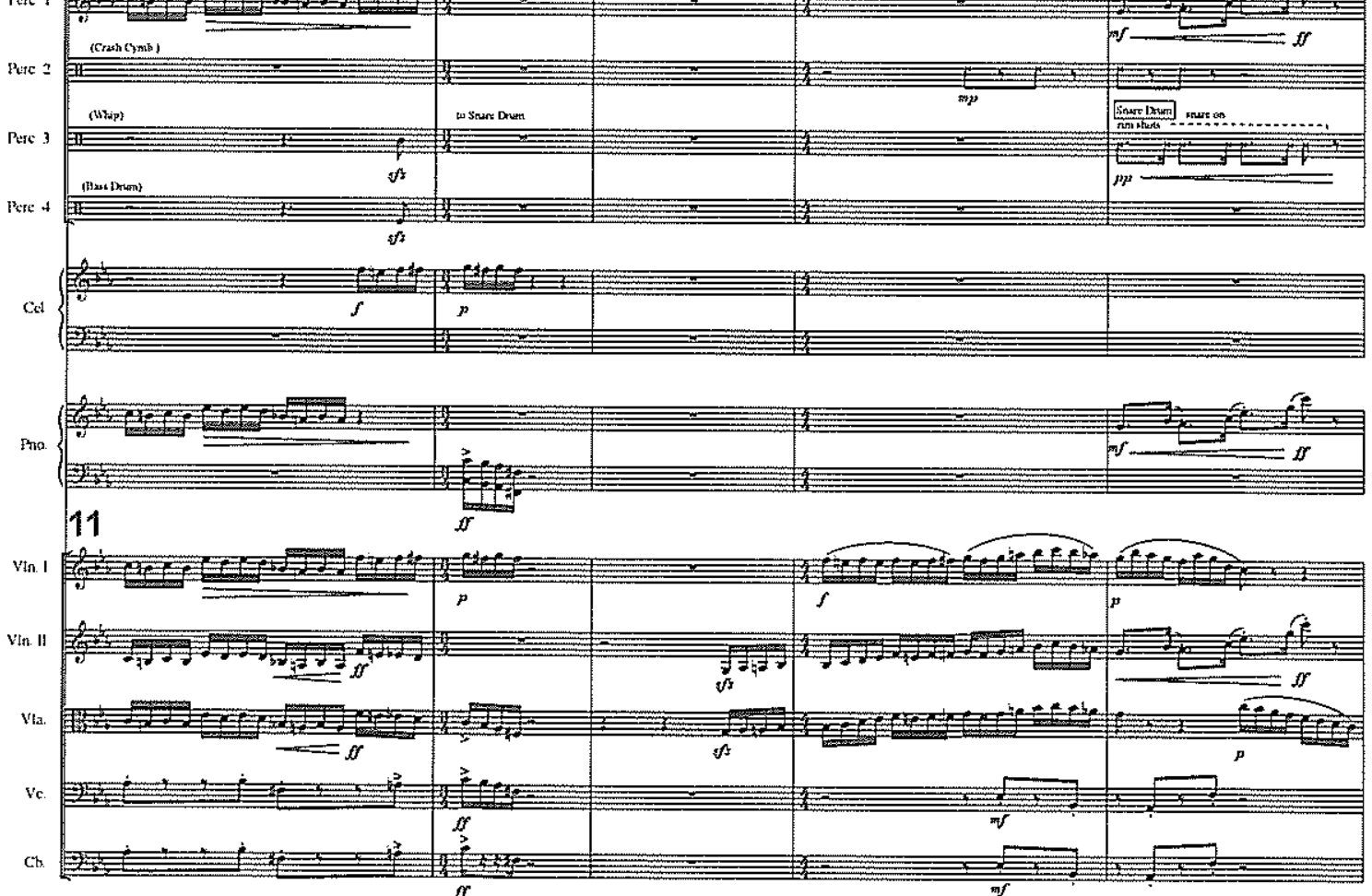


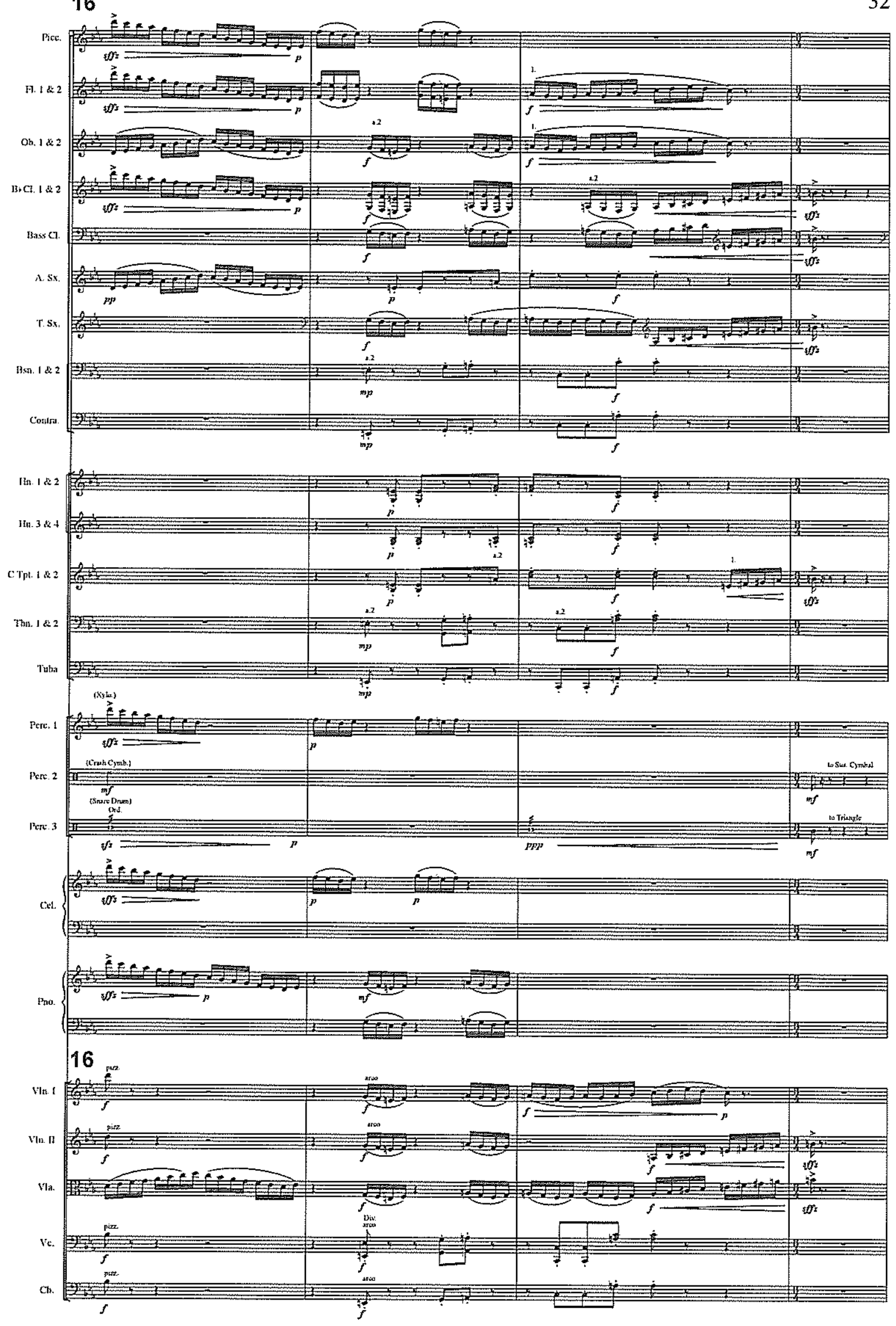



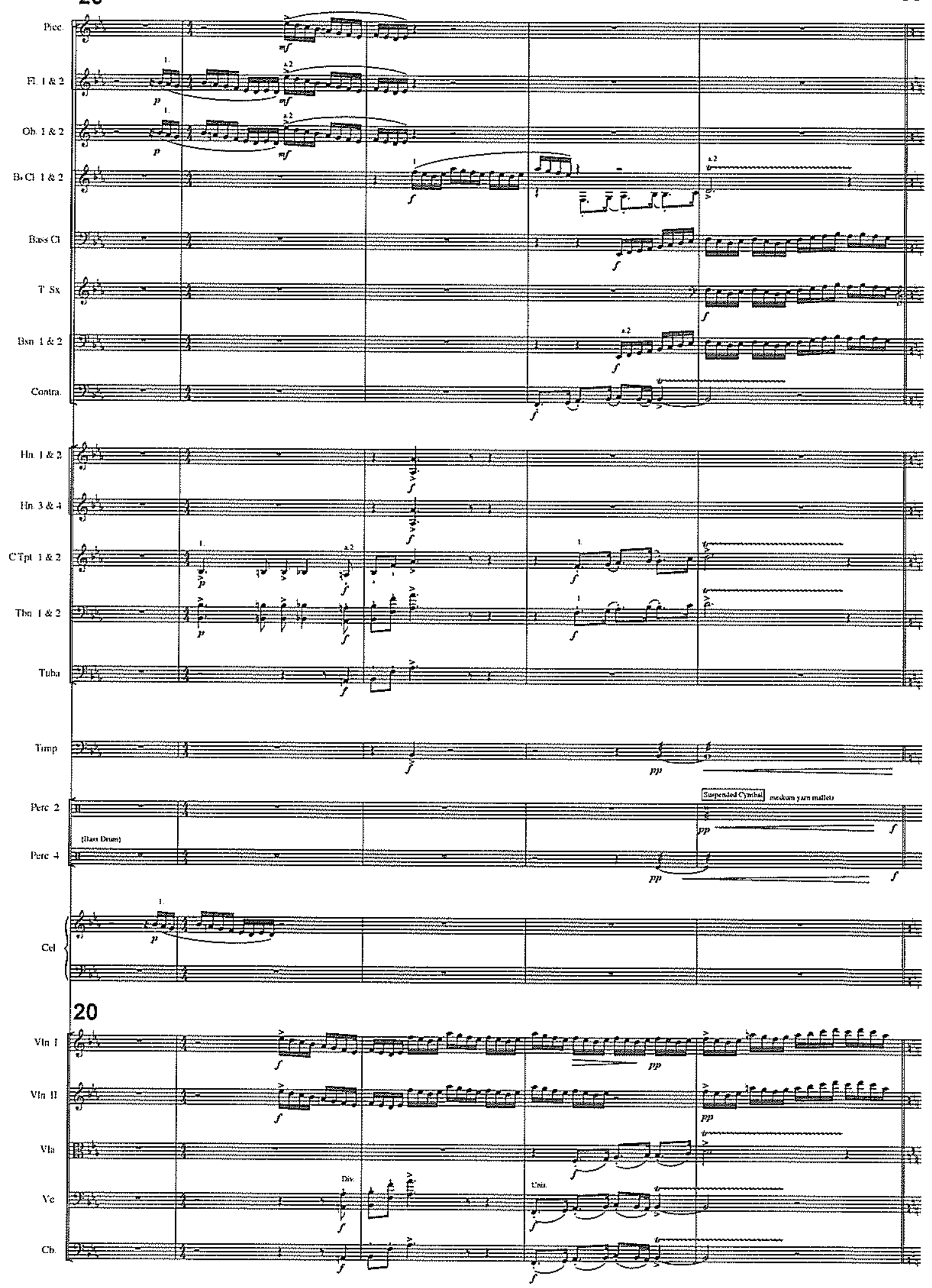


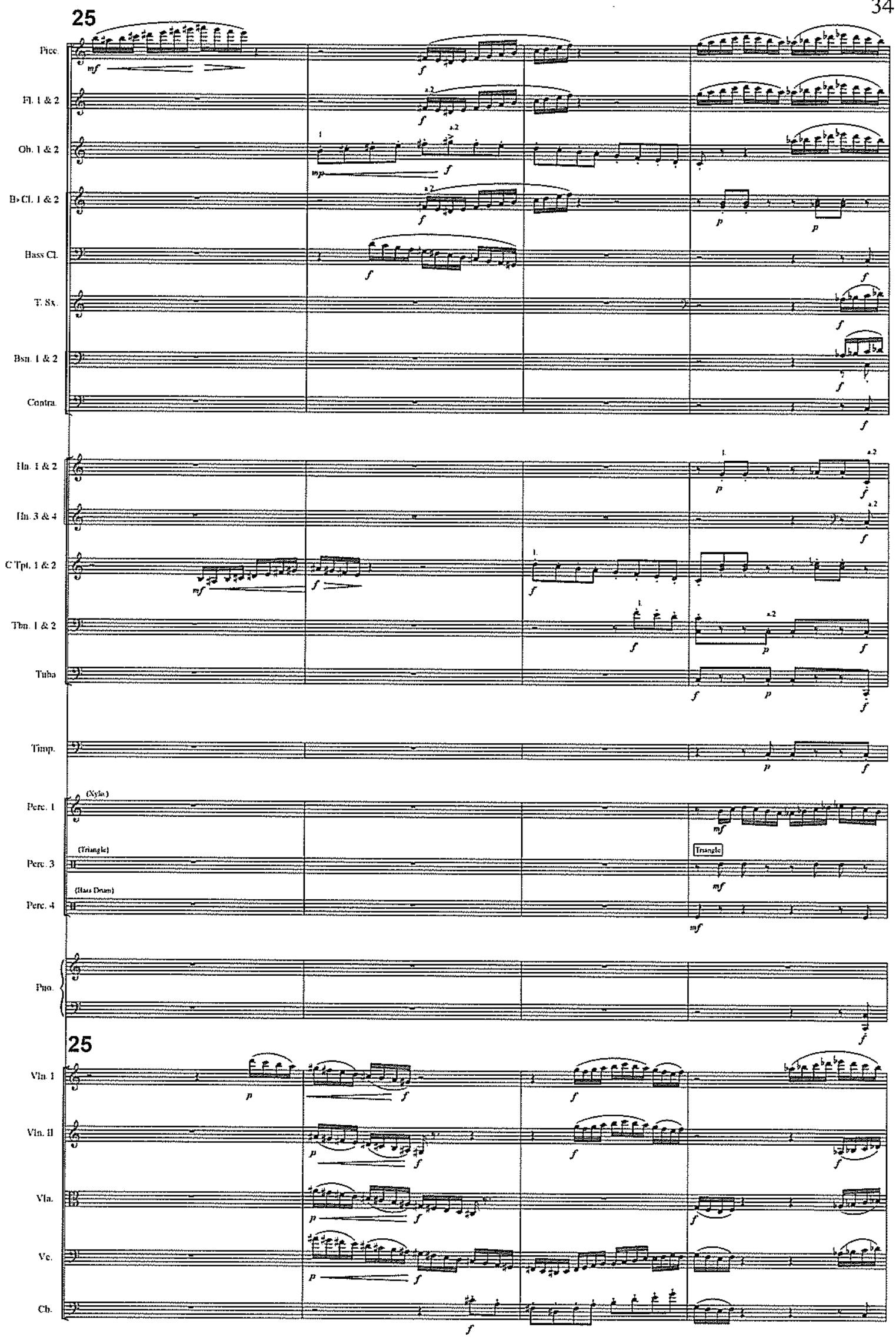




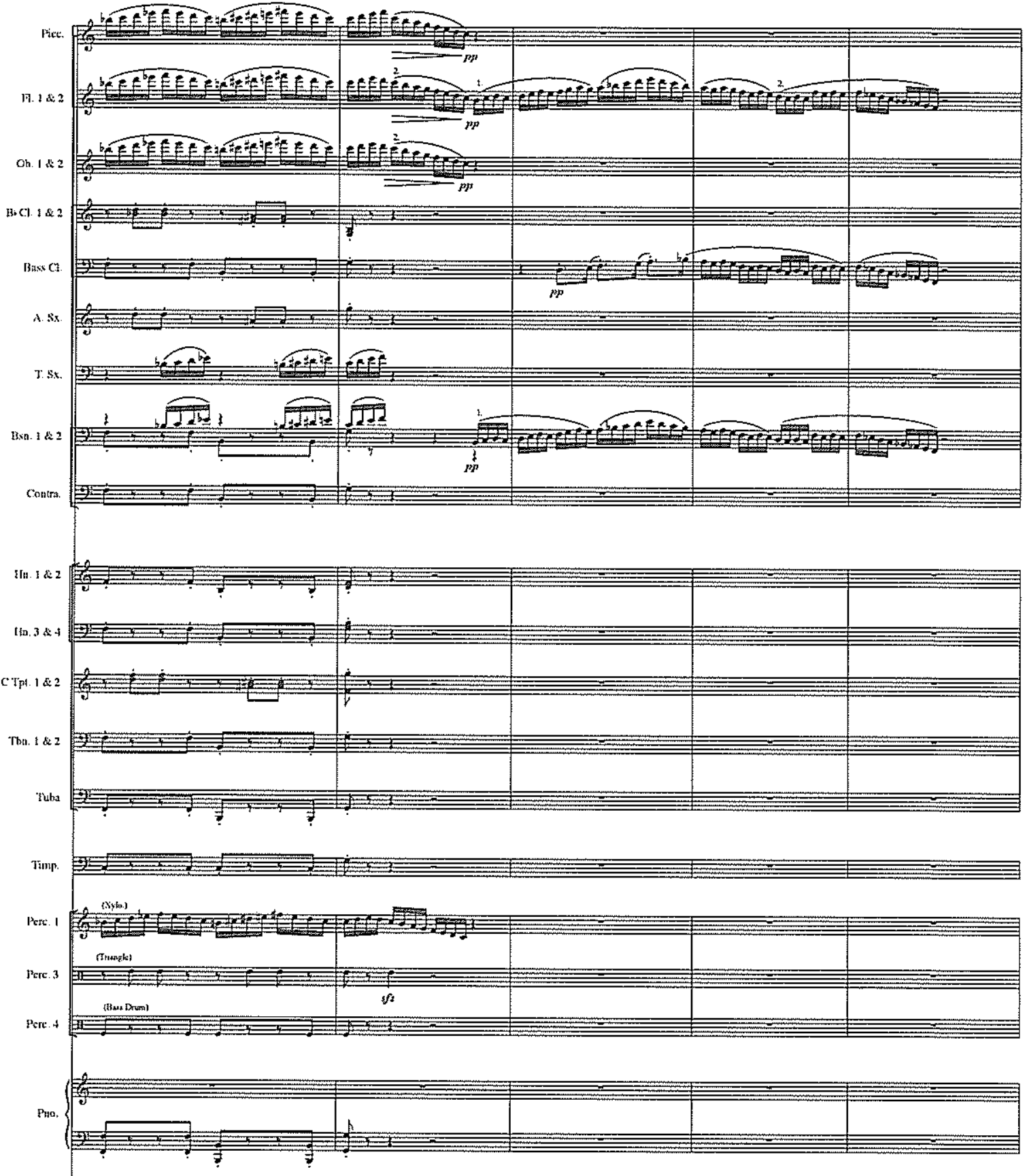

29

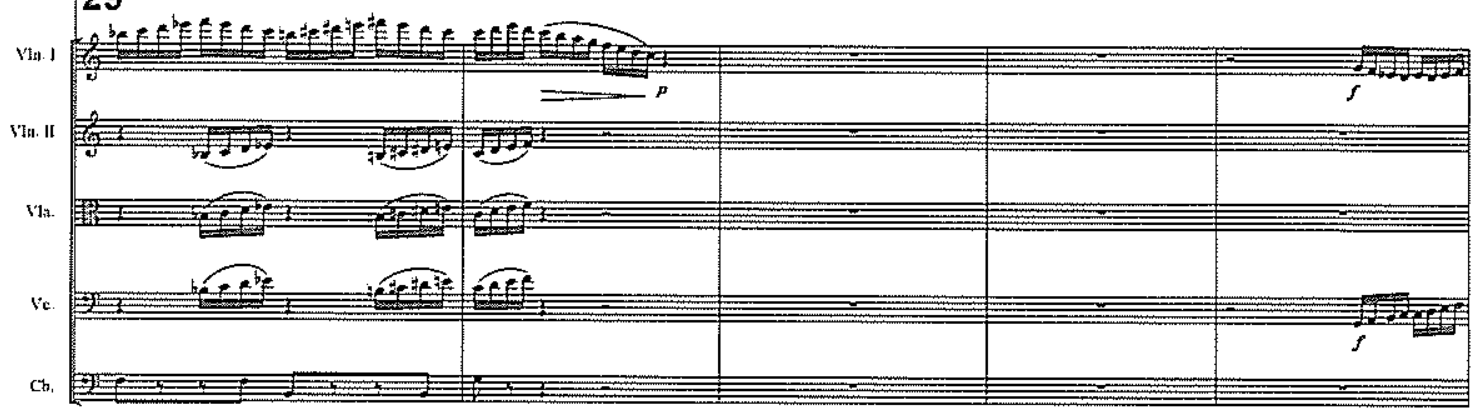



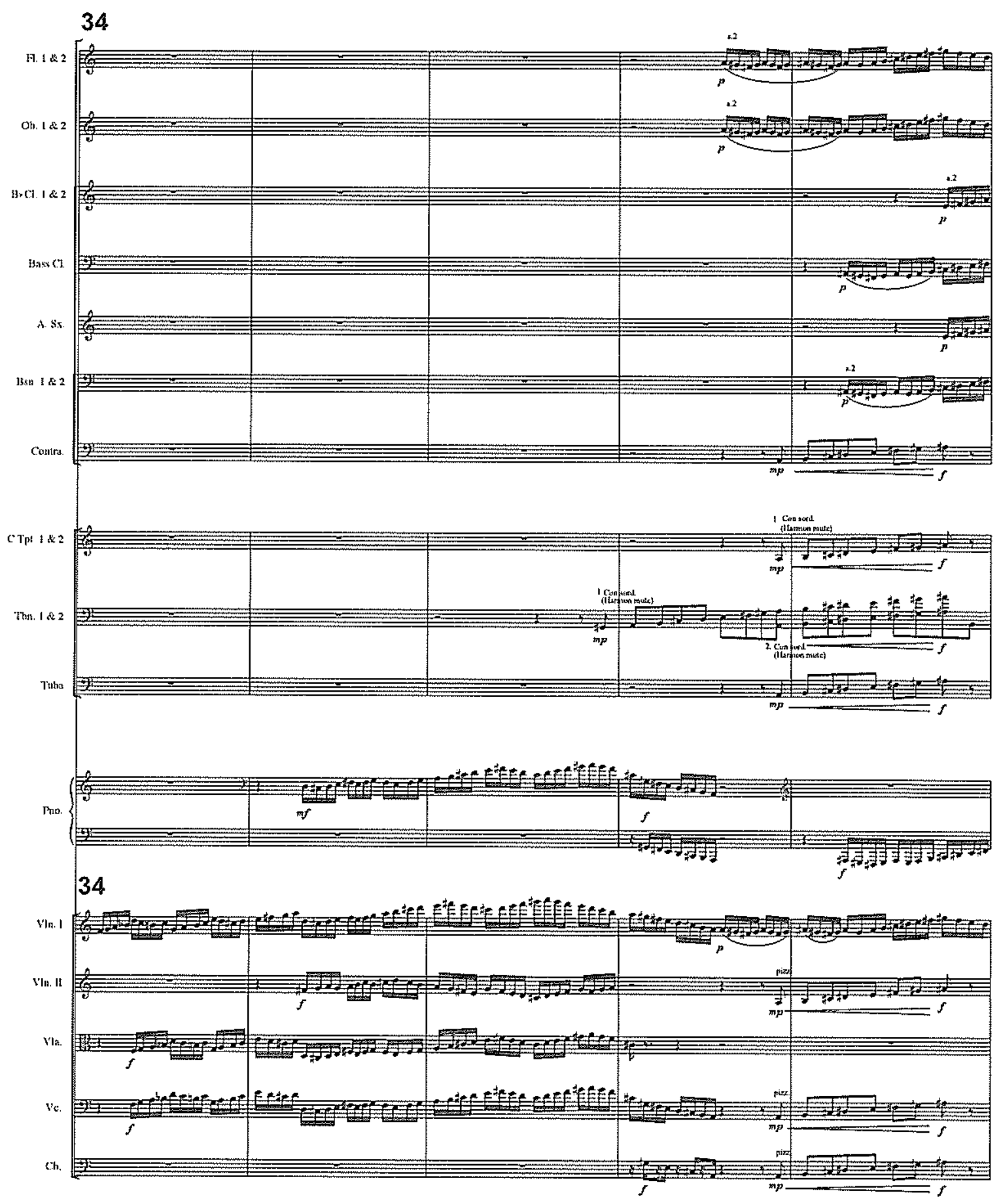


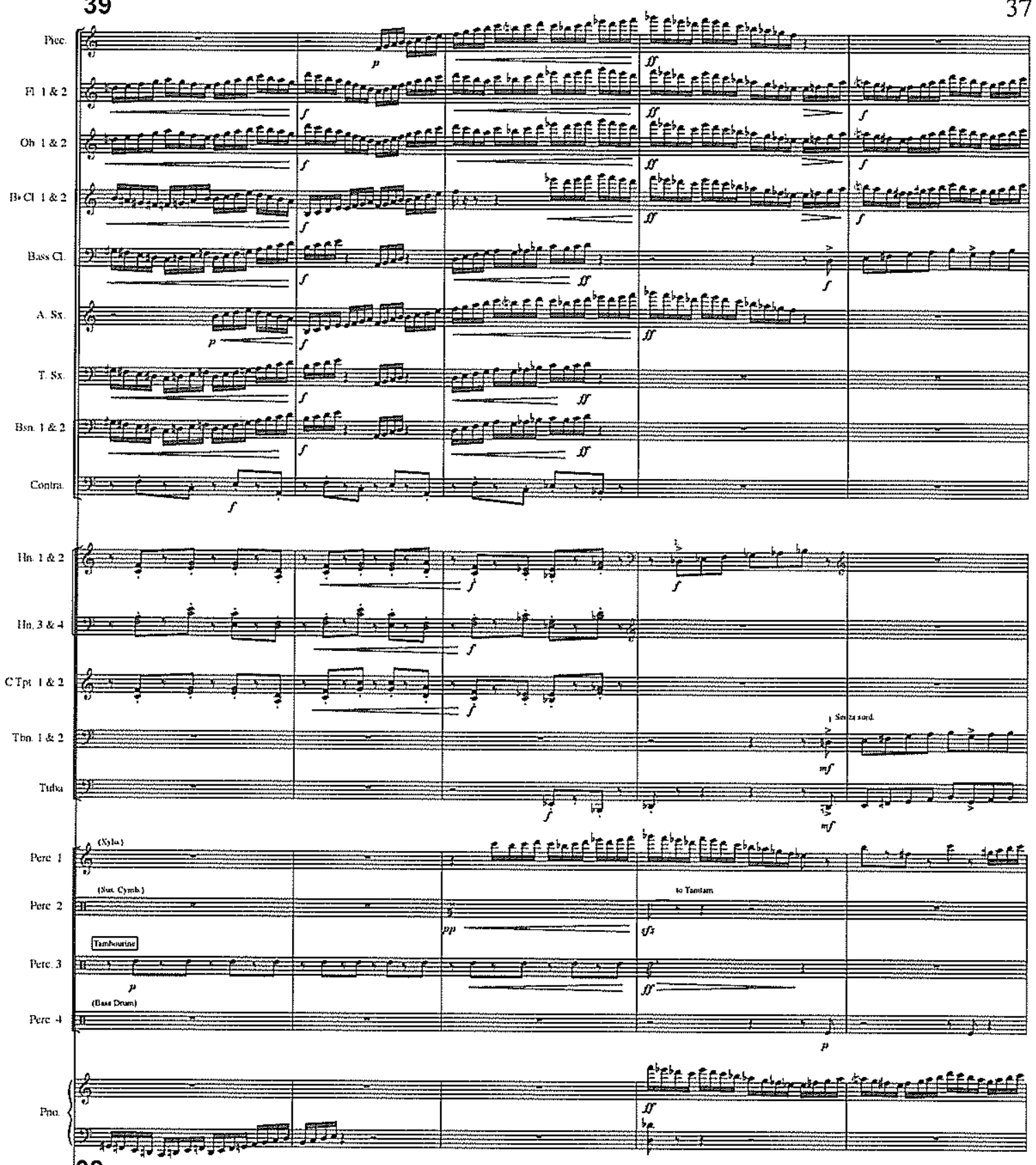
39

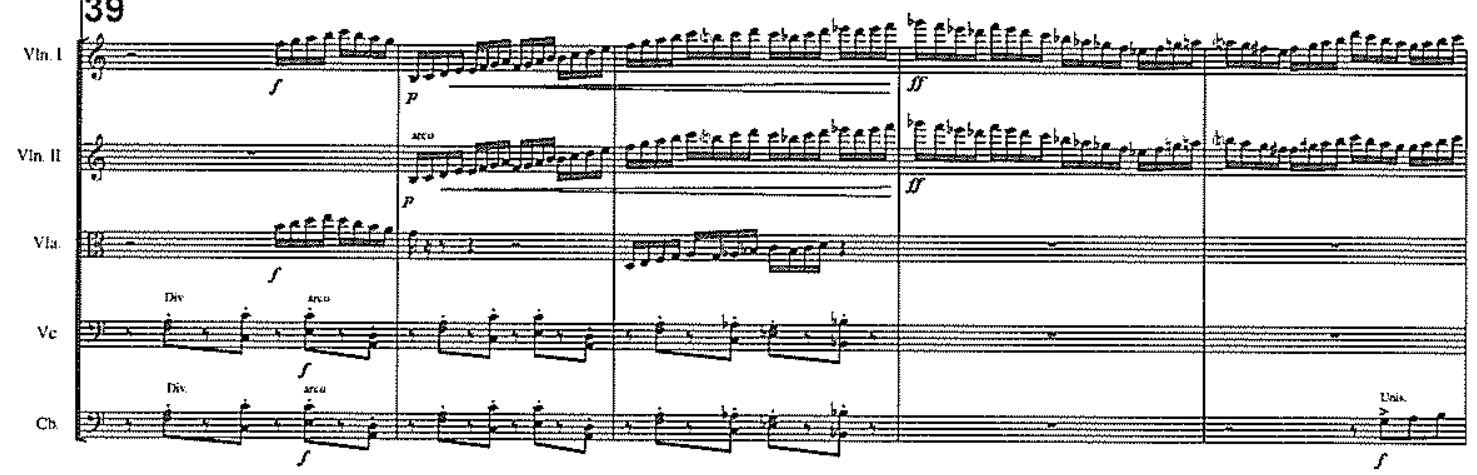




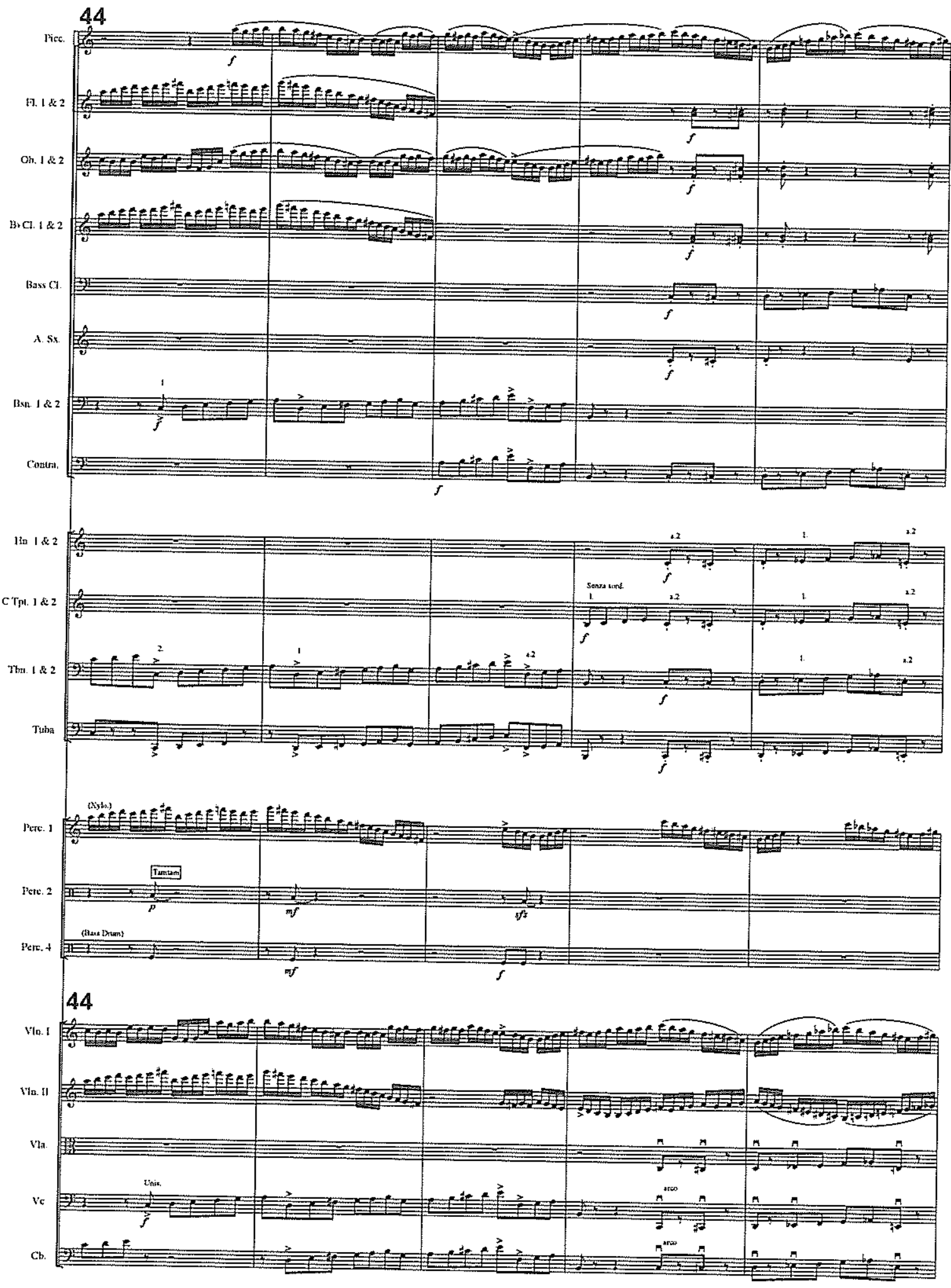




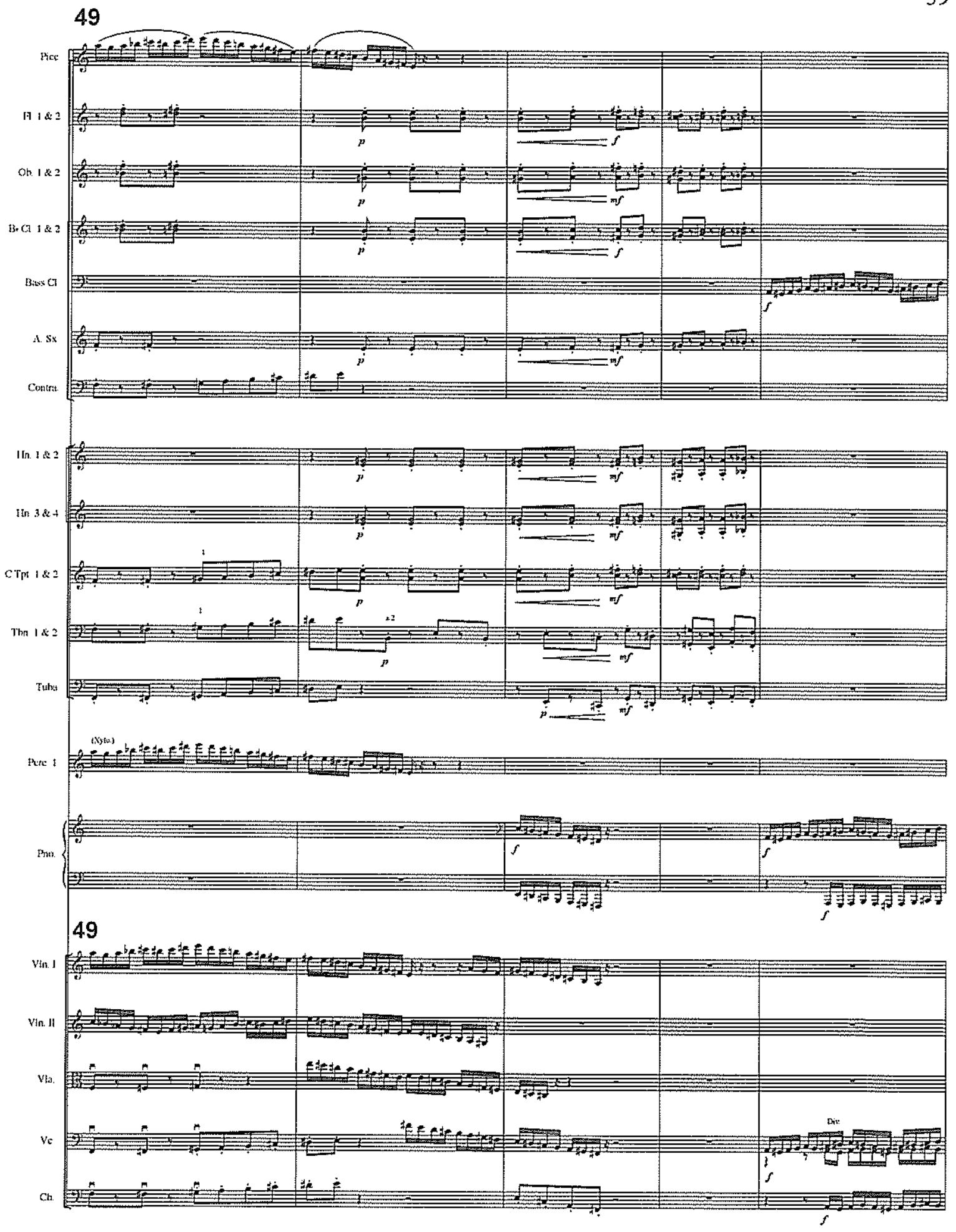


54

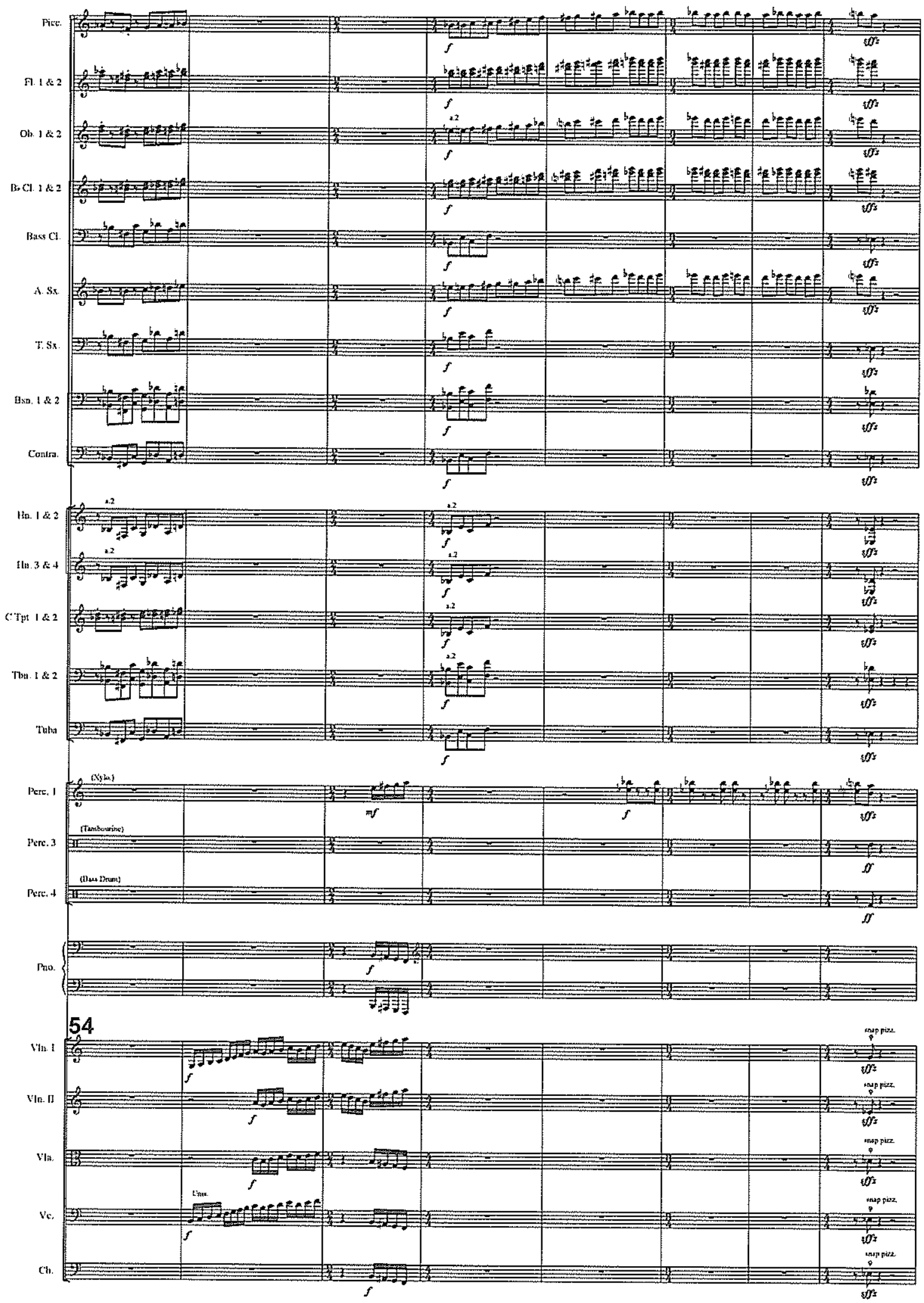



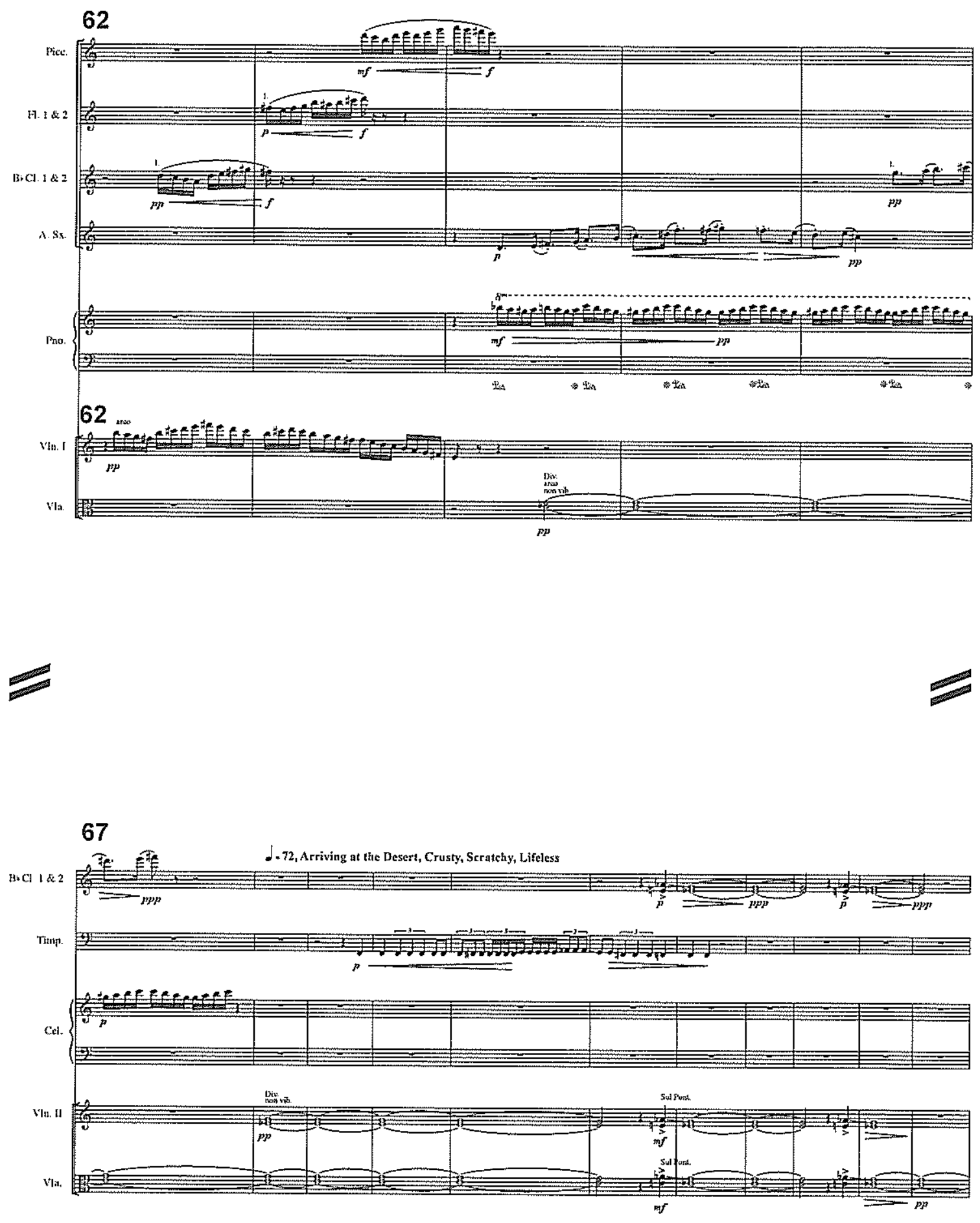


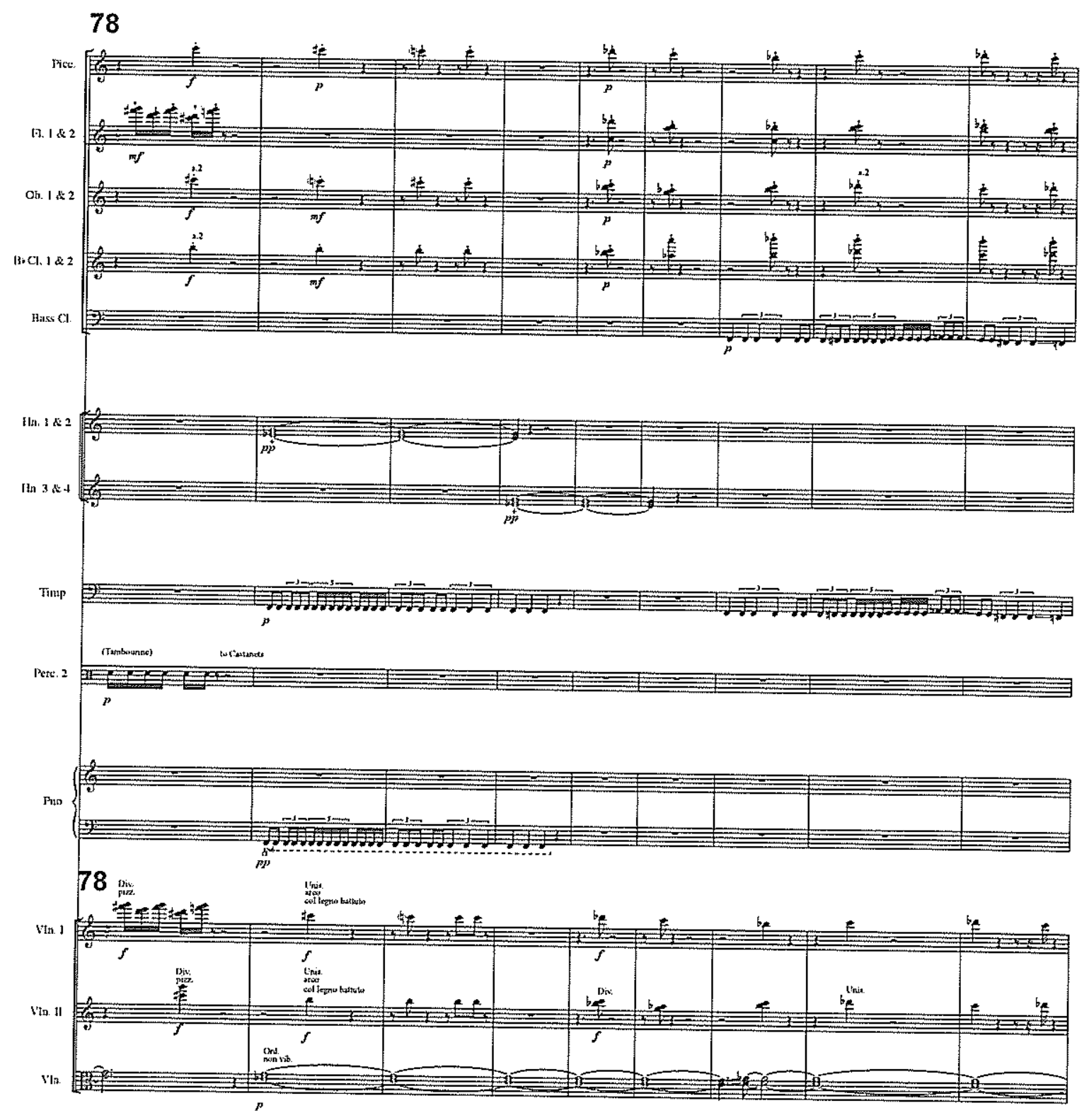


87
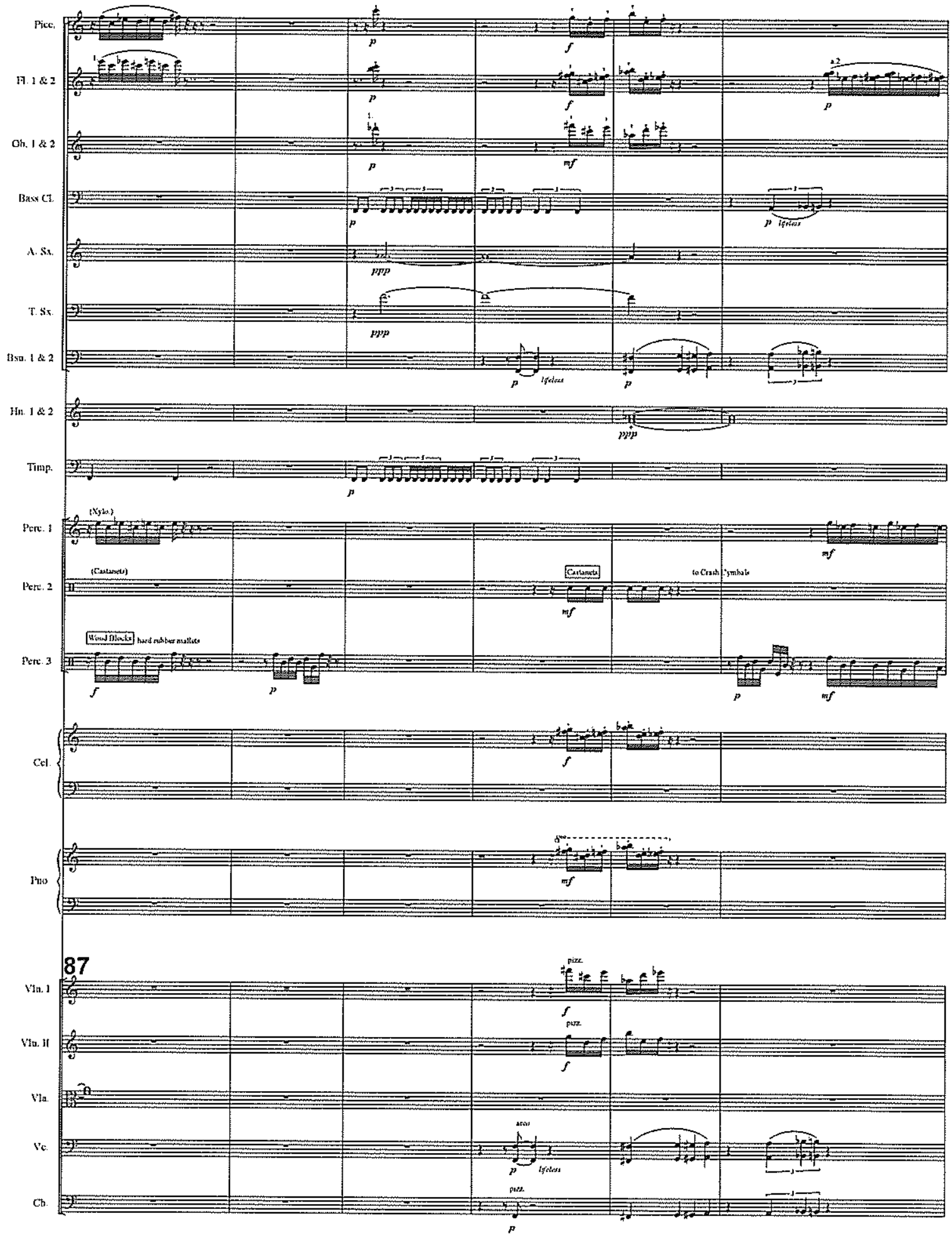


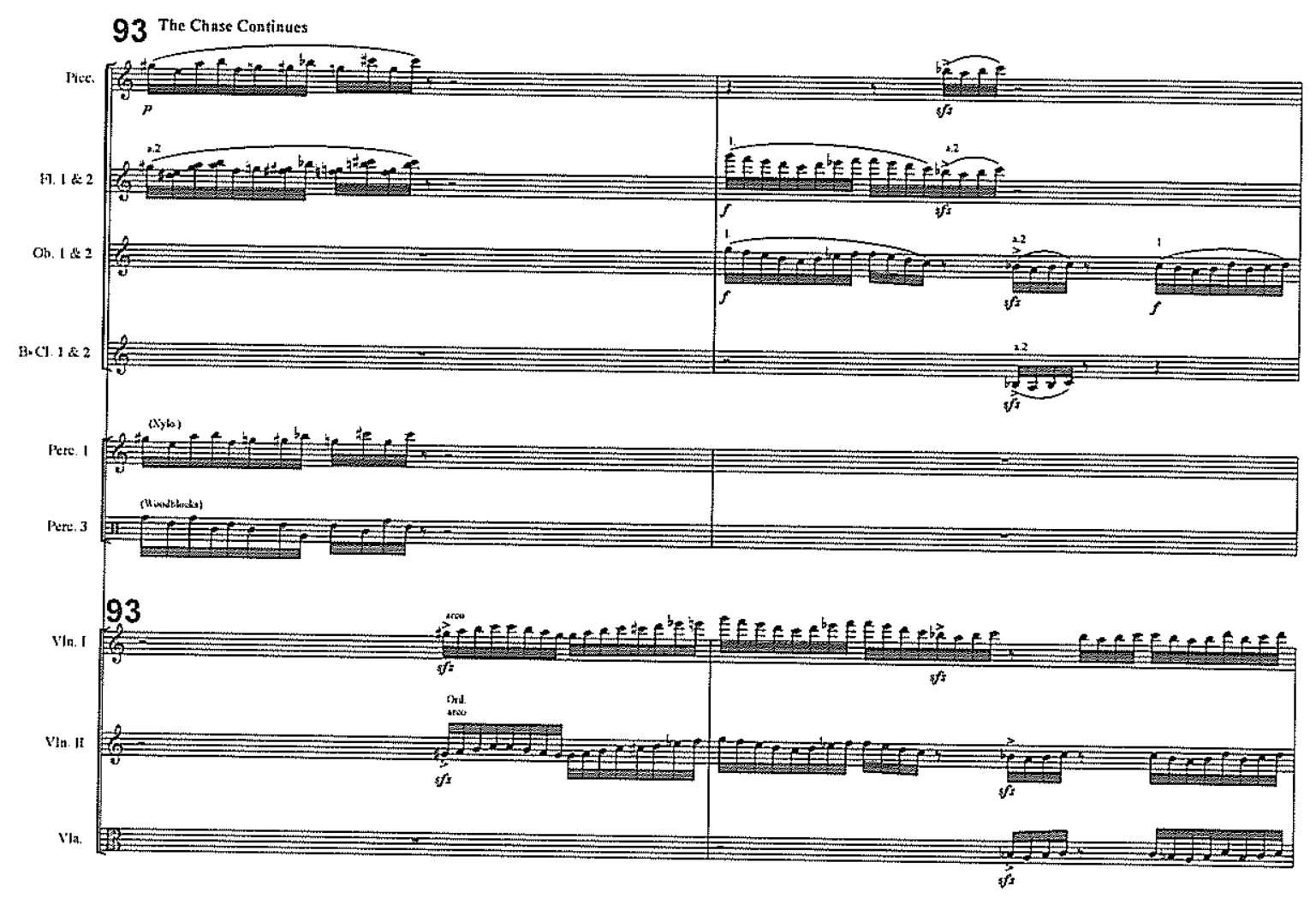




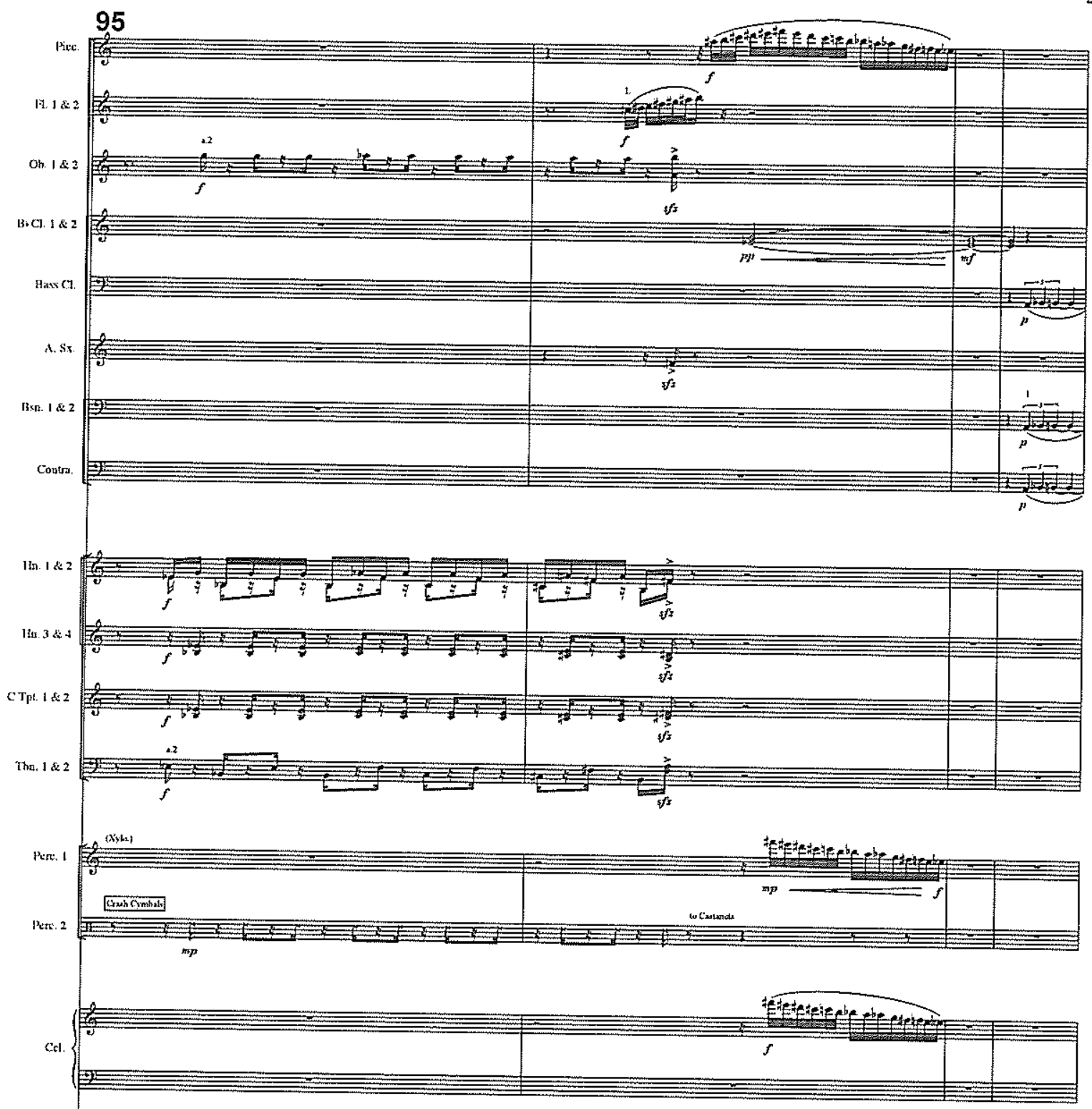

95

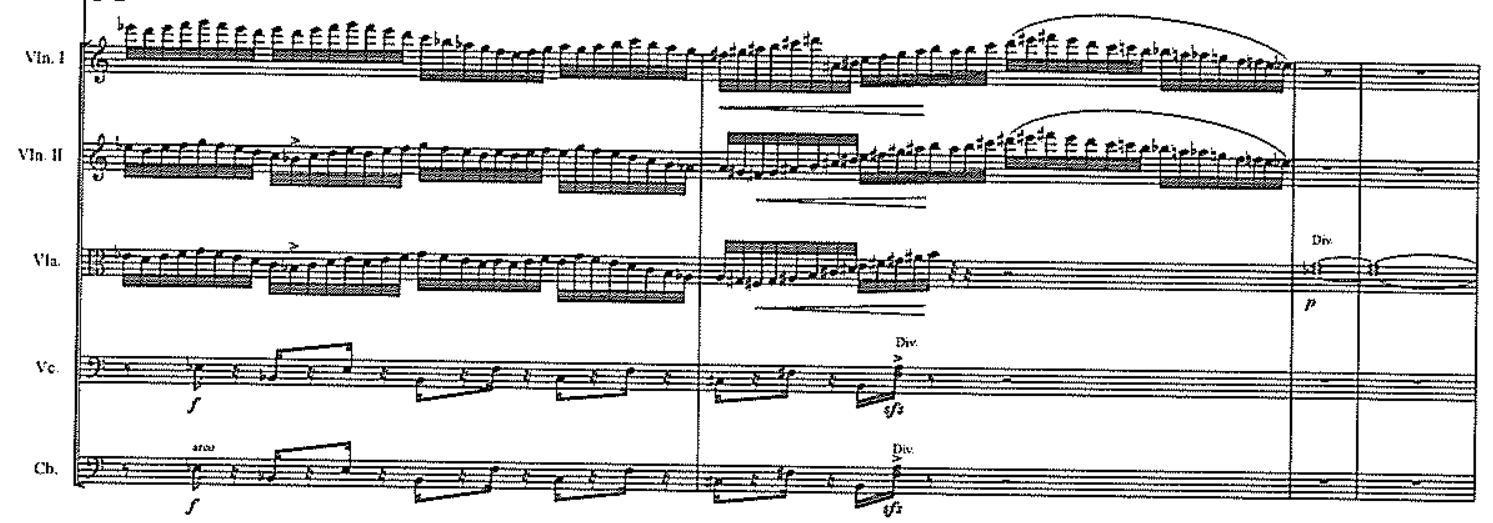




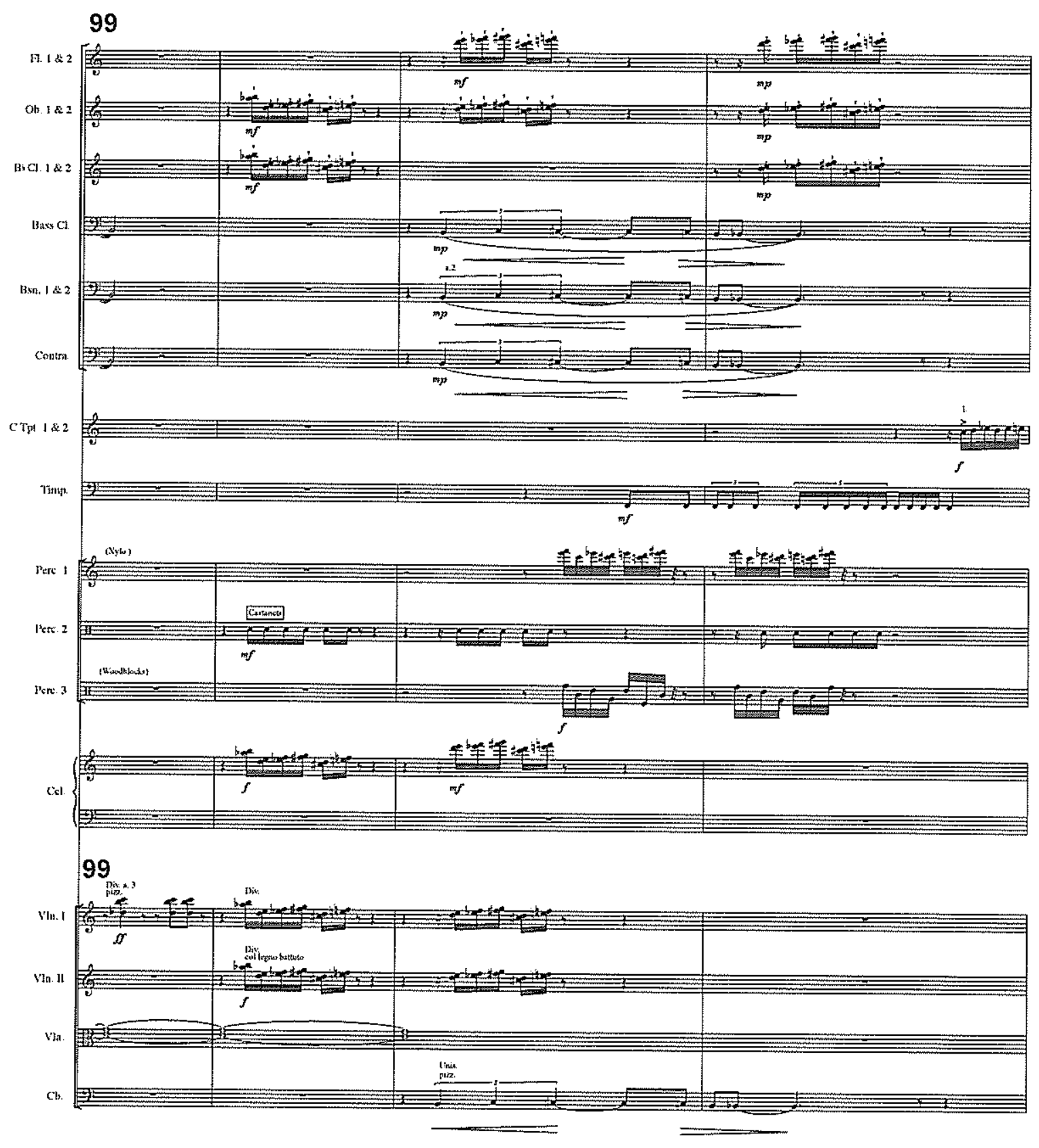




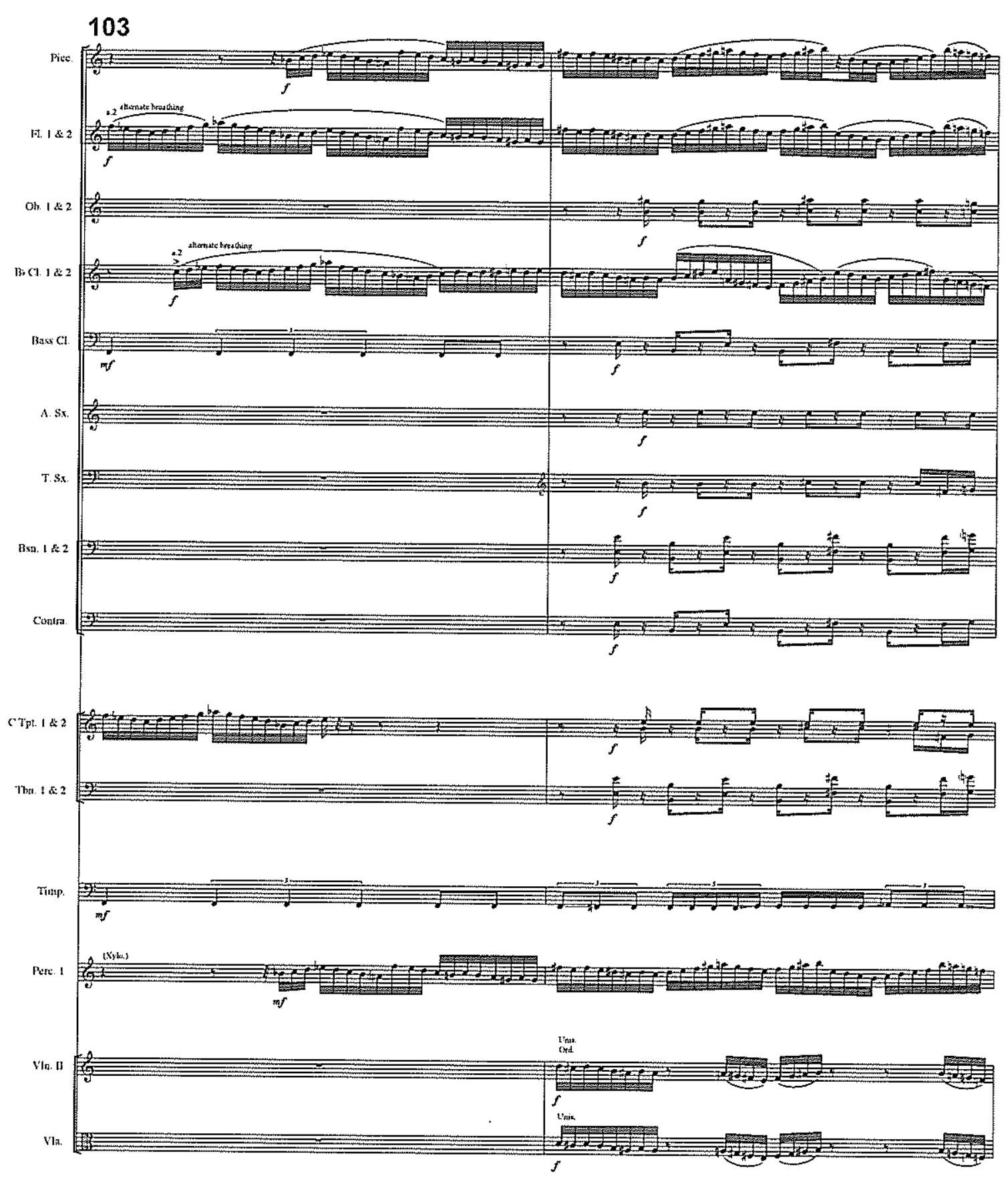




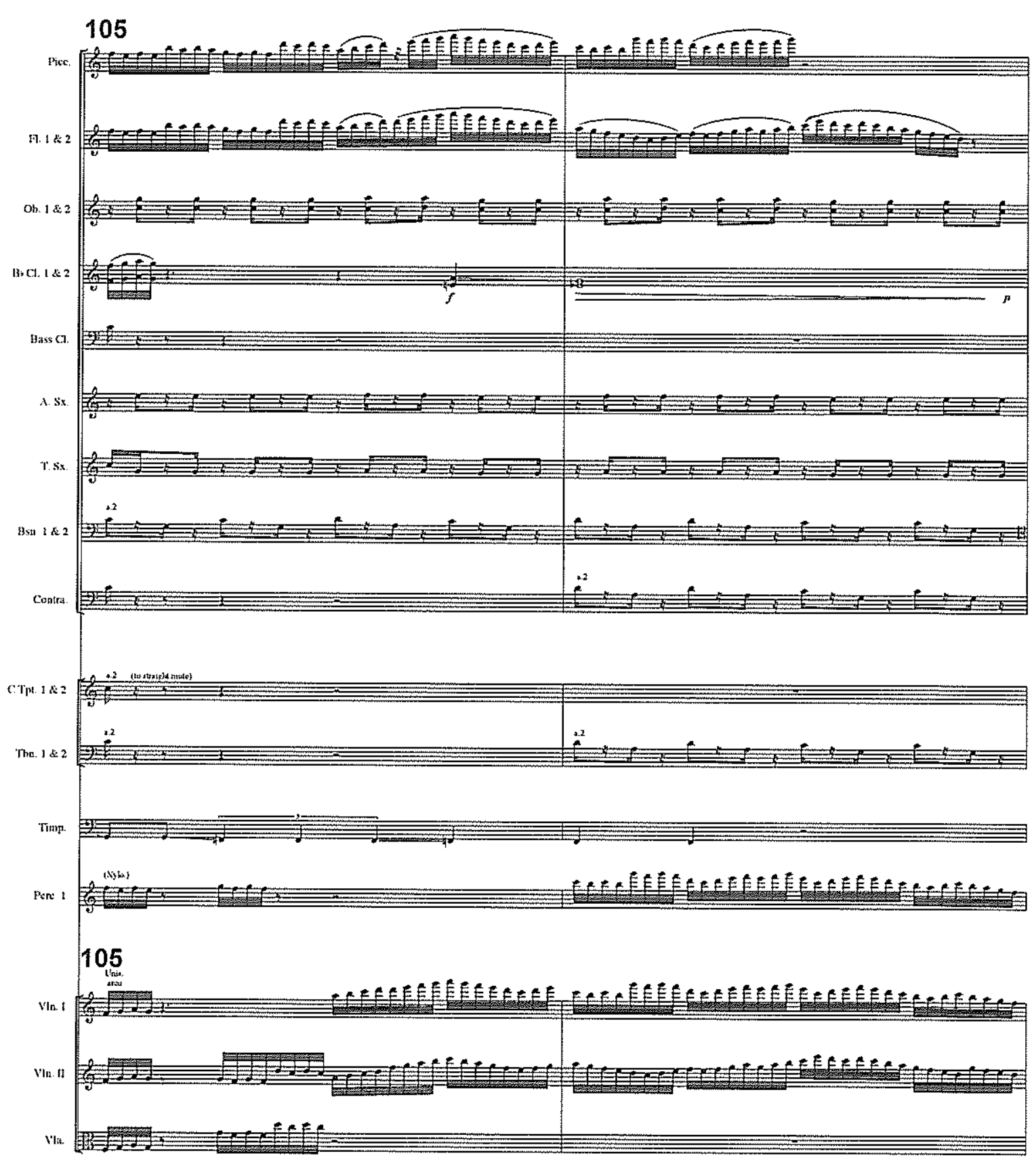




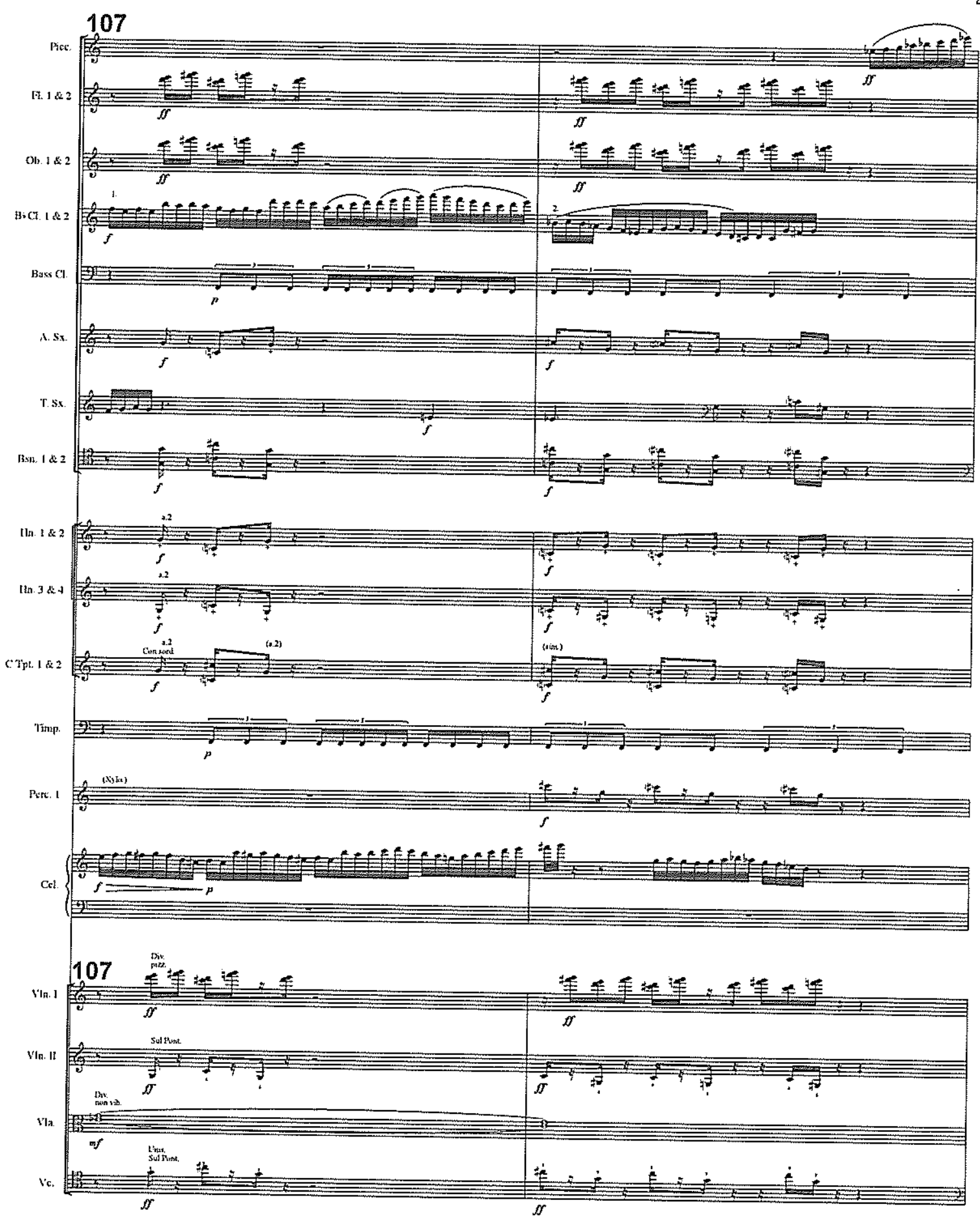




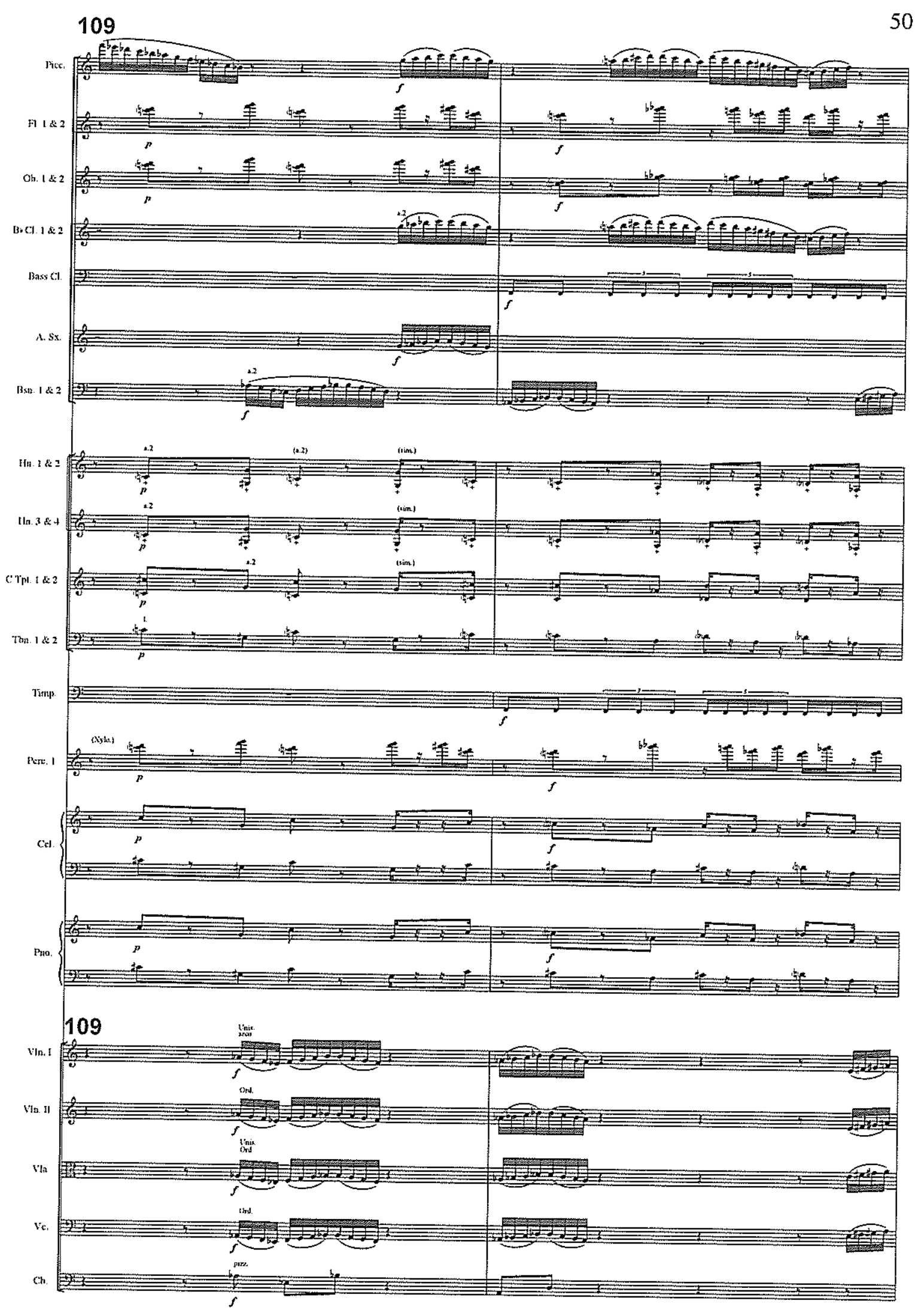


111

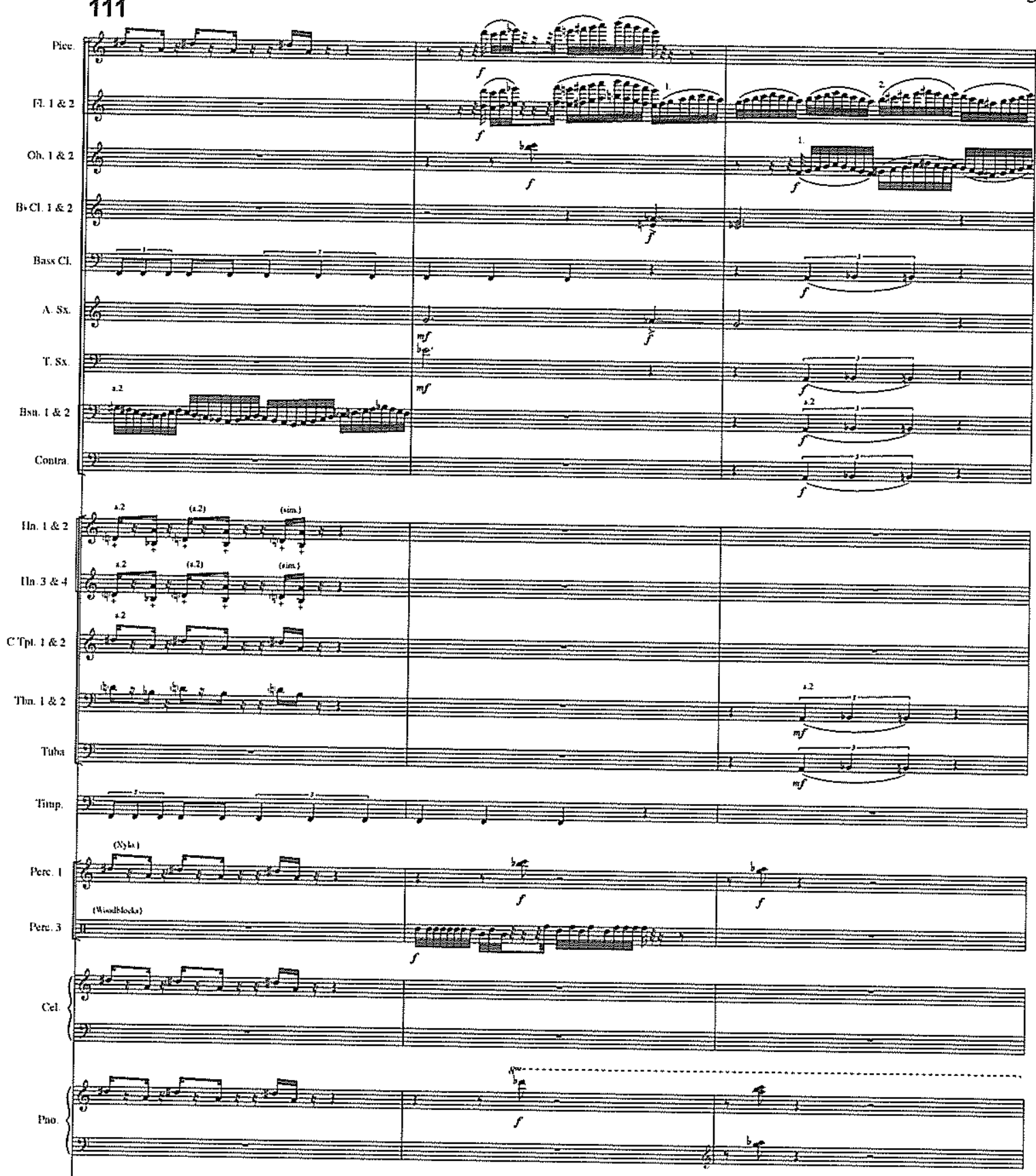

111

Vi.1) 


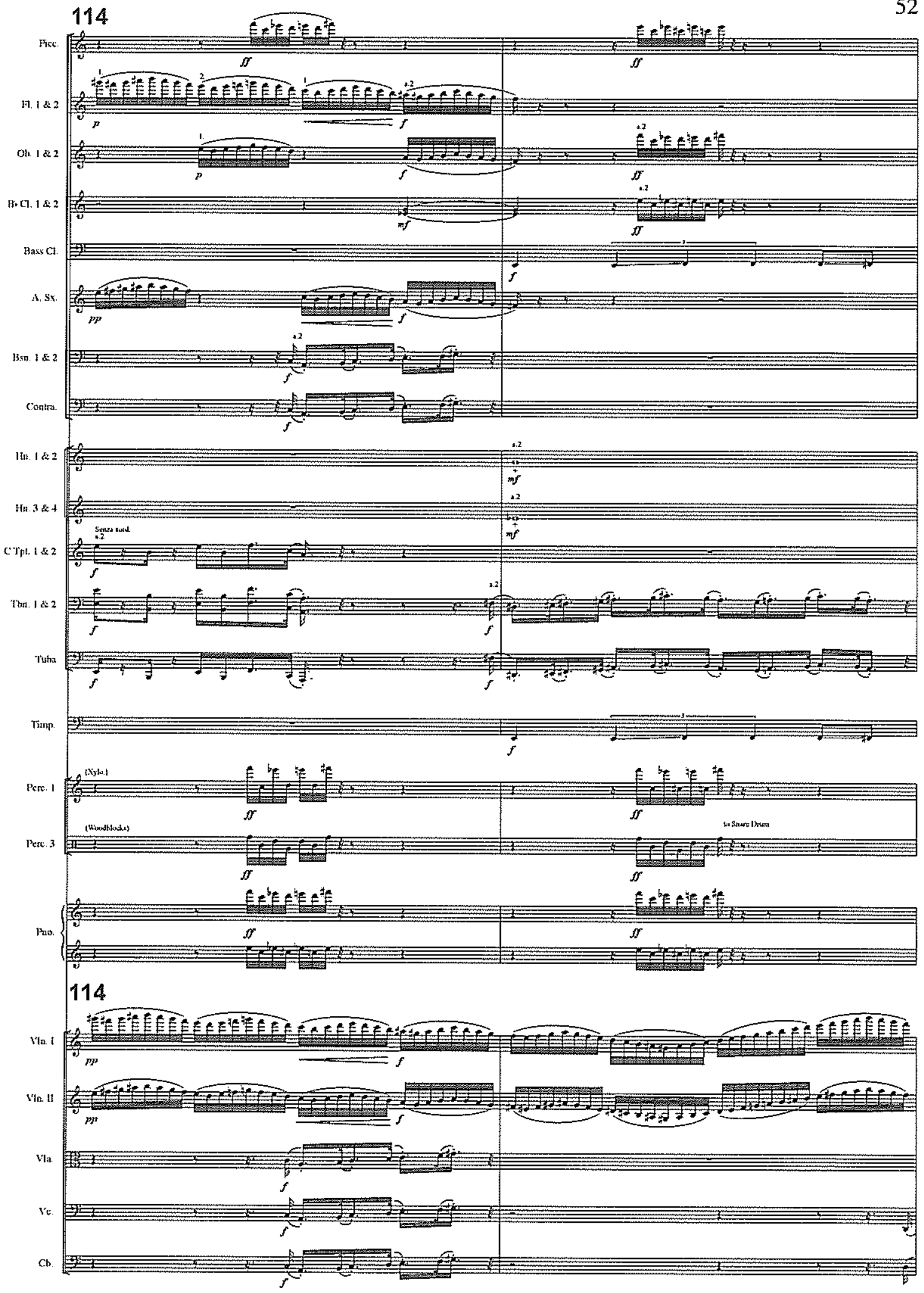


116

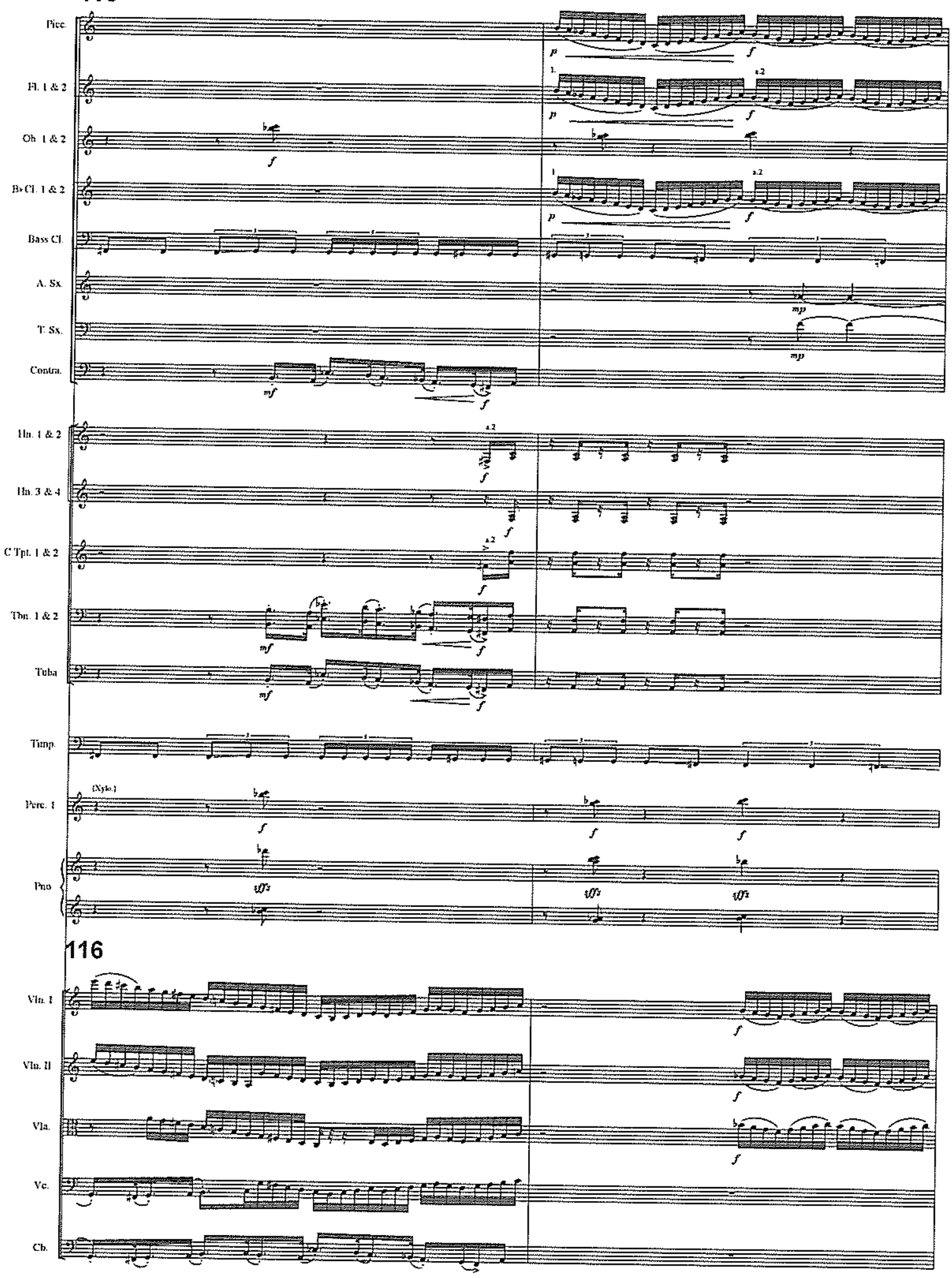




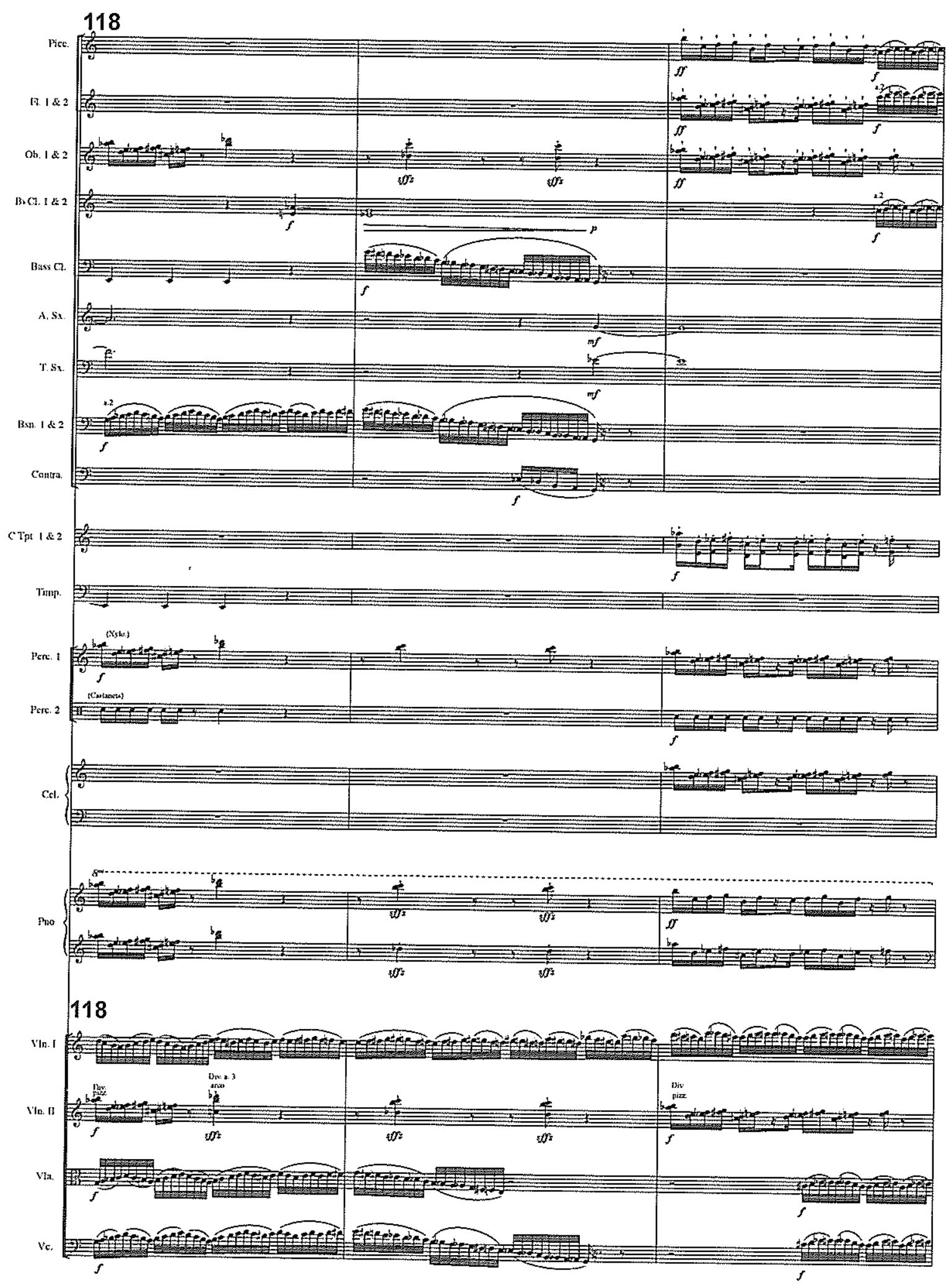




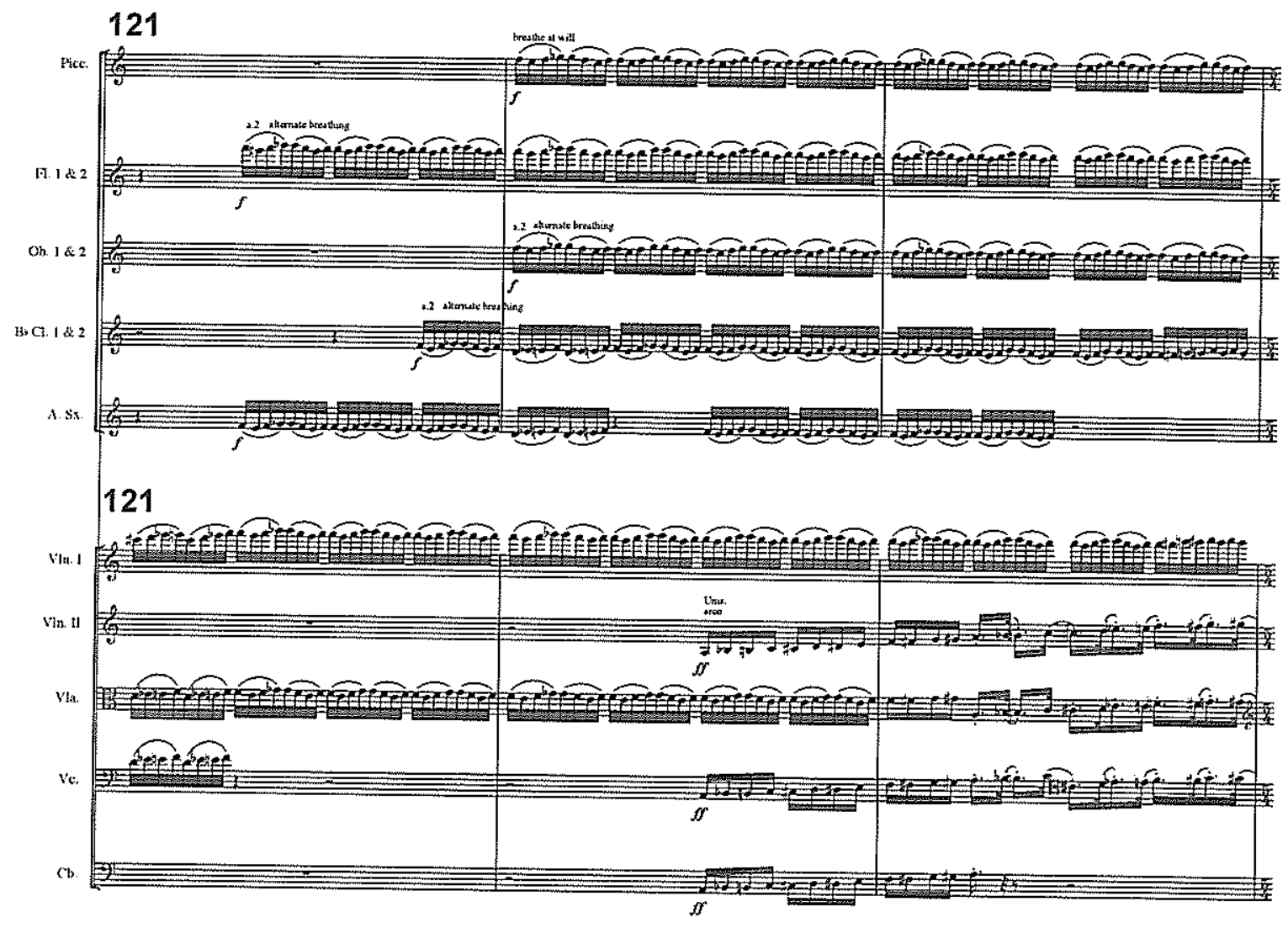




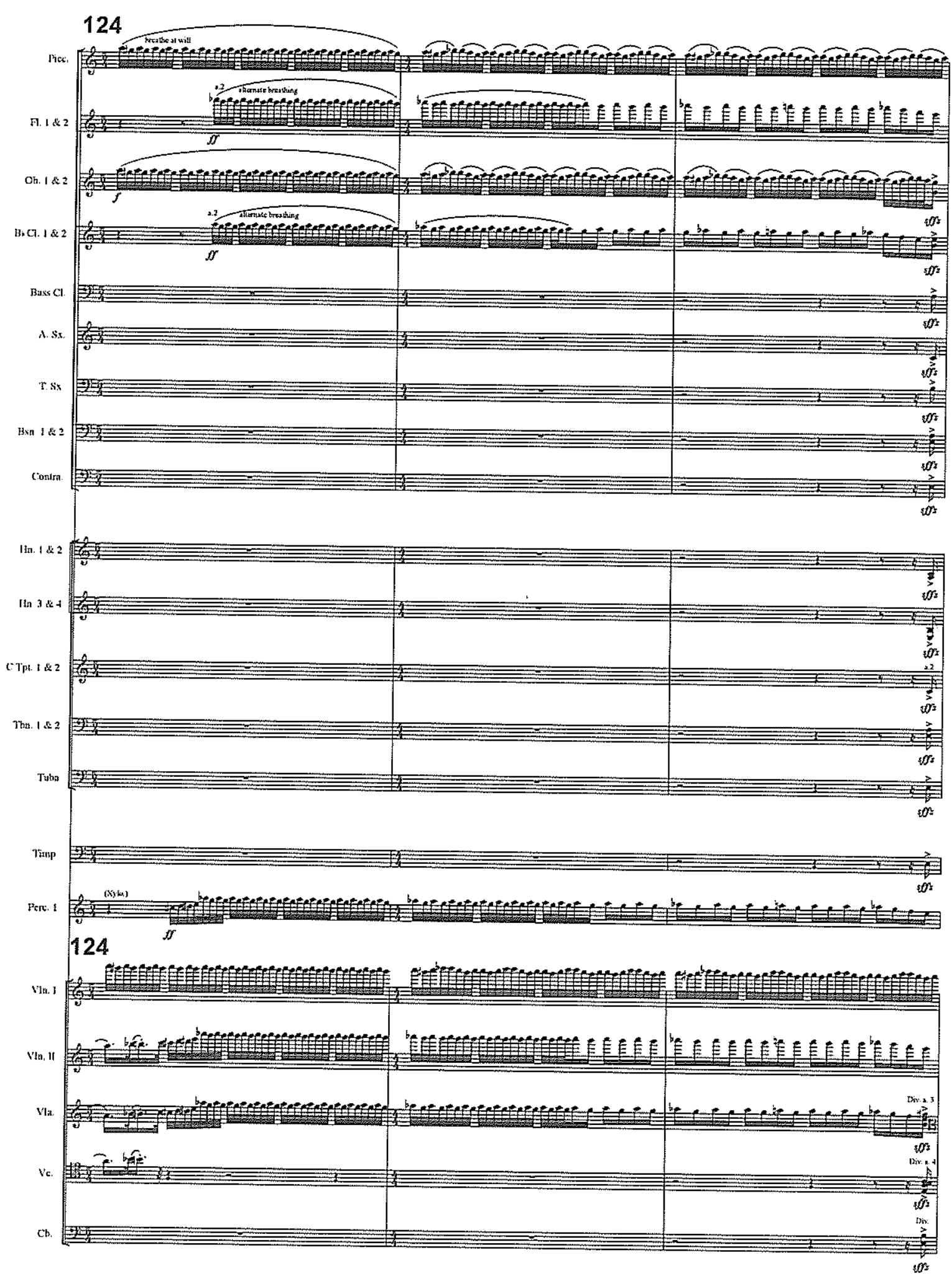




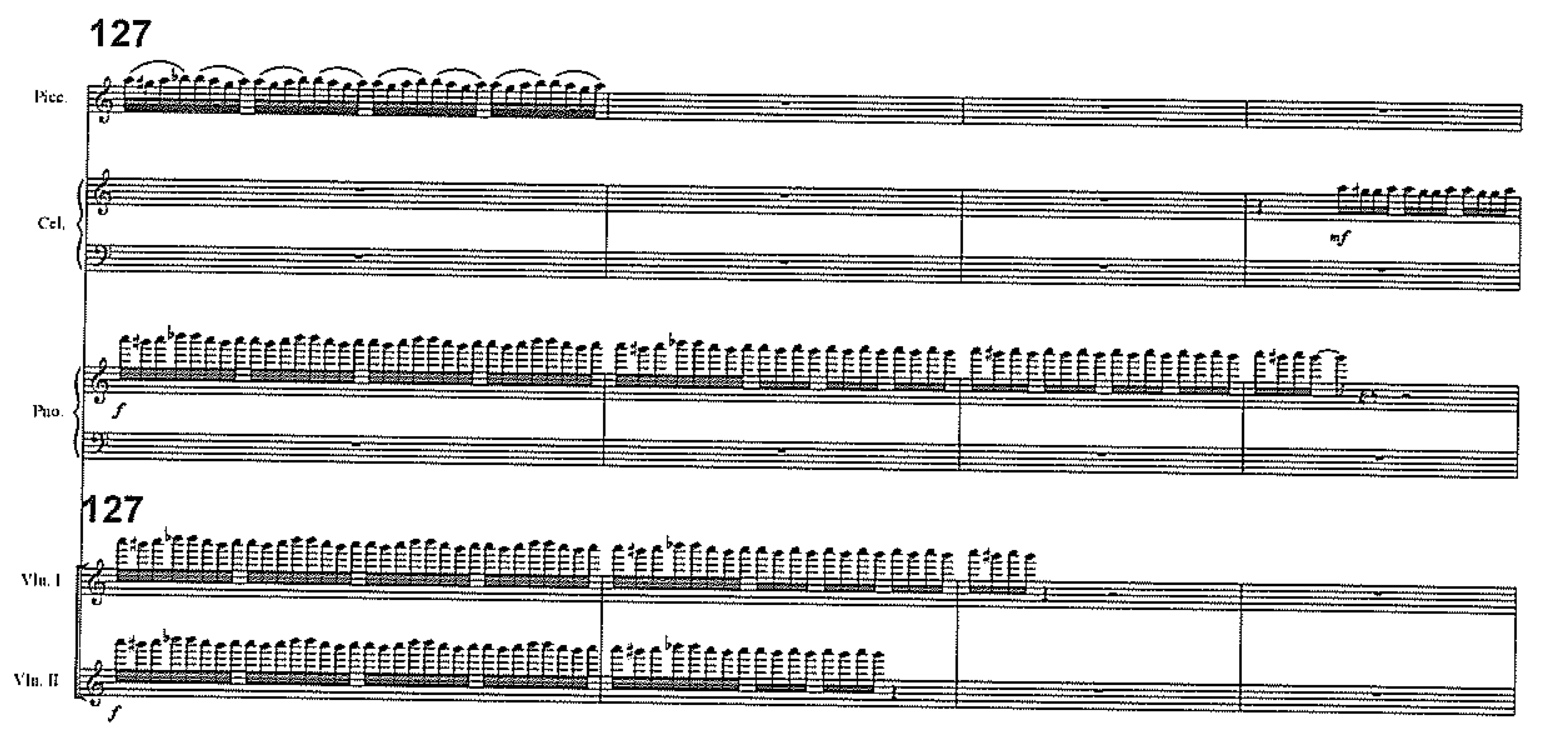




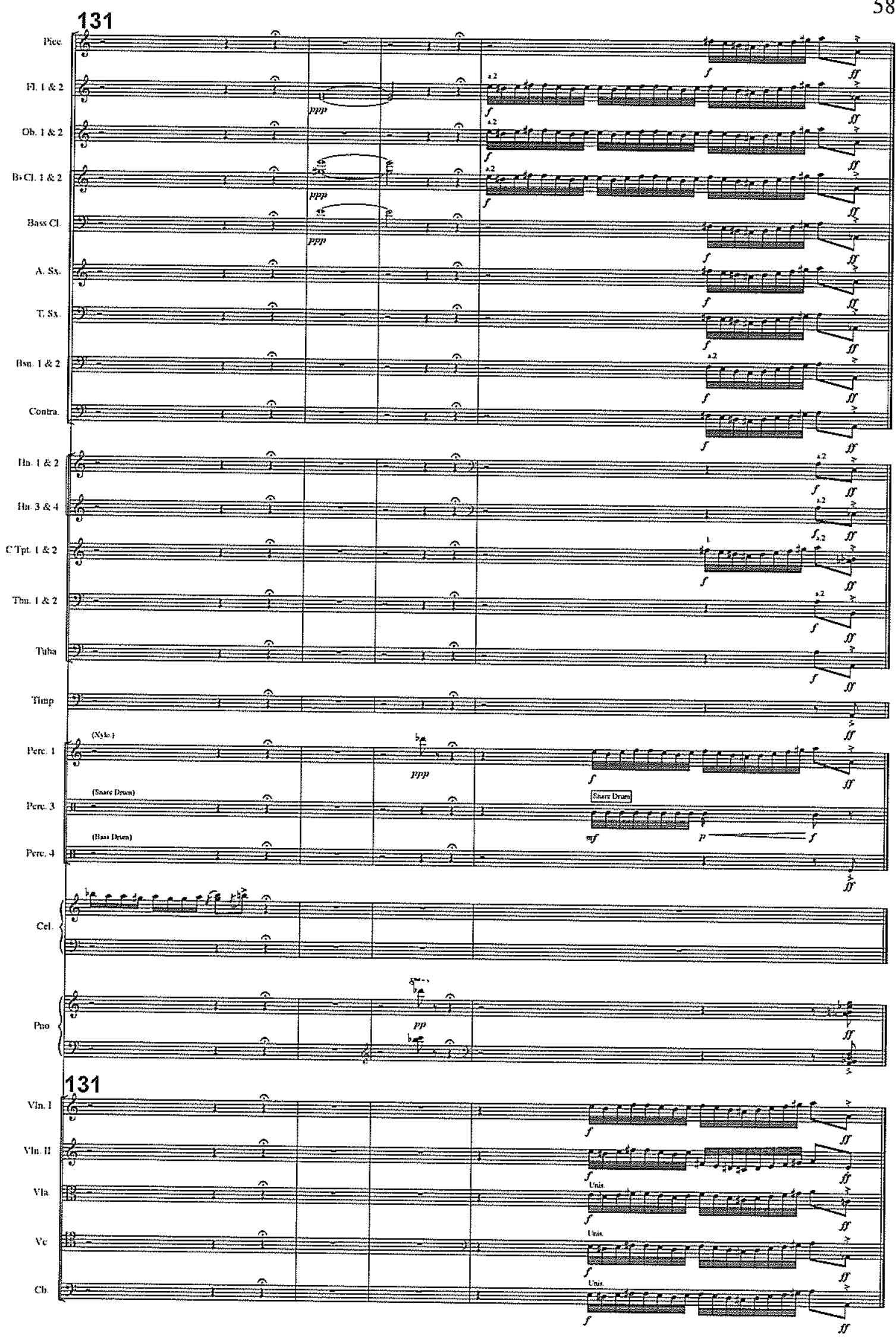

